University of Louisville

ThinkIR: The University of Louisville's Institutional Repository

Electronic Theses and Dissertations

$5-2014$

\title{
Enhancement of anaerobic digestion of actual industrial wastewaters : reactor stability and kinetic modeling.
}

Mahyar Ghorbanian

University of Louisville

Follow this and additional works at: https://ir.library.louisville.edu/etd

Part of the Chemical Engineering Commons

\section{Recommended Citation}

Ghorbanian, Mahyar, "Enhancement of anaerobic digestion of actual industrial wastewaters : reactor stability and kinetic modeling." (2014). Electronic Theses and Dissertations. Paper 494.

https://doi.org/10.18297/etd/494

This Doctoral Dissertation is brought to you for free and open access by ThinkIR: The University of Louisville's Institutional Repository. It has been accepted for inclusion in Electronic Theses and Dissertations by an authorized administrator of ThinkIR: The University of Louisville's Institutional Repository. This title appears here courtesy of the author, who has retained all other copyrights. For more information, please contact thinkir@louisville.edu. 


\title{
ENHANCEMENT OF ANAEROBIC DIGESTION OF ACTUAL INDUSTRIAL WASTEWATERS: REACTOR STABILITY AND KINETIC MODELING
}

\author{
By \\ Mahyar Ghorbanian \\ B.S., Petroleum University of Technology, Iran, 2008 \\ M.S., University of Louisville, KY, USA, 2010 \\ A Dissertation Submitted to the Faculty of the J. B. Speed School of Engineering of the \\ University of Louisville in Partial Fulfillment of the Requirement for the Degree of
}

Doctor of Philosophy

Department of Chemical Engineering

University of Louisville

Louisville, KY

May 2014 
Copyright 2014 by Mahyar Ghorbanian

All rights reserved 

ENHANCEMENT OF ANAEROBIC DIGESTION OF ACTUAL INDUSTRIAL WASTEWATERS: REACTOR STABILITY AND KINETIC MODELING

By

Mahyar Ghorbanian

B.S., Petroleum University of Technology, Iran, 2008

M.S., University of Louisville, KY, USA, 2010

A Dissertation Approved on

$\underline{04 / 18 / 2014}$

(Date)

By the Following Dissertation Committee:

Dr. R. Eric Berson, (Dissertation Director)

Dr. Thomas D. Rockaway

Dr. Jagannadh V. Satyavolu

Dr. Mahendra K. Sunkara

Dr. James C. Watters 


\title{
DEDICATION
}

This dissertation is dedicated to my beloved wife

\author{
Mrs. Roxanna A. Ghorbanian \\ my dearest parents \\ Mr. Mohsen Ghorbanian \\ and \\ Mrs. Roghayyeh Mirhassannia
}

who have given me invaluable support and an unexhausted helpful hand 


\section{ACKNOWLEDGEMENTS}

I am sincerely thankful to my supervisor, Dr. R. Eric Berson, who kept me encouraged and supported from the beginning to the final stage. Dr. Berson provided me enthusiastic circumstances and trained me well to develop an understanding of the new subjects and work.

I would like to express my appreciation to the Department of Chemical Engineering and the Conn Center for Renewable Energy Research for their financial supports during my Ph.D. here at the University of Louisville.

I would also like to thank the committee members, Dr. Thomas D. Rockaway, Dr. Jagannadh V. Satyavolu, Dr. Mahendra K. Sunkara, Dr. James C. Watters, and my colleague Dr. Robert Lupistkyy for their comments and assistance over the past three years.

It is an honor for me to offer my regards and blessings to my family for their love and support in any respect during the completion of the project. 


\begin{abstract}
ENHANCEMENT OF ANAEROBIC DIGESTION OF ACTUAL INDUSTRIAL WASTEWATERS: REACTOR STABILITY AND KINETIC MODELING

Mahyar Ghorbanian
\end{abstract}

April 18, 2014

Industrial plants pay disposal costs for discharging their wastewater that can contain pollutants, toxic organics and inorganics, to the sewer based on the Biological Oxygen Demand (BOD) or Chemical Oxygen Demand (COD) of the streams. It has become increasingly expensive for industry to meet stringent regulatory standards. One solution to reduce this cost is to anaerobically degrade the COD content, which in turn generates useful methane gas that can be used to generate useful energy or heat. Anaerobic Digestion (AD) is one of the most suitable renewable resources of conversion of industrial wastewaters to bioenergy, but it is not widely utilized in the US. As a result, this research focused on understanding and improving fundamental technical and economic obstacles such as long residence times, large reactor sizes/footprints and product quality that hamper its industrial applications in the US.

Kinetic modeling of these anaerobic digestion processes is important for evaluating experimental results, predicting performance, and optimizing reactor designs, but the modeling can be especially difficult for complex wastewater compositions. Respirometry tests were first conducted to assess the impact of substrate loading on kinetic parameters during $\mathrm{AD}$ of three industrial/agricultural 
wastewaters: soybean processing WW, brewery WW, and recycled beverage WW. Results showed that the rate order statistically increased with increasing initial COD content, demonstrating that conventional kinetic modeling is inadequate for these WW of complex composition. COD degradation models revealed the Monod model gave the best overall fit to experimental data throughout the duration of the AD process, but the reactions were best fit to first-order kinetics during the first 7-9 hours and then best fit to higher order kinetics after about 8-13 hours depending on initial COD load.

Expanded granular sludge bed (EGSB) reactors are two-stage continuous systems developed to reduce the residence time and footprint by expanding the sludge bed and escalating hydraulic mixing. However, higher molecular weight and slowly degrading organics, such as crude proteins and fats, cannot efficiently diffuse into the granular biomass to be digested before exiting the reactor, which limits AD efficiency. COD removal efficiency increased by up to $42 \%$ and biogas production rate by up to $32 \%$ for equivalent organic loading rates by properly manipulating COD load and feed rate.

Hydrogen gas, an intermediate product generated during stage-one preacidification (PA), escapes the PA tank but theoretically can be captured and sent to the second stage EGSB reactor to enhance the biogas quality by biologically converting the carbon dioxide to methane. Introducing supplemental hydrogen gas in amounts less than theoretically generated in the PA tank increased energy yield by up to $42 \%$ and enhanced biogas quality by up to $20 \%$. In addition, COD removal efficiency remained constant at $\sim 98 \%$, indicating that hydrogen injection did not negatively affect overall substrate removal. 


\section{TABLE OF CONTENTS}

DEDICATION III

ACKNOWLEDGEMENTS IV

ABSTRACT $\quad$ V

LIST OF TABLES $\quad X$

LIST OF FIGURES $\quad$ XI

CHAPTER 1 : INTRODUCTION 1

CHAPTER 2 : LITERATURE REVIEW 8

2.1. Biological TREATMENT

2.2. AEROBIC BIODEGRADATION

2.3. ANAEROBIC BIODEGRADATION 11

2.4. INHIBITION 15

2.5. AnAEROBIC Digestion KinETICS 17

2.6. REACTOR CONFIGURATIONS 21

2.7. EXPANDED GRANULAR SLUdGE BED REACTOR 23

2.8. Biogas UtiLiZATION 24

2.9. BIOGAS ENHANCEMENT 26

CHAPTER 3 : EXPERIMENTAL 29 
3.2. MATERIALS 31

3.2.1. Equipment 31

3.2.2. Inoculum 33

3.2.3. Substrate 33

3.3. Procedure: ImPACT OF SUbSTRATE-TO-INOCULUM RATIO AND INHIBITION ON Kinetics During AnAerobic Digestion of Agricultural And BeVERAGE

$\begin{array}{ll}\text { Processing WASTEWATERS } & 35\end{array}$

3.4. Procedure: Impact of Hydraulic Retention Time at Constant Organic

LOADING RATE IN AN EXPANDED GRANULAR SLUdGE BED REACTOR 37

3.5. Procedure: ImPaCt OF Hydrogen AdDition on BIOGAS QuALITy

ENHANCEMENT AND SUBSTRATE REMOVAL EFFICIENCY IN AN EXPANDED GRANULAR

$\begin{array}{ll}\text { SLUdGE BED REACTOR } & 40\end{array}$

CHAPTER 4 : IMPACT OF SUBSTRATE-TO-INOCULUM RATIO ON KINETICS

DURING ANAEROBIC DIGESTION OF AGRICULTURAL AND BEVERAGE

PROCESSING WASTEWATERS 44

4.1. GaS ANALYSIS 44

4.2. Batch Methane Production Tests 45

4.3. Modeling APPROACH

4.3.1. Monod Model

4.3.2. Kinetic Parameters as a Function of SI Ratio

4.4. SUMMARY 
CHAPTER 5 : IMPACT OF HYDRAULIC RETENTION TIME AT CONSTANT ORGANIC LOADING RATE IN A TWO-STAGE EXPANDED GRANULAR SLUDGE BED REACTOR

CHAPTER 6 : IMPACT OF HYDROGEN ADDITION ON BIOGAS QUALITY ENHANCEMENT AND SUBSTRATE REMOVAL EFFICIENCY IN AN EXPANDED GRANULAR SLUDGE BED REACTOR

$\begin{array}{ll}\text { 6.1. REACTOR STABILITY } & 70\end{array}$

6.2. THEORETICAL INTERMEDIATE HYDROGEN 72

6.3. Enhanced Reactor Performance with Hydrogen 73

6.4. BIOGAS ENERGY YIELD 76

6.5. IMPACT OF HYDROGEN INJECTION ON SUBSTRATE REMOVAL EFFICIENCY AND $\begin{array}{ll}\text { KINETICS } & 78\end{array}$

$\begin{array}{ll}\text { 6.6. SUMMARY } & 79\end{array}$

$\begin{array}{lr}\text { CHAPTER } 7: \text { CONCLUSIONS } & 81\end{array}$

CHAPTER 8 : RECOMMENDATIONS FOR FUTURE STUDY 85

$\begin{array}{lc}\text { REFERENCES } & 88\end{array}$

$\begin{array}{ll}\text { APPENDIX-A } & 99\end{array}$

$\begin{array}{ll}\text { APPENDIX-B } & 102\end{array}$

$\begin{array}{ll}\text { CURRICULUM VITAE } & 105\end{array}$ 


\section{LIST OF TABLES}

Table 2-1 Characteristics of various AD reactor configurations ................................22

Table 3-1 Average characteristics of the each wastewater (settled supernatant)..........34

Table 3-2 Summary of experimental setup to assess the impact of substrate loading/inhibition for each wastewater: wastewater volume added and SI ratio in each

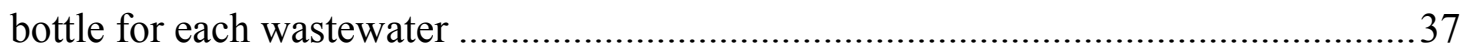

Table 3-3 Summary of COD and OLR loading to assess the impact of HRT ............40

Table 3-4 Summary of hydrogen utilization and OLR to assess the impact of hydrogen

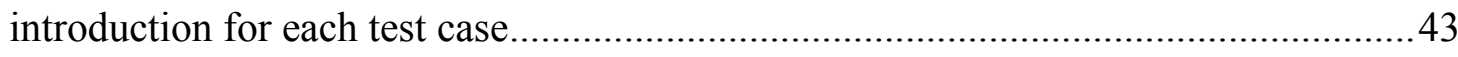

Table 4-1 Average biogas composition (percentage) for each wastewater ................45

Table 4-2 Kinetic parameters from the Monod model for soybean processing WW ..55

Table 5-1 Substrate and product levels for each OLR and HRT .............................65

Table 5-2 Kinetic parameters (Monod model) for all cases ...................................68

Table 6-1 Experimental parameters for different operational conditions ..................72

Table 6-2 Kinetic parameters (Monod model) for all cases ...................................79 


\section{LIST OF FIGURES}

Figure 1-1 - Major wastewater discharges by industry (excluding power) in the United

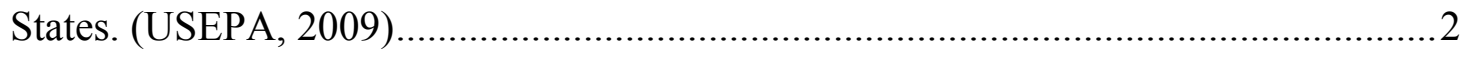

Figure 2-1 Aerobic processes principle ..........................................................

Figure 2-2 Anaerobic processes principle........................................................ 11

Figure 2-3 Schematic diagram of four-stage anaerobic digestion steps ................... 12

Figure 2-4 Anaerobic granules from the UASB reactor (Hulshoff Pol et al., 2004); (b)

Granule composition as proposed by McLeod et al. (MacLeod et al., 1990)..............24

Figure 3-1 (A) Lab-scale batch respirometry (PF-8000 model); (B) Schematic diagram showing the functional elements of an anaerobic respirometer (Young \& Cowan, 2004). 32

Figure 3-2 (A) 60 liter continuous up-flow AD reactor system; (B) Main AD reactor 33 Figure 3-3 Distillery wastewater pulled from production lines, that was provided by a

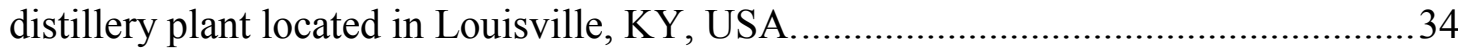

Figure 3-4 Simple schematic diagram of the anaerobic expanded granular sludge bed reactor: (1) pre-acidification tank; (2) heating tank/jacket; (3) feeding line; (4) connection block; (5) pump; (6) recirculation line; (7) granular biomass; (8) gas diffuser; (9) heating jacket; (10) hydrogen gas tank; (11) main reactor; (12) produced biogas line; (13) effluent; (14) gas tank transparent; (15) gas meter; (16) exhaust gas. 
Figure 3-5 Gas flow controller setup to inject the hydrogen gas to the main reactor ...42

Figure 3-6 Experimental setup to inject the hydrogen gas to the main reactor .42

Figure 3-7 Ceramic diffuser used to inject the hydrogen gas ..................................43

Figure 4-1 Total biogas produced per gram of initial COD added at COD $=6 \mathrm{~g} / \mathrm{L}(\mathrm{A})$, $\mathrm{COD}=8 \mathrm{~g} / \mathrm{L}(\mathrm{B}), \mathrm{COD}=10 \mathrm{~g} / \mathrm{L}(\mathrm{C})$, and $\mathrm{COD}=12 \mathrm{~g} / \mathrm{L}(\mathrm{D})$

Figure 4-2 Specific methane production rates at $\mathrm{COD}=6 \mathrm{~g} / \mathrm{L}(\mathrm{A}), \mathrm{COD}=8 \mathrm{~g} / \mathrm{L}(\mathrm{B})$, $\mathrm{COD}=10 \mathrm{~g} / \mathrm{L}(\mathrm{C})$, and $\mathrm{COD}=12 \mathrm{~g} / \mathrm{L}(\mathrm{D})$

Figure 4-3 Rate order and rate constant as a function of SI ratio. 54

Figure 4-4 Experimental and simulated plots (Monod model) of COD consumption for soybean processing wastewater at $\mathrm{COD}=8 \mathrm{~g} / \mathrm{L}(\mathrm{A}), \mathrm{COD}=10 \mathrm{~g} / \mathrm{L}(\mathrm{B})$, and $\mathrm{COD}=$ $12 \mathrm{~g} / \mathrm{L}(\mathrm{C})$ 57

Figure 5-1 Total COD removal efficiency (A) and biogas production rate (B) as a function of HRT for each OLR .66

Figure 6-1 Biogas composition of (A) $\mathrm{CH}_{4},(\mathrm{~B}) \mathrm{CO}_{2}$, (C) $\mathrm{CH}_{4} / \mathrm{CO}_{2}$ ratio, and (D) biogas production rate as a function of organic loading rate. 76

Figure 6-2 Biogas energy yield (A) per day and (B) per gram substrate added as a function of organic loading rate. 


\section{CHAPTER $1:$ INTRODUCTION}

Wastewater (WW) generated from industrial activities contain pollutants such as suspended solids, nutrients, heavy metals, oils and greases, and other toxic organic and inorganic chemicals, which can be a major public health concern, particularly in many urban areas. Figure 1-1 shows the major wastewater discharges by industry (excluding power) in the United States. The environmental issues and potential release of the hazardous compounds from industrial and agricultural sites have motivated countries to limit the discharge of polluting wastewater (Borja et al., 1995).

It has become increasingly expensive for industry to meet stringent regulatory standards and limits on wastewater effluent that is discharged to the sewer system. In the Unites States, the Environmental Protection Agency (USEPA) is the organization in charge of issuing effluent guidelines of national standards for industrial wastewater discharges to surface waters and publicly owned treatment works (sometimes called municipal sewage treatment plants). USEPA issues effluent guidelines for categories of existing sources and new sources under Title III of the Clean Water Act (CWA). Some of the USEPA limitations and standards are Best Practicable Control Technology Currently Available (BPT), Best Conventional Pollutant Control Technology (BCT), Best Available Technology Economically Achievable (BAT), New Source Performance Standards (NSPS), Pretreatment Standards for New Sources (PSNS), and Pretreatment 
Standards for Existing Sources (PSES), etc. For example, the "Meat and Poultry Products" industry is subjected to the standards of BPT, BCT, BAT, and NSPS; and the "Grains Mills Manufacturing" industry is exposed to the standards of BPT, BCT, PSNS, and NSPS (USEPA, 2013b).

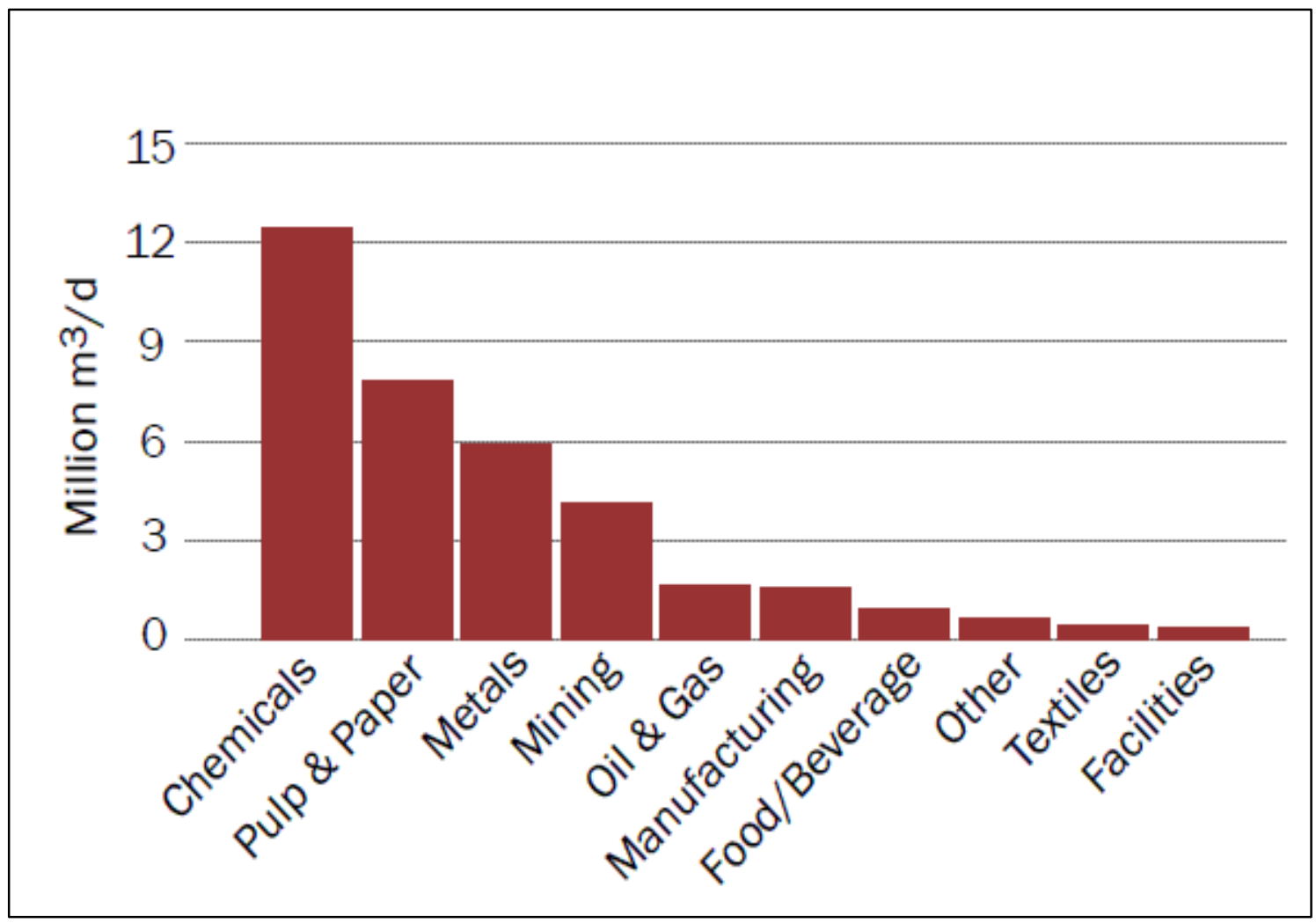

Figure 1-1 - Major wastewater discharges by industry (excluding power) in the United States. (USEPA, 2009)

If a specific industry cannot meet a regulation, it will be charged for effluent wastewater releases to the sewer system. As an example, one industrial site located in Louisville, KY, USA spends $\sim \$ 71,000$ per month to discharge its wastewater to the sewer system. The effluent charge is based on the Biological Oxygen Demand (BOD) and Chemical Oxygen Demand (COD) (organic content) of their waste streams. BOD and 
COD represent the amount of oxygen required to decompose, either biologically or chemically, the organic matter in wastewater.

One solution to pre-treat the wastewater is to degrade and reduce the organic content using anaerobic digestion (AD), which in turn generates useful biogas (methane). The methane gas, that is over 20 times worse than carbon dioxide on climate change over a 100-year period as a greenhouse gas (GHG) (USEPA, 2013a), can then be used to generate useful steam or electricity per industry needs. Thus, the AD process can help meet regulations as well as reduce sewer treatment costs.

Biogas formation has been occurring for ages in nature. This natural and biological process has seen increased interest in anaerobically treating man-made wastes and industrial wastewater (WW) for conversion to methane as a fuel for the past several decades (Chen et al., 2008; Jewell, 1987; Kelleher et al., 2002; McCarty \& Smith, 1986; Speece, 2008; Speece, 1983). Europe has been the leader in applying this technology for the past decades, with far more installations than in the United States (McCarty \& Smith, 1986). Traditional anaerobic biotechnology offers numerous advantages, such as low sludge production, low energy requirement, high organic loading rate (OLR), energy recovery (compared to aerobic digestion), and odor and carbon emission control (Chen et al., 2008; Ghorbanian et al., 2014a; Ghosh \& Pohland, 1974; Kelleher et al., 2002; McCarty \& Smith, 1986; Speece, 1983; Turkdogan-Aydinol et al., 2011). Despite this, a recent USEPA (2010) survey identified only 259 AD projects (including organic waste digestion, forestry, landfill methane, livestock digestion, etc.) across the U.S. (DuBuisson, 2010) and only one of them is located in Kentucky (Beaver Dam, KY). This 
plant uses the wastewater coming from their poultry slaughterhouse as the feed to the digester.

Fundamental technical and economic obstacles need to be overcome for AD to become more widely used in the US. Current AD systems are able to achieve high conversion (over $\sim 90 \%$ ), but they are mostly batch systems with very long residence times (on the order of 14-21 days) and/or require large reactor sizes and footprints. Product quality, measured by the amount of methane relative to $\mathrm{CO}_{2}$ produced, also hampers its industrial applications in the US.

Actual industrial and agricultural wastewaters often consist of complex compositions containing unknown constituents that are inhibitory to microorganism activity, are often found to be the main cause of reactor upset and instability. Inhibition can fail to maintain the balance of microorganisms in the AD system (Demirel \& Yenigun, 2002; McCarty \& Smith, 1986; Speece, 2008; Speece, 1983). Kinetic modeling of these anaerobic digestion processes is important for evaluating experimental results, predicting performance, and optimizing reactor designs, but the modeling can be especially difficult in the presence of complex and unknown wastewater compositions. There are a number of published models such as Monod, Andrews, Chen-Hashimoto, and first-order or second-order Grau, but many are based on simplified substrates (not actual wastewater) or constant first or second order kinetics (Abuhamed et al., 2004; Bhunia \& Ghangrekar, 2008; Davies-Venn et al., 1992; Foresti \& Paula Jr, 1992; Grau et al., 1975; Hashimoto, 1986; Jeison \& Chamy, 1999; Kato et al., 1994; Kim et al., 1997; Kim et al., 1994; MacLeod et al., 1990; Rajagopal et al., 2013). 
The presence of inhibitors and/or competing constituents in actual wastewaters would necessarily increase with increasing substrate load, implying that wastewater COD loading could affect the steady-state rate of methane gas production and, hence, kinetic modeling constants. Therefore, conventional kinetic modeling may be inadequate for these WW of unknown and complex composition. Tests were conducted here to assess the impact of substrate loading on kinetic parameters during anaerobic digestion (AD) of three industrial wastewaters: soybean processing WW, brewery WW, and recycled beverage WW.

Various reactor configurations have been used in anaerobic biotechnology in an attempt to decrease the digestion time and required land space, and at the same time increase the biogas production and organic loading rate (OLR). Various configurations include: tank digester (Ho \& Tan, 1985; Ugoji, 1997), anaerobic filter (Borja \& Banks, 1994b; Rajagopal et al., 2013), anaerobic fluidized reactor (Borja \& Banks, 1995), anaerobic baffled reactor (Faisal \& Unno, 2001; Setiadi et al., 1996), up-flow anaerobic sludge bed (UASB) (Borja \& Banks, 1994b; Borja et al., 1996a; Jeison \& Chamy, 1999; Kato et al., 1994; Lettinga et al., 1980; Sponza \& Uluköy, 2008; Turkdogan-Aydinol et al., 2011), and hybrid reactors (Borja et al., 1996b; Büyükkamaci \& Filibeli, 2002; Najafpour et al., 2006). UASB operates using granular biomass where diffusion is the mechanism by which soluble wastewater substrates enter the granules for digestion.

To modify and enhance UASB performance, expanded granular sludge bed (EGSB) reactors have been recently developed to improve the contact between the substrate and the inoculum within the system by expanding the sludge bed and escalating the hydraulic mixing (Bhattacharyya \& Singh, 2010; Fang et al., 2011a; Fang et al., 
2011b; Ghorbanian et al., 2014b; Liu et al., 2012; Scully et al., 2006; Zhang et al., 2008; Zupančič et al., 2012). Even with a recirculation loop the overall retention time is only on the order of hours. Since it is a low hydraulic retention time (HRT) system, higher molecular weight and slowly degrading organics, such as proteins and lipids, would be flushed through the reactor before they are fully degraded, limiting AD efficiency (Girault et al., 2011). HRT is, therefore, an important operational parameter that must be considered carefully to achieve efficient digestion relative to the organic loading. Many studies on the impact of HRT on reactor performance treating various substrates have been reported for different AD reactor configurations (Espinoza-Escalante et al., 2009; Fongsatitkul et al., 2010; Kim et al., 2006; Rincón et al., 2008; Salminen \& Rintala, 2002). However these studies have not been performed for continuous EGSB reactors. It is believed that proper manipulation of COD loading and feed rate can significantly enhance biogas production and COD removal efficiency for a given organic loading rate.

In two-stage EGSBs that consist of a fermentation stage and an acetogenesis and methanogenesis stage, about 20 to $40 \%$ of the wastewater is desirably pre-acidified in the first stage, and is then fed to the main reactor for anaerobic digestion. This increases the stability of the main reactor where a sudden increase in OLR would cause an accumulation of volatile fatty acids (VFAs) since acetogens grow at a slower rate than acidogens (Wang et al., 2010). Hydrogen, one of the products of the acidification process, escapes from the pre-acidification tank during stage one. This hydrogen gas, if captured, could theoretically react with the carbon dioxide in the main reactor to produce more methane, increasing the overall energy yield and biogas quality. Capturing hydrogen and feeding it into the stage two digester, along with the liquid recirculation line employed by 
EGSBs that allows for longer contact between hydrogen and carbon dioxide, should be advantageous over the single stage CSTR employed by Luo and Angelidaki (2012 and 2013) for biogas enhancement. Consequently, there is a need to assess biogas quality enhancement and reactor stability/performance in terms of whether energy yield, COD removal efficiency, and biogas production will be affected after introducing hydrogen gas in an EGSB reactor fed with an actual industrial wastewater.

Specific objectives of this dissertation are summarized below.

1. Determine the effectiveness of conventional kinetic models on actual industrial wastewaters and the impact of substrate-to-inoculum (SI) ratio on the kinetic parameters.

2. Maximize COD removal efficiency and biogas production by manipulating the hydraulic retention time at constant organic loading rate in an Expanded Granular Sludge Bed Reactor.

3. Investigate the ability to upgrade biogas quality and energy yield via supplemental hydrogen addition, theoretically captured from a pre-acidification tank, in an Expanded Granular Sludge Bed Reactor 


\section{CHAPTER 2 : LITERATURE REVIEW}

\subsection{Biological Treatment}

Industrial activities have increased tremendously in the last century, and therefore the discharge of pollutants into the environment has increased significantly. Wastewaters from the these activities can contain pollutants such as suspended solids, nutrients, heavy metals, oils and greases, and other toxic organic and inorganic chemicals. The loading rates of these pollutants to the natural ecosystems often exceed natural conversion capabilities. This results in an imbalance in nature such as pollution in surface waters and sea habitat populations (Mulder and Thomas, 2003).

The environmental issues and potential release of hazardous compounds from industrial and agricultural sites has motivated countries to impose high fees for discharge of polluting wastewater (Borja et al., 1995) and with these increasingly expensive fees, biological treatment becomes an important and integral part of any industry or wastewater treatment plant that treats wastewater having soluble organic impurities or a mix of wastewater sources.

The economic advantage, in terms of capital and operation costs, of biological treatment has established its place over other treatment processes like chemical oxidation,

thermal oxidation, etc. in any treatment plant (Mittal, 2011). Biological treatment has been occurring for ages in natural ecosystems and is now performed in human- 
made tanks and reactors. However, the conversion rates in these tanks and reactors are required to be much higher than in natural systems. Biological treatment occurs by several groups of microorganisms to convert the organic content present in the wastewater. The biological microorganisms are classified as either aerobic or anaerobic, which are described below. The required energy to drive the reactions is provided by the bacterial biochemical conversions of the organics (Mulder and Thomas, 2003).

\subsection{Aerobic Biodegradation}

Aerobic, as the title implies, means in the presence of air (oxygen). Therefore, aerobic treatment processes occur in the presence of air and utilize microorganisms called aerobes, which use molecular/free oxygen to assimilate organic impurities and convert them into carbon dioxide, water, and biomass (Figure 2-1).

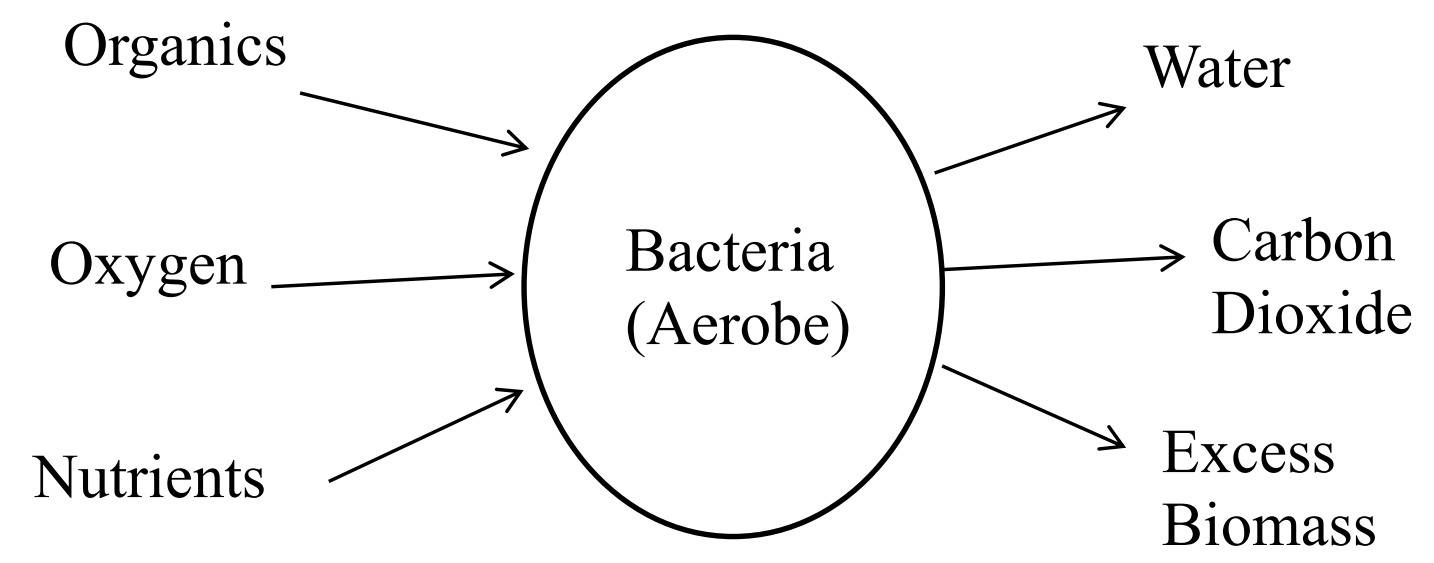

Figure 2-1 Aerobic processes principle 
There are two types of aerobic processes: heterotrophic oxidation and autotrophic reaction. In aerobic heterotrophic oxidation, the bacteria obtain their energy via enzymatic oxidation of organics present in the wastewater to be converted to carbon dioxide, water, and biomass (Equation 2-1) (Young and Cowan, 2004):

Organic substrates $+\mathrm{O}_{2} \rightarrow \mathrm{CO}_{2}+\mathrm{H}_{2} \mathrm{O}+$ Biomass

Normally, oxygen uptake is the parameter of choice to monitor the progress of the reactions. Oxygen uptake is a direct measure of COD changes and, hence it is considered the best measure of energy and carbon transformations in aerobic reactions.

In aerobic autotrophic oxidation, the required energy for biomass synthesis is acquired by oxidation of the reduced inorganics such as $\mathrm{NH}_{3}$ to form $\mathrm{NO}_{2}^{-}$and $\mathrm{NO}_{3}^{-}$, etc. It can be expressed as follows (Equation 2-2) (Young and Cowan, 2004):

Reduced Inorganic $\left(\mathrm{NH}_{3}\right)+\mathrm{O}_{2} \rightarrow$ Oxidized Inorganics $\left(\mathrm{NO}_{3}{ }^{-}\right)+\mathrm{H}_{2} \mathrm{O}$

Similar to heterotrophic oxidation, oxygen uptake is the parameter of choice to monitor the progress of autotrophic reactions. The carbon source for autotrophic reactions is carbon dioxide and the energy produced in the reaction of Equation 2-2 is utilized by microorganisms to increase the energy of carbon dioxide to intermediates such as pyruvate, acetic acid, etc. Then, the intermediates can be synthesized to form biomass (Equation 2-3) (Young and Cowan, 2004). 


$$
\mathrm{CO}_{2}+\mathrm{H}_{2} \mathrm{O} \rightarrow \text { Intermediates } \rightarrow \mathrm{C}_{5} \mathrm{H}_{7} \mathrm{O}_{2} \mathrm{~N} \text { (Biomass) }
$$

In general, heterotrophic microorganisms are not able to perform autotrophic reactions and autotrophic microorganisms are not able to carry out heterotrophic reactions. These two reactions can take place in the same environment and in many cases compete for oxygen or the available energy source.

\subsection{Anaerobic Biodegradation}

As the title implies, anaerobic means in the absence of air (oxygen). Anaerobic treatment processes occur in the absence of oxygen by microorganisms called anaerobes which biochemically convert organic substrates present in the wastewater into methane, carbon dioxide, and biomass (Figure 2-2).

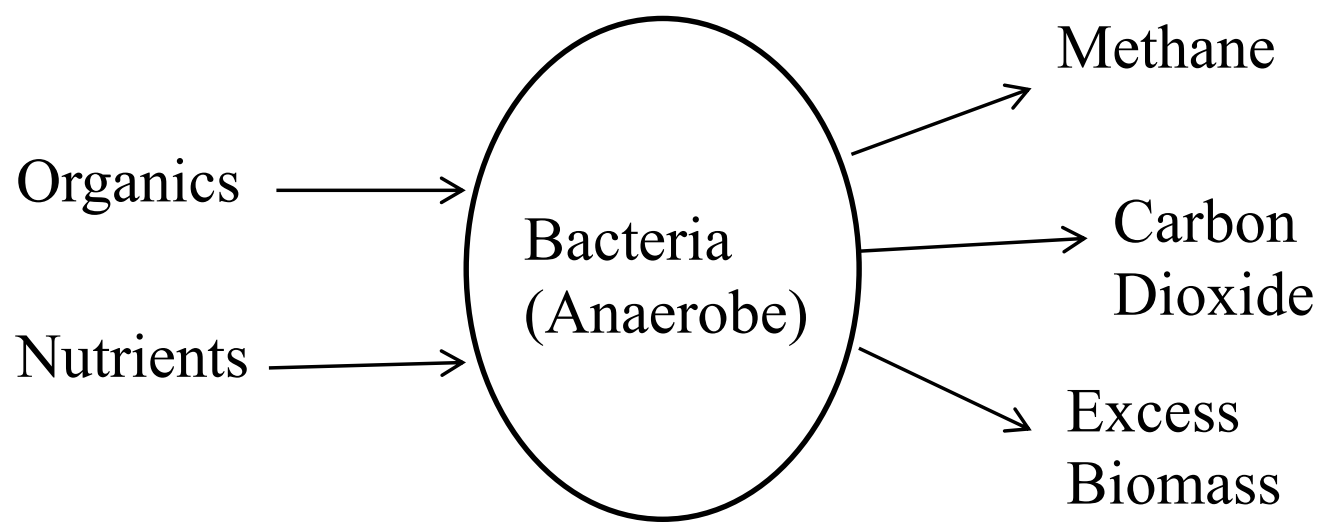

Figure 2-2 Anaerobic processes principle

In anaerobic biotechnology, microorganisms obtain the required energy through a series of metabolic reactions in which oxidized organics and/or hydrogen are utilized to 
provide energy for biomass cell growth. Anaerobic biodegradation consists of four major steps: Hydrolysis, Acidification, Acetogenesis, and Methanogenesis. A schematic diagram for describing the interrelationship between these four steps is shown in Figure 2-3 and discussed below.

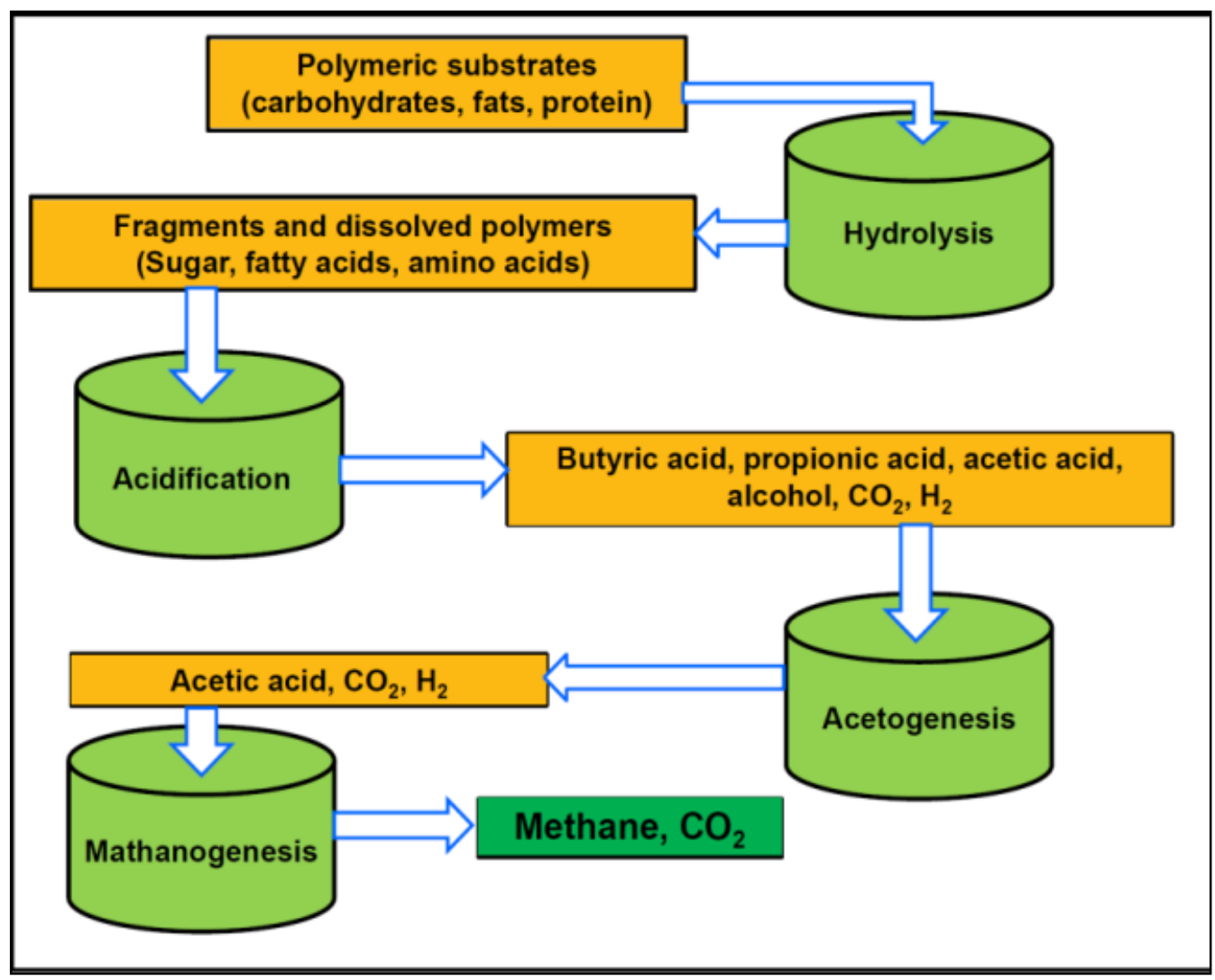

Figure 2-3 Schematic diagram of four-stage anaerobic digestion steps

Hydrolysis: A reaction where complex undissolved organic substances like complex polymers such as fats, cellulose, and proteins are converted into smaller, soluble components like long-chain fatty acids, simple sugars, and amino acids by extracellular enzymes. This process occurs relatively slowly and the microorganisms obtain little or no energy, therefore the net biomass yield is low, but the lower molecular weight products 
can serve as substrates through the next stages (acidification and acetogenesis). The process speed is controlled by the $\mathrm{pH}$ value, the biomass concentration, and the presence of organic substrate. The ideal $\mathrm{pH}$ value is $\sim 6$ for this stage (Young and Cowan, 2004).

Acidification: An oxidation-reduction process in which the bacteria convert the dissolved polymers into one or more intermediates such as fatty acids, butyric acid, propionic acid, acetic acid, alcohols, carbon dioxide and hydrogen. The type of products are formed in this stage depends on the type of microorganisms, the chemical composition of the organic substrate and the process conditions. In general, some of the acidifying bacteria have a high $\mathrm{pH}$ tolerance. Acid production occurs up to a $\mathrm{pH}$ value of less than 4 . Some of the acidifying bacteria can also exist under aerobic conditions and can oxidize the dissolved oxygen in the wastewater, which is discharged in the form of carbon dioxide. Similar to the hydrolysis stage, the net biomass yields are low in the acidification stage (Equation 2-4):

Organics $\rightarrow$ Intermediates $+\mathrm{CO}_{2}+\mathrm{H}_{2} \mathrm{O}+\mathrm{H}_{2}+$ Biomass

It is complicated to measure the gaseous products (hydrogen and carbon dioxide) in this stage due to the gas-liquid interactions between carbon dioxide and its relationship to the $\mathrm{pH}$ value. The produced gaseous hydrogen can possibly be measured by absorbing carbon dioxide in caustic scrubbers (Young and Cowan, 2004).

Acetogenesis: In the third phase, the soluble intermediate substrates formed in acidification (fatty acids, alcohols) are converted into carbon dioxide, hydrogen and acetic acid (Equation 2-5): 
Organics intermediates $\rightarrow$ acetic acid $+\mathrm{CO}_{2}+\mathrm{H}_{2} \mathrm{O}+\mathrm{H}_{2}+$ Biomass

During acetogenesis, organics are almost entirely converted to acetic acid and hydrogen. In addition, sometimes acetic acid is produced from carbon dioxide and hydrogen through the action of homo-acetogenic microorganisms. Under standard conditions, this stage is endergonic which is achieved by a syntrophic coupling between acetogenic bacteria and hydrogen-consuming methanogenic bacteria.

Methanogenesis: The conversion of intermediates produced in the third stage to biogas, which occurs in two stages because methanogenesis involves two physiologically different groups of microorganisms: acetoclastic methanogens and hydrogenotrophic methanogens. Acetoclastic methanogens decarboxylate acetic acid to form methane and carbon dioxide (Equation 2-6):

Acetic acid $\rightarrow \mathrm{CH}_{4}+\mathrm{CO}_{2}+$ Biomass

Hydrogenotrophic methanogens converts the hydrogen released as a metabolic product in the acidification and acetogenesis stages by autotrophic oxidation of hydrogen to form methane (Equation 2-7):

$8 \mathrm{H}+\mathrm{CO}_{2} \rightarrow \mathrm{CH}_{4}+2 \mathrm{H}_{2} \mathrm{O}+$ Biomass 
This hydrogen conversion is important in anaerobic processes to reduce the hydrogen to levels for the syntrophic coupling between acetogenic bacteria and hydrogen-consuming methanogenic bacteria.

Each group of microorganisms responds to the presence of different types of waste components and possibly toxic chemicals in the balance of intermediates and products formed. Inhibition of any one of the intermediate reactions can obstruct the entire degradation process. The exact ratio of methane to carbon dioxide depends on the composition of the wastewater fed to the $\mathrm{AD}$ reactor and the buffer capacity of the wastewater (Young and Cowan, 2004).

These four steps can be run using either single-stage $\mathrm{AD}$ system or two-stage AD system. In general, two-stage anaerobic digestion has been reported to be more efficient than single-stage systems (Wang et al., 2010), since the operational conditions that optimize each step can be efficiently regulated. In a two-stage system, the first stage involves hydrolysis and acidogenesis, and the second stage involves acetogenesis and methanogenesis. This increases the stability in the reactor (stage-two) since a sudden increase in OLR there would cause an accumulation of VFAs, since the acetogens grow at a slower rate than the acidogens (Wang et al., 2010).

\subsection{Inhibition}

Actual industrial wastewaters often consist of complex compositions and contain unknown chemicals that are inhibitory to microorganism activity and are often found to be the main cause of reactor upset and instability. In anaerobic biotechnology, the acidogenic and the methanogenic microorganisms are different extensively in terms of 
biochemical and physiochemical processes, nutrient requirements, growth kinetics, and sensitivity to environmental conditions such as $\mathrm{pH}$, temperature, reactor configuration and substrate to inoculum ratio (McCarty and Smith, 1986; Pohland and Ghosh, 1971; Speece, 2008; Speece, 1983). Inhibition can fail to maintain the balance between these two groups of bacteria and is the primary cause of $\mathrm{AD}$ reactor operational instability (Demirel and Yenigun, 2002; McCarty and Smith, 1986; Speece, 2008; Speece, 1983). Literature on $\mathrm{AD}$ reveals considerable variation in the inhibition/toxicity levels reported for most components and constituents of wastewater. The main reason for these variations is the complexity of the digestion process where $\mathrm{AD}$ mechanisms could significantly affect the phenomenon of inhibition (Chen et al., 2008).

There are two types of inhibition to describe the general restriction of biological/biochemical reactions. The task group in Anaerobic Digestion Model No. 1 (Batstone et al., 2002) uses two definitions: one, biocidal inhibition such as detergents, cyanide, etc. which cause reactive toxicity and is normally irreversible. Two, biostatic inhibition such as product inhibition, $\mathrm{pH}$ inhibition and cation inhibition, etc. which cause nonreactive toxicity and is normally reversible. Speece (2008) defined the first one as an adverse effect, not necessarily lethal, on bacterial metabolism and defined the second one as an impairment of bacterial function. Inhibition is usually indicated by a decrease in the steady-state rate of methane gas production and accumulation of organic acids (Chen et al., 2008). Throughout this dissertation inhibition refers to both definitions.

The inhibitory substances found in the wastewaters may include ammonia, sulfide, metals ions, chlorophenols, halogenated aliphatics, etc. (Chen et al., 2008). Of those, sulfate is a common inhibitory constituent of many industrial wastewaters 
(O'Flaherty et al., 1998). In anaerobic reactors, sulfate is reduced to sulfide by the sulfate reducing bacteria (SRB) (Hilton and Oleszkiewicz, 1988; Koster et al., 1986). SRB thermodynamically and kinetically should out-compete other anaerobes for substrate (Oude Elferink et al., 1994; Colleran et al., 1995; O'Flaherty et al., 1998). In practice, the $\mathrm{COD} / \mathrm{SO}^{2-}{ }_{4}$ ratio, the relative population of $\mathrm{SRB}$ and other anaerobes, and the sensitivity of SRB and other anaerobes to sulfide toxicity impact the competition. There are two inhibitions from sulfate. One is inhibition due to competition for common organic and inorganic substrates from SRB, which suppresses methane production (Harada et al., 1994). The second one is inhibition resulting from the toxicity of sulfide to various bacteria groups (Chen et al., 2008; Colleran et al., 1995; Colleran et al., 1998; J.W.H et al., 1994).

\subsection{Anaerobic Digestion Kinetics}

Kinetic modeling of anaerobic digestion processes, which is a very complex process involving various bacterial populations and substrates, is important for evaluating experimental results, predicting performance, and optimizing reactor designs. Kinetic modeling of anaerobic digestion processes can be especially difficult when the exact composition of the feed stream is unknown, for example when the feed to the digester enters directly as a waste stream from a complex industrial chemical process, which may contain inhibitors of unknown nature and quantity. The kinetic modeling process (selecting a model structure, identifying the model values, and planning the experimental measurements) should be in coherence with the objective engaged. In general, the three most common reasons of using an $\mathrm{AD}$ model are: understanding the $\mathrm{AD}$ system's behavior and interaction of the elements; quantitatively expressing or verifying the 
hypothesis, and predicting the behavior of the $\mathrm{AD}$ system in the future or under other similar conditions (Donoso-Bravo et al., 2011).

The operation mode of the experiment plays an important role on the information content of the collected data, and hence, on the quality of the estimated parameters. The two common $\mathrm{AD}$ operations are batch and continuous operations. $\mathrm{AD}$ batch operation can be defined as a biological process in which there is no interchange of substrate with the environment, therefore, there is no input or output (except for the produced biogas flow). In the $\mathrm{AD}$ continuous operation, the substrate (wastewater) is continuously replaced with an equal volume of fresh substrate solution and therefore a continuous discharge of biomass also takes place (Donoso-Bravo et al., 2011).

There are a number of published kinetic models on the stability or maintenance of the balance between different groups of bacteria (Dupla et al., 2004). These models include: classical Monod model (Bhunia and Ghangrekar, 2008; Davies-Venn et al., 1992; Kim et al., 1994), Heldane (often called Andrews) inhibition model (Bhunia and Ghangrekar, 2008; Davies-Venn et al., 1992; Kim et al., 1997; Kim et al., 1994; Raposo et al., 2003), 1st order model (De la Rubia et al., 2011; Jimenez et al., 2004; Raposo et al., 2009), Grau 2nd order model (Bhunia and Ghangrekar, 2008; Buyukkamaci and Filibeli, 2002; Rajagopal et al., 2013; Raja Priya et al., 2009), and Stover-Kincannon model (Rajagopal et al., 2013; Raja Priya et al., 2009; Sandhya and Swaminathan, 2006). The general form of each model is as follows:

Monod:

$$
k=\frac{k_{m} S_{e}}{K_{S}+S_{e}}
$$

Heldane: 


$$
k=\frac{k_{m} S_{e}}{K_{s}+S_{e}+\frac{S_{e}}{K_{i}}}
$$

1st Order:

$$
-\frac{d S}{d t}=k_{1 s} X \frac{S_{e}}{S_{0}}
$$

Grau 2nd Order:

$$
-\frac{d S}{d t}=k_{2 s} X\left(\frac{S_{e}}{S_{0}}\right)^{2}
$$

Stover-Kincannon:

$$
\left(\frac{d S}{d t}\right)^{-1}=\frac{V}{Q\left(S_{0}-S_{e}\right)}=\frac{K_{B}}{U_{\max }}\left(\frac{V}{Q S_{i}}\right)+\frac{1}{U_{\max }}
$$

where $\mathrm{S}_{\mathrm{e}}$ is the substrate concentration $(\mathrm{g} / \mathrm{L}) ; \mathrm{S}_{0}$ is the initial substrate concentration $(\mathrm{g} / \mathrm{L}) ; \mathrm{k}_{\mathrm{m}}$ is the maximum substrate removal rate $\left(\mathrm{d}^{-1}\right) ; \mathrm{K}_{\mathrm{s}}$ is the half-saturation coefficient $(\mathrm{g} / \mathrm{L}) ; \mathrm{dS} / \mathrm{dt}$ is the substrate removal rate $(\mathrm{g} / \mathrm{L} / \mathrm{day}) ; \mathrm{k}_{2 \mathrm{~s}}$ and $\mathrm{k}_{1 \mathrm{~s}}$ are the substrate removal rate constants (g COD/g VSS/day); $\mathrm{X}$ is the microorganisms' concentration (g VSS/L); $\mathrm{t}$ is time (day); $\mathrm{Q}$ is the inflow rate $(\mathrm{L} / \mathrm{d}) ; \mathrm{V}$ is the reactor volume $(\mathrm{L}) ; \mathrm{U}_{\max }$ is the maximum utilization rate constant (g/L.d); $K_{i}$ is the constant of inhibition (g/L.d) and $K_{B}$ is the saturation value constant (g/L.d).

The 1st order model was found to be used only for the batch systems; however, classical Monod and Heldane models can be used for both batch and continuous systems; whereas Grau 2nd order and Stover-Kincannon models can only be used for continuous systems considering the steady-state condition. 
For example, De la Rubia et al. (2011) utilized the 1st order model to study the influence of particle size and chemical composition on methane production kinetics for a Sunflower Oilcake wastewater with 1.1 to $1.24 \mathrm{~g}$ Oxygen per g Total Solids (dry basis) in batch mode $\left(\mathrm{R}^{2}=0.99\right)$. Bhunia and Ghangrekar (2008) employed the Monod model, Heldane model, and Grau 2nd order model to study the reactor performance and substrate removal for an artificial wastewater with 0.3 to $4 \mathrm{~g} \mathrm{COD} / \mathrm{L}$ in a UASB. They concluded that Grau second-order model provided the best fit $\left(\mathrm{R}^{2}=0.98\right)$ among the mentioned models for the performance evaluation and prediction in their UASB reactor. In a similar system, Sponza and Ulukoy (2008) employed the Monod model, Grau 2nd order model, and Stover-Kincannon model to study reactor performance and substrate removal for a synthetic carbonaceous substrate $(2,4$ dichlorophenol) with 6 to $44 \mathrm{~g} \mathrm{COD} / \mathrm{L} / \mathrm{d}$ in a UASB. They reported that Monod model provided the best fit $\left(\mathrm{R}^{2}=0.95-0.98\right)$ among the mentioned models in their UASB reactor. In another case, Debik and Coskun (2009) employed the Grau 2nd order model and Stover-Kincannon model to study reactor performance and substrate removal for a static granular bed reactor (down-flow SGBR system) treating a poultry slaughterhouse wastewater with 4.2 to $9.1 \mathrm{~g} \mathrm{COD} / \mathrm{L}$. They expressed that the Stover-Kincannon model provided the better fit $\left(\mathrm{R}^{2}=0.99\right)$ than the Grau 2nd order model in their down-flow reactor. In a different study, Raposo et al. (2003) studied the inhibition kinetics of an olive-mill wastewater containing known concentrations of phenols in a CSTR using the Heldane model which is a modified version of the Monod model including an inhibition term.

It was observed that in various kinetic studies, the models are based on a simplified constant first or second order kinetics, or the substrate is a simplified and 
synthetic wastewater and/or an actual wastewater containing a known concentration of inhibitors.

\subsection{Reactor Configurations}

The biomass containing $\mathrm{AD}$ microorganisms responsible for anaerobic biotechnology can be placed in a variety of process configurations. Various configurations include: tank digester (Ho and Tan, 1985; Ugoji, 1997), anaerobic filter (Borja and Banks, 1994b; Rajagopal et al., 2013), anaerobic fluidized reactor (Borja and Banks, 1995), anaerobic baffled reactor (Faisal and Unno, 2001; Setiadi et al., 1996), upflow anaerobic sludge bed (UASB) (Borja and Banks, 1994a; Borja et al., 1996a; Jeison and Chamy, 1999; Kato et al., 1994; Lettinga et al., 1980; Sponza and Ulukoy, 2008; Turkdogan-Aydinol et al., 2011), and hybrid reactors (Borja et al., 1996b; Büyükkamaci and Filibeli, 2002; Najafpour et al., 2006).

Selection of the appropriate process configuration is essential and has a significant influence on successful operation. Each configuration has implications for the ratio of solids retention time to hydraulic retention time (SRT/HRT), which are fundamental design parameters of biotechnology systems. High SRT is necessary for process stability and minimal sludge production. Low HRT reduces the reactor volume and hence reduces the capital costs (Speece, 1983). Wang et al., (2010) generally distinguish two broad categories of anaerobic digesters: conventional and high-rate systems.

Conventional reactors: conventional anaerobic digesters or Conventional Stirred Tank Reactor (CSTR) are the simplest configuration from a construction standpoint. They are a mixed digester or reactor where the biomass (microorganisms) is 
mechanically well-mixed/stirred with wastewater or substrate to secure the homogeneity of the liquid phase. These digesters can be run either as batch or continuous. Although, the SRT is equal to the HRT in a CSTR which increases the reactor's stability, but requires long residence times and large volume reactor and footprints.

High rate reactors: as the name implies, high rate anaerobic reactors were developed to achieve a high rate of substrate (high OLR) consumption and increase the biogas production, and at the same time reduce the residence time and volume/footprint of the reactor. There are two types of high rate systems: (a) attached growth high rate anaerobic reaction systems and (b) suspended growth high rate anaerobic reaction systems. Examples of attached growth reactors include the Anaerobic Contact Reactor and the Anaerobic Attached (Film Expanded) Bed Reactor (AAFEBR). Suspendedgrowth reactors include the Anaerobic Fluidized Reactor (AFR), Anaerobic Filter Reactor (AFR), and Up-flow Anaerobic Sludge Blanket (UASB) reactor. The characteristics of various reactor configurations are summarized in Table 2-1 (Rajeshwari et al., 2000).

Table 2-1 Characteristics of various AD reactor configurations

\begin{tabular}{llll}
\hline Reactor type & Effluent recycle & Typical OLR, $\mathrm{kgCOD} / \mathrm{m}^{3} / \mathrm{d}$ & HRT, d \\
\hline CSTR & Not required & $0.25-3$ & $10-60$ \\
Contact & Not required & $0.25-4$ & $12-15$ \\
AFR (filter) & Not required & $1-40$ & $0.5-12$ \\
AAFEB & Required & $1-50$ & $0.2-5$ \\
AFB & Required & $1-100$ & $0.2-5$ \\
UASB & Not required & $5-30$ & $0.5-7$ \\
\hline
\end{tabular}


Despite all the benefits of the high rate reactors, they mostly utilize granular biomass, so have the following potential limitations: granules settling may limit the process efficiency, high solids containing wastewaters may damage the granules, and granule formation may require controlling too many operational parameters.

\subsection{Expanded Granular Sludge Bed Reactor}

UASB reactors are usually cylindrical vessels in which the waste moves upward through a sludge blanket at a linear velocity. UASB operates using granular biomass (Figure 2-4) where diffusion is the mechanism by which soluble wastewater substrates enter the granules for digestion. To modify and enhance UASB performance, expanded granular sludge bed (EGSB) reactors have been recently developed to improve the contact between the substrate and the inoculum within the system by expanding the sludge bed and escalating the hydraulic mixing. EGSB reactors are becoming extensively employed (Fang et al., 2011a; Fang et al., 2011b; Liu et al., 2012; Scully et al., 2006; Zhang et al., 2008; Zupančič et al., 2012). Even with a recirculation loop the overall retention time is only on the order of hours. Since it is a low HRT system, higher molecular weight and slowly degrading organics, such as proteins and lipids, may be flushed through the reactor before they are fully degraded (Girault et al., 2011). HRT is, therefore, an important operational parameter that must be considered carefully to achieve efficient digestion while maintaining reasonable organic loading rates. 

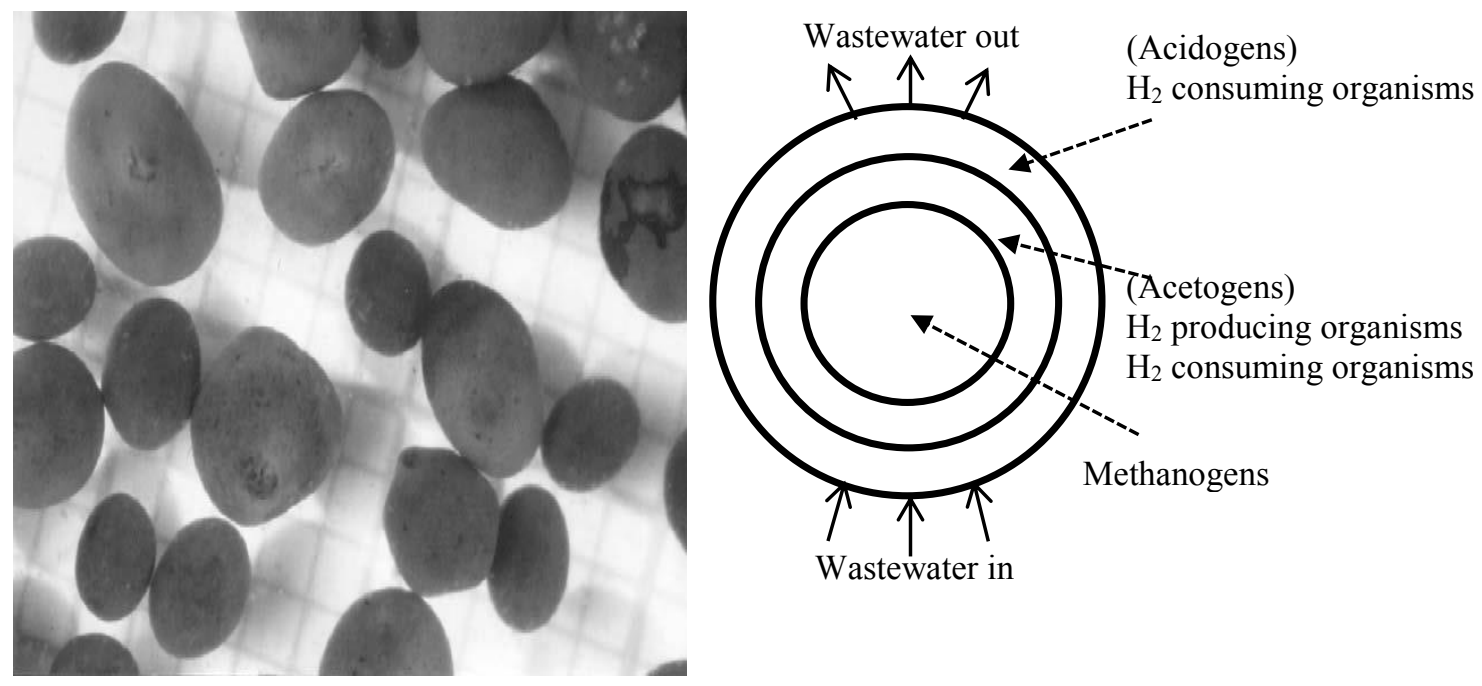

Figure 2-4 Anaerobic granules from the UASB reactor (Hulshoff Pol et al., 2004); (b) Granule composition as proposed by McLeod et al. (MacLeod et al., 1990)

Many studies on the impact of HRT on reactor performance treating various substrates have been reported for different $\mathrm{AD}$ reactor configurations (EspinozaEscalante et al., 2009; Fongsatitkul et al., 2010; Kim et al., 2006; Rincón et al., 2008; Salminen and Rintala, 2002). However these studies have not been performed for modern EGSB reactors nor has the impact of varying HRT at constant OLR been characterized.

\subsection{Biogas Utilization}

The produced biogas can be employed in a wide range of industrial applications. By upgrading its methane quality near natural gas quality, it can be used as a fuel like compressed natural gas $(\mathrm{CNG})$ in transportation and vehicles. More importantly and popularly, the upgraded and purified biogas can be used to generate electricity for private 
uses mostly and in rare cases for uploading to the power grids (Chang et al., 2011; Hosseini and Wahid, 2013; Kabasci, 2009). The upgrading and purification process, leading to an almost pure methane gas stream and natural gas quality, can include removal of carbon dioxide and contaminants that are harmful to the equipment. For example, manufacturers like Caterpillar Inc. and General Electric Company reported that their power generators are sensitive to contaminants like hydrogen sulfide (sulfur compounds), siloxane (silicon compounds), water vapor, halide compounds ( $\mathrm{Cl}$ and $\mathrm{F})$, ammonia, and particle matters.

Also popular is a combined heat and power (CHP) application, also known as cogeneration, which is the simultaneous generation of electricity while also capturing usable heat produced in the process. Biogas can fuel the internal combustion engine in the CHP. It is an integrated energy system technology and its most common configurations are gas turbine or engine with heat recovery unit and steam boiler with steam turbine (USEPA, 2013c). For example, one industrial site in Beaver Dam, KY, averaged 72 Million cubic feet of biogas ( $74 \%$ methane) in 52 weeks, that converted to 5.1 Million kWh using CHP.

The produced biogas also has been employed for household applications, primarily for cooking and heating purposes. Another application of the biogas is its utilization as a conditioner for fruits, and vegetables storage and preservation, and seeds de-insectization and storage due to very high concentrations of methane and carbon dioxide which are harmless to fruits (Chang et al., 2011). 


\subsection{Biogas Enhancement}

The biogas is typically composed of $51.8-85.0 \%$ methane, with an average and standard deviation of 66.3 and $5.1 \%$, respectively; $4.0-40 \%$ carbon dioxide, with an average and standard deviation of 28.8 and $4.7 \%$, respectively; and some trace gases such as hydrogen sulfide, carbon monoxide, and hydrogen (Speece, 2008). In order to increase the heating value of the biogas and extend its utilization, it can be enhanced to natural gas quality and used as a fuel in road vehicles and generators, or any other high gas quality applications (Deng and Hägg, 2010; Ryckebosch et al., 2011).

Currently, methods for biogas purification and carbon dioxide and hydrogen sulfide removal include water washing, pressure swing adsorption, polyglycol adsorption, chemical treatment, and chemo-autotrophic purification (Osorio and Torres, 2009; Strevett et al., 1995). Strevett et al. (1995) reported that they achieved about $96 \%$ biogas purification using the chemo-autotrophic method. However, these common methods occur outside the main reactor and require additional expenses such as chemicals, pumps, membranes, etc. A small fraction of methane is usually removed during these carbon dioxide stripping processes, which detracts from the product yield and increases greenhouse gas and carbon emissions (Weiland, 2010).

Hydrogen is an intermediate product generated during the acidogenic phase of anaerobic digestion. Equations (2-13) to (2-16) show a simple example mechanism for the digestion of ethanol to methane and carbon dioxide. A more advantageous process for upgrading the biogas would be to introduce supplemental gaseous hydrogen and use hydrogen-consuming methanogens in the main $\mathrm{AD}$ reactor to biologically convert the carbon dioxide to methane, such as has been demonstrated by Luo and Angelidaki (2012 
and 2013). This method is effective as long as the consumption rate by the hydrogenconsuming methanogens is equal to or greater than the combined hydrogen production and injection rate. Otherwise, the reversible Equation (2-13) may shift to the direction of hydrogen consumption and, therefore, lead to the inhibition of volatile fatty acid (VFA) degradation (Luo and Angelidaki, 2013; Luo and Angelidaki, 2012; Luo et al., 2012; Siriwongrungson et al., 2007).

$\mathrm{CH}_{3} \mathrm{CH}_{2} \mathrm{OH}(\mathrm{aq})+\mathrm{H}_{2} \mathrm{O}(\mathrm{l})=\mathrm{CH}_{3} \mathrm{COO}^{-}(\mathrm{aq})+\mathrm{H}^{+}(\mathrm{aq})+2 \mathrm{H}_{2}(\mathrm{~g}) \quad \Delta \mathrm{G}_{0}=9.65 \mathrm{~kJ}$

$2 \mathrm{H}_{2}(\mathrm{~g})+1 / 2 \mathrm{CO}_{2}(\mathrm{~g})=1 / 2 \mathrm{CH}_{4}(\mathrm{~g})+\mathrm{H}_{2} \mathrm{O}(\mathrm{l})$

$\Delta \mathrm{G}_{0}=-65.37 \mathrm{~kJ}$

$\mathrm{CH}_{3} \mathrm{COO}^{-}(\mathrm{aq})+\mathrm{H}^{+}(\mathrm{aq})=\mathrm{CH}_{4}(\mathrm{~g})+\mathrm{CO}_{2}(\mathrm{~g})$

$\Delta \mathrm{G}_{0}=-35.83 \mathrm{~kJ}$

Net: $\mathrm{CH}_{3} \mathrm{CH}_{2} \mathrm{OH}(\mathrm{aq})=3 / 2 \mathrm{CH}_{4}(\mathrm{~g})+1 / 2 \mathrm{CO}_{2}(\mathrm{~g})$

$\Delta \mathrm{G}_{0}=-91.55 \mathrm{~kJ}$

Luo and Angelidaki (2013) studied in-situ hydrogen utilization to enhance the biogas quality in a one liter continuously stirred tank reactor (CSTR) co-digesting solid waste at thermophilic temperature $\left(55^{\circ} \mathrm{C}\right)$. They used manure with acidic whey (low $\mathrm{pH}$ : 4.5 or lower) to control the increase in $\mathrm{pH}$ during the process and found that biogas quality was enhanced up to $\sim 20 \%$ by hydrogen injection (Luo and Angelidaki, 2013). However, further investigation and studies are required for different configurations (such as up-flow reactors) and operational conditions (such as mesophilic) digesting various 
types of wastes, in order to employ this idea in scale-up and industrial AD designs. Further, reactor stability and substrate removal efficiency needs to be examined.

Expanded granular sludge bed (EGSB) reactors are modern AD systems becoming extensively employed by industry (Fang et al., 2011a; Fang et al., 2011b; Liu et al., 2012; Scully et al., 2006; Zhang et al., 2008; Zupančič et al., 2012). Two-stage EGSBs consist of a fermentation and acidification stage and an acetogenesis and methanogenesis stage. About 20 to $40 \%$ of the wastewater will be desirably pre-acidified in the first stage, and is then fed to the main reactor for anaerobic digestion. Hydrogen, one of the products of the acidification process (Equation 2-13), may escape during stage one leading to a deficiency of hydrogen gas to react with the carbon dioxide in the main reactor to convert to methane (Equation 2-14).

Other authors have suggested that supplemental hydrogen required for the biogas enhancement can potentially be provided by renewable sources such as hydrogen producing $\mathrm{AD}$ reactors, coal gasification, petroleum refinery, petrochemical plants, and soda manufacture (Luo and Angelidaki, 2012; Luo and Angelidaki, 2013; Luo et al., 2012; Ni et al., 2011). However, capturing hydrogen and feeding it into the stage two digester, along with the liquid recirculation line employed by EGSBs that allow for longer contact between hydrogen and carbon dioxide, should be advantageous over the single stage CSTR employed by Luo and Angelidaki (2012 and 2013). Hence, there is a need to assess biogas quality enhancement and reactor stability after introducing hydrogen gas in the modern EGSB reactor fed with actual industrial wastewater. 


\section{CHAPTER 3 : EXPERIMENTAL}

\subsection{Experimental Plan}

Actual industrial wastewaters were used in this project to study reactor stability or the maintenance of the balance between different groups of $\mathrm{AD}$ bacteria in terms of substrate loading (and thereby inhibition), hydraulic retention time, and biogas quality enhancement by means of hydrogen introduction under mesophilic conditions $\left(35^{\circ} \mathrm{C}\right)$ in an expanded granular sludge bed reactor.

Bench-scale respirometry tests were first conducted to assess the impact of substrate loading of various industrial wastewaters, which contain some known and potentially unknown inhibitors, on rate law parameters and the gas quality at mesophilic temperature $\left(35^{\circ} \mathrm{C}\right)$. Tests were performed on three actual industrial wastewaters: soybean processing WW, brewery WW, and recycled beverage WW. The procedure involved adding wastewater at four $\operatorname{COD}$ concentrations $(6,8,10$, and $12 \mathrm{~g} / \mathrm{L})$ to bacterial biomass (12 g/L VSS) to test four substrate-to-inoculum (SI) ratios. Control reactors without toxicant (ethanol) were tested as a basis for comparison. Culture seed blank reactors (no feed) were included to obtain background gas production. Kinetic parameters were quantified using the rate law, Monod, and Grau models to determine limitations of each model and conditions for the applicability of each. 
To assess the impact of HRT and determine how capable this continuous low residence time system is for handling high molecular weight and slowly degrading substrates, pilot-scale tests were conducted on the digestion process in an EGSB reactor at constant OLR. An experimental plan was developed to compare COD removal efficiency, biogas production, and kinetic rate constants at equivalent OLR's obtained by running either higher COD strengths fed at a slower rate or lower COD strengths fed at a faster rate. A distillery wastewater was used as the substrate for this study, which was introduced at one of four COD strengths $(\sim 5,10,20$, and $30 \mathrm{~g} \mathrm{COD} / \mathrm{L})$. Each of the COD strengths was run at four flow rates, resulting in four OLRs $(\sim 3,5,7$, and $9 \mathrm{~g} \mathrm{COD} / \mathrm{L} / \mathrm{d})$. $\mathrm{pH}$, temperature, COD and VFA (in influent, pre-acidification tank, and effluent), and biogas production were monitored. Then, kinetic model parameters were determined as a function of OLR and HRT.

The purpose of the hydrogen introduction study was to investigate the biogas quality enhancement by feeding supplemental hydrogen in a two-phase pilot-scale (EGSB) reactor. In the tests, a distillery wastewater was used as the substrate, which was introduced at $\sim 30 \mathrm{~g} \mathrm{COD} / \mathrm{L}$ strength and run at 3 to 4 flow rates, resulting in four OLRs $(\sim 3,5,7$, and $9 \mathrm{~g} \mathrm{COD} / \mathrm{L} / \mathrm{d})$. The amount of hydrogen introduced, 0.15 or $0.30 \mathrm{~L} / \mathrm{L}_{\text {biogas }} / \mathrm{d}$, was less than what could be theoretically captured escaping from the PA tank. The reactor stability in terms of $\mathrm{pH}$, temperature, $\mathrm{COD}$ and VFA (in influent, pre-acidification tank, and effluent), and biogas production were monitored when the reactor operated with either no supplemental hydrogen or with supplemental hydrogen. Substrate removal kinetics was compared for each case using Monod model in order to assess the impact of hydrogen injection on reactor performance and stability. 


\subsection{Materials}

\subsubsection{Equipment}

Each wastewater sample was characterized prior to testing for $\mathrm{pH}, \mathrm{COD}, \mathrm{VFA}$, ammonia, TKN, sulfate, phosphorus and solids content. Settled supernatant from the wastewaters were used for measurements and reactor feeds. $\mathrm{pH}$ was measured using a Accumet portable meter, model \# AP85. Concentrations of COD, VFA, ammonia, sulfide, and phosphorus were measured by colorimetry using a spectrophotometer (Hach, model \# DR 3900) and test vials pre-loaded with analytic reagents (Hach, TNT vials: $823,832,845,864,880$, and 872). Total solids (TS), total dissolved solids (TDS), and total suspended solids (TSS) were measured using standard methods from United States Geological Survey (USGS, 1989). The fractions of protein, fat and carbohydrate were reported by the distillery wastewater supplier.

Gas analysis to determine methane, carbon dioxide, nitrogen, hydrogen and hydrogen sulfide concentrations was performed using a SRI 8610C Gas Chromatograph (SRI Instruments Inc., Las Vegas NV) with a HayeSep D column (Restek Corporation) and thermal conductivity detector (TCD) for methane and carbon dioxide detection; a MXT-1 column (Restek Corporation) and flame photometric detector (FPD) was used for hydrogen sulfide detection.

Batch kinetic testing was performed with a system of batch pulse-flow respirometers (Figure 3-1) (Respirometer Systems \& Applications LLC, Fayetteville, AZ, USA, model \# RSA, PF-8000), which continuously monitored biogas generation in real time. The produced biogas flows into an internal storage chamber and is released when a 
pre-set pressure buildup is detected by a pressure transducer. These incremental volumes are carefully controlled through accurate calibrations established by RSA (Respirometer Systems \& Applications LLC). The pressure transducer was connected to a computer with data acquisition software (developed by Respirometer Systems \& Applications LLC) to record and monitor gas production data (Figure 3-1A).

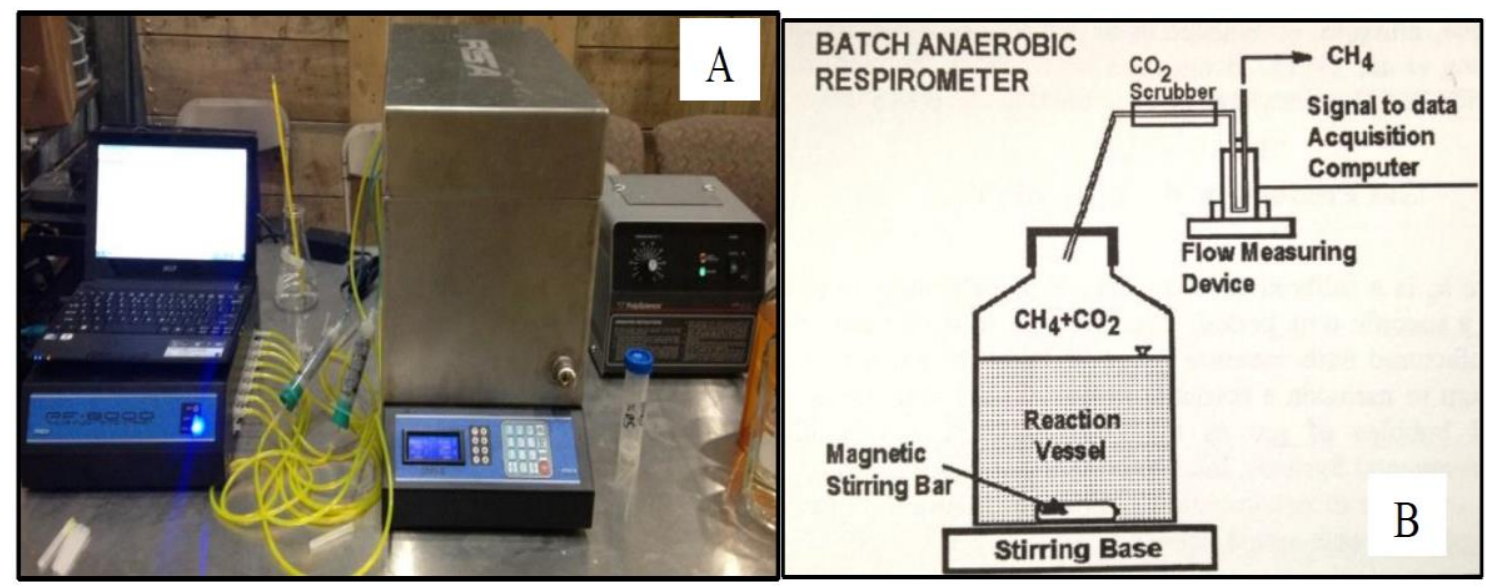

Figure 3-1 (A) Lab-scale batch respirometry (PF-8000 model); (B) Schematic diagram showing the functional elements of an anaerobic respirometer (Young \& Cowan, 2004).

The AD tests were performed in a pilot-scale EGSB (Figure 3-2) from Voith Paper Environmental Solutions GmbH \& Co. KG, Germany, which has a target COD loading of $\sim 10 \mathrm{~g} / \mathrm{L} /$ day. This system digests the wastewater in two phases using two different reaction reactions vessels: (1) a 45 liter pre-acidification (PA) tank where 20$40 \%$ of the wastewater COD was first pre-acidified naturally (without adding any reactants), and then the temperature, $\mathrm{pH}$, and nitrogen and phosphorus were adjusted to the desired mesophilic conditions (temperature of $\sim 35{ }^{\circ} \mathrm{C}, \mathrm{pH}$ of $\sim 5.5-7.5$, and a maximum COD to nutrient ratio of COD:N:P=350:5:1) (Speece, 1983); and (2) the main 
60 liter reactor where the pre-acidified sample was fed to the granular biomass to be digested through acetogenesis and methanogenesis to produce biogas. During testing, gas production, COD, and volatile fatty acid (VFA) concentrations were measured every 24 hours.
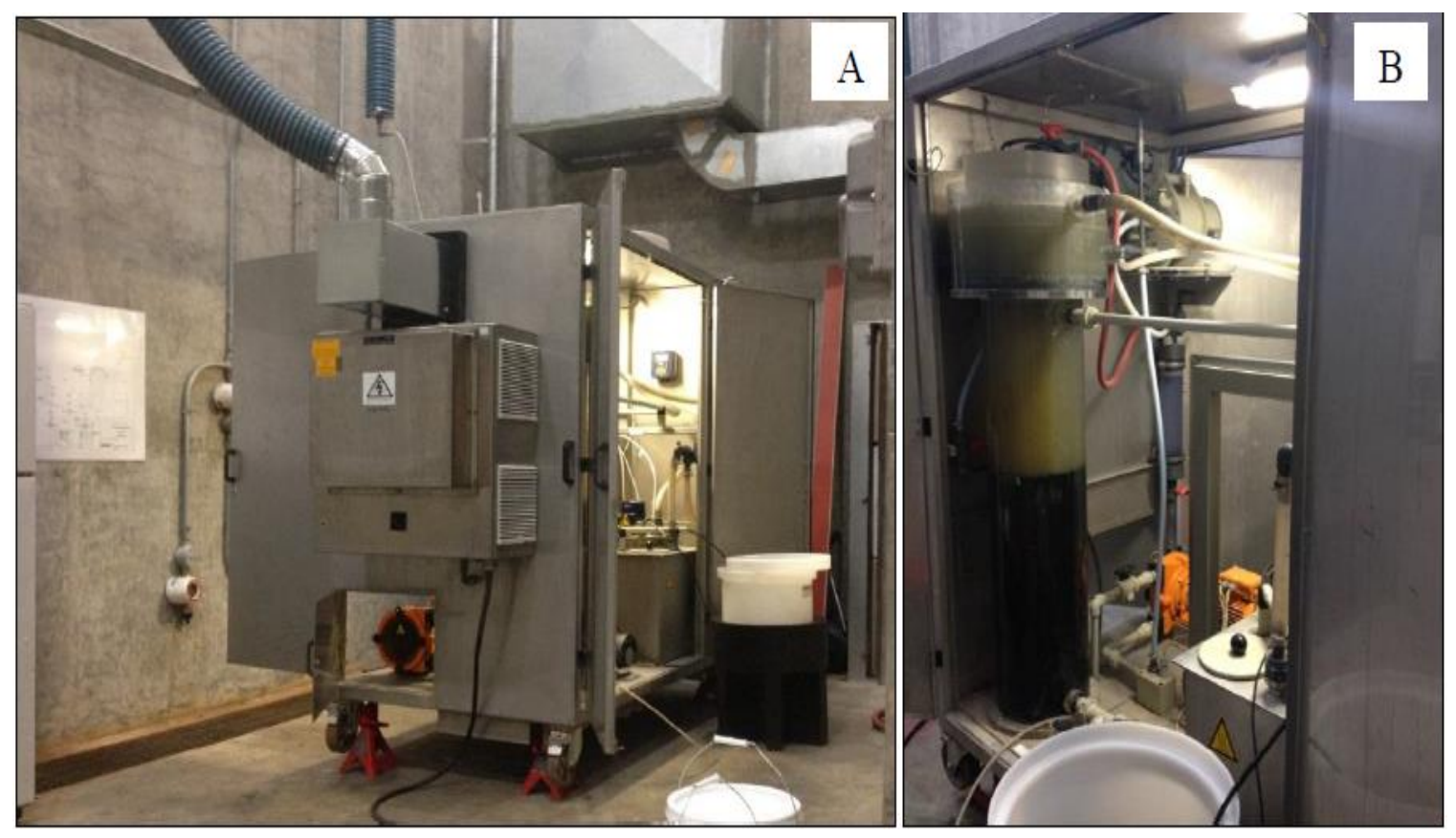

Figure 3-2 (A) 60 liter continuous up-flow AD reactor system; (B) Main AD reactor

\subsubsection{Inoculum}

The reactors were inoculated with active methanogenic biomass supplied by Cargill, Incorporated (Hammond, IN, USA). The characteristics of the biomass were: $\mathrm{pH}$ $=\sim 7$; total suspended solid $(\mathrm{TSS})=61 \mathrm{~g} / \mathrm{L}$; and volatile suspended solid $(\mathrm{VSS})=52 \mathrm{~g} / \mathrm{L}$.

\subsubsection{Substrate}

Actual industrial wastewaters (substrate) pulled from production lines were provided by a brewery plant, a soybean processing plant, and a beverage recycling plant 
located in Louisville, KY, USA. One of the three wastewaters is shown in Figure 3-3, as an example. The characteristics of the three wastewaters are summarized in Table 3-1.

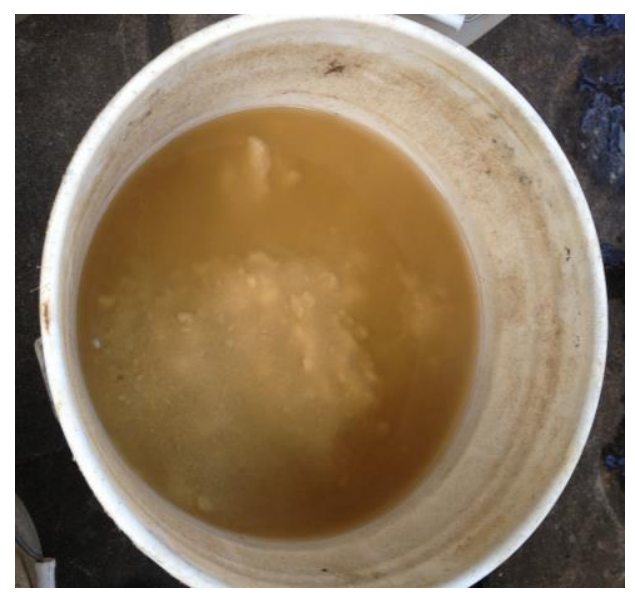

Figure 3-3 Distillery wastewater pulled from production lines, that was provided by a distillery plant located in Louisville, KY, USA.

Table 3-1 Average characteristics of the each wastewater (settled supernatant)

Parameter

$\begin{array}{lll}\text { Brewery } & \text { Soybean } & \text { Beverage } \\ \text { WW } & \text { WW } & \text { WW }\end{array}$

\begin{tabular}{lccc}
\hline $\mathrm{pH}$ & 4.3 & 4.1 & 3.9 \\
Total solids (TS), mg/L & 60 & 24 & 69.6 \\
Total suspended solids (TSS), mg/L & 33 & 1.8 & 65.7 \\
Total dissolved solids (TDS), mg/L & 26 & 20 & 3.9 \\
$\mathrm{COD}, \mathrm{g} / \mathrm{L}$ & 30 & 16 & 87 \\
Sulfates, mg/L & 190 & 5,000 & 257 \\
COD/Sulfate & 163.2 & 3.2 & 338.5 \\
Phosphorus, mg/L & 133 & 90 & 352 \\
Ammonia, mg/L & 618 & 56 & 24 \\
Crude protein of dried solubles, \% & 30 & - & - \\
Crude fat of dried solubles, \% & 9 & - & - \\
Carbohydrate of dried solubles, \% & 53 & - & - \\
Ash of dried solubles, \% & 8 & - & - \\
\hline
\end{tabular}


The $\mathrm{pH}$ of the wastewater was adjusted to the required range (5.5 to 7.5 ) by adding caustic $(\mathrm{NaOH})$ in the pre-acidification (PA) tank. Total suspended solids in the wastewater was less than $150 \mathrm{mg} / \mathrm{L}$, which has been reported as the upper limit that is not harmful to biomass granules (Mulder \& Thomas, 2003). Solids were removed by gravity settling in all cases, since the wastewater used and fed was settled supernatant. The sulfate concentration was below the toxic level of $150 \mathrm{mg} / \mathrm{L}$ of un-ionized $\mathrm{H}_{2} \mathrm{~S}$, which corresponds to $\sim 300 \mathrm{mg} / \mathrm{L}$ sulfate $\left(\mathrm{SO}^{2-}{ }_{4}\right)$ (Speece, 1983).

\subsection{Procedure: Impact of Substrate-to-Inoculum Ratio and Inhibition on Kinetics During Anaerobic Digestion of Agricultural and Beverage Processing Wastewaters}

The tests were initiated by transferring the biomass under anaerobic conditions to $0.5 \mathrm{~L}$ serum bottle test reactors. All serum bottles were flushed with nitrogen gas before and after transferring the biomass to prevent any air and oxygen passage. After transferring the biomass, the remainder of each bottle was filled by a medium consisting of nutrients, mineral elements, and buffer in previously established proportions (Kim et al., 1994; Young \& Cowan, 2004) to support the reactions and obtain the desired VSS concentration of $12 \mathrm{~g} / \mathrm{L}$ in each serum bottle.

All bottles were sealed using rubber septa caps. All serum bottles were placed in a water bath with a controlled temperature of $35^{\circ} \mathrm{C}$ so the reactions would occur under mesophilic conditions. The bottles were connected to the pressure transducers with needles and tygon tubes. Stirring was maintained at $300 \mathrm{rpm}$ with magnetic stirrers. Then, the first thing that should be done when setting up runs from biomass that is stored is to 
stabilize it. Therefore, $6 \mathrm{ml}$ of the volume of each bottle was wasted using a syringe and 6 $\mathrm{ml}$ of fresh ethanol stock substrate solution (control solution) containing $200 \mathrm{~g} \mathrm{COD} / \mathrm{L}$ was added to give a COD of $2.4 \mathrm{~g} / \mathrm{L}$ in each bottle so that the COD/VSS ratio would be 0.20. This helped stabilize the biomass in the reactors prior to the addition of the actual wastewater. After the gas production was leveled off, the process of wasting $6 \mathrm{ml}$ of the bottle and adding $6 \mathrm{ml}$ of fresh ethanol stock or stabilization process was repeated three to four times to recover the biomass from the shock of storage and temperature change.

Tests were then performed using conventional batch anaerobic toxicity assay and biochemical methane potential techniques (Davies-Venn et al., 1992; Kim et al., 1994; Young \& Cowan, 2004). For each wastewater, tests were run with four COD concentrations $(6,8,10$, and $12 \mathrm{~g} / \mathrm{L})$ to give four levels of COD/VSS ratio $(0.5,0.67$, 0.83 and 1.0). Because of the different initial COD's of each WW feedstock (Table 3-1), an appropriate volume of each wastewater (Table 3-2) was added to the designated bottle to obtain the desired COD level. For example, for the beverage WW with a COD of 87 $\mathrm{g} / \mathrm{L}$, a $1.0 \mathrm{~g} \mathrm{COD} / \mathrm{g}$ VSS ratio required feeding $69 \mathrm{~mL}$ of WW to $12 \mathrm{~g} \mathrm{VSS} / \mathrm{L}$ in the 500 $\mathrm{mL}$ culture volume (i.e. $87 \mathrm{gCOD} / \mathrm{L} \times 0.069 \mathrm{~L}=6 \mathrm{~g} \mathrm{COD}$ to $6 \mathrm{~g}$ VSS). For each COD, two bottles using ethanol as a control were tested for comparison. Also, two bottles of culture seed blank (no feed) were run to get a basis for correcting for background gas production. To obtain accurate BMP data, each COD test bottle was triplicated in each test run and each test run was repeated twice. Total biogas and methane production was measured throughout the course of the reaction for each test, each of which ran until gas production leveled off. The contents and number of bottles are summarized in Table 3-2. 
Table 3-2 Summary of experimental setup to assess the impact of substrate loading/inhibition for each wastewater: wastewater volume added and SI ratio in each bottle for each wastewater

\begin{tabular}{llccc}
\hline Materials Added & Function & $\begin{array}{c}\text { Substrate Volume } \\
\text { added, mL }\end{array}$ & $\begin{array}{c}\text { COD, } \\
\text { g/L }\end{array}$ & $\begin{array}{c}\text { SI } \\
\text { Ratio }\end{array}$ \\
\hline Biomass & Blank & 0 & 0 & 0 \\
Biomass, ethanol & Control & 15 & & \\
Biomass, wastewater & Soybean WW & 187.5 & 6 & 0.5 \\
Biomass, wastewater & Brewery WW & 97 & & \\
Biomass, wastewater & Beverage WW & 34.5 & & \\
Biomass, ethanol & Control & 20 & \multirow{2}{*}{0.67} \\
Biomass, wastewater & Soybean WW & 250 & & \\
Biomass, wastewater & Brewery WW & 129 & & \\
Biomass, wastewater & Beverage WW & 46 & 10 & 0.83 \\
Biomass, ethanol & Control & 25 & & \\
Biomass, wastewater & Soybean WW & 312.5 & & \\
Biomass, wastewater & Brewery WW & 161.3 & & \\
Biomass, wastewater & Beverage WW & 57.5 & & \\
Biomass, ethanol & Control & 30 & 12 & \\
Biomass, wastewater & Soybean WW & 375 & & \\
Biomass, wastewater & Brewery WW & 193.5 & 69 & \\
Biomass, wastewater & Beverage WW & 6 & & \\
\hline
\end{tabular}

\subsection{Procedure: Impact of Hydraulic Retention Time at Constant Organic Loading Rate in an Expanded Granular Sludge Bed Reactor}

Supernatant from settled distillery wastewater was loaded into the PA tank for pre-acidifying the wastewater and for $\mathrm{pH}$, temperature, and nutrient adjustment. The wastewater was retained in the PA tank for $\sim 24$ hours (constant retention time), where 
$20-40 \%$ of the initial COD was converted to VFAs, an intermediate product prior to methane formation. Temperature was maintained between $32-38{ }^{\circ} \mathrm{C}$, and the $\mathrm{pH}$ was adjusted to the required range of 5 or greater, which was chosen based on the acclimation behavior of this specific (distillery) wastewater, by adding caustic $(\mathrm{NaOH})$ in the preacidification (PA) tank. For this particular wastewater there was a sufficient amount of nitrogen and phosphate (Table 3-1), so these did not require adjustments.

The main 60 liter EGSB AD reactor was seeded with 45 liters of the active fresh biomass. The wastewater (with no dilution) was fed to the $\mathrm{AD}$ reactor with a constant flow rate $(\sim 0.2-0.3 \mathrm{~L} / \mathrm{h})$ for $\sim 20$ days to stabilize and acclimate the biomass to the substrate. To enhance mixing and conversion efficiency, thirty percent of the feed passing through the main reactor was recycled via the recirculation line (Figure 3-4). Tests were then run for four COD strengths, each of which were run at four volumetric flow rates to yield four OLR's. Each test was run for a duration of $\sim 1-2$ HRT's. The desired HRTs were calculated based on the volume of the main reactor and fresh influent only (exclusive of recycle). For HRTs of less than three days, the testing was run for about five days to ensure steady-state, which was determined based on COD and VFA measurements. The wastewater was diluted with tap water to obtain each COD concentration. 


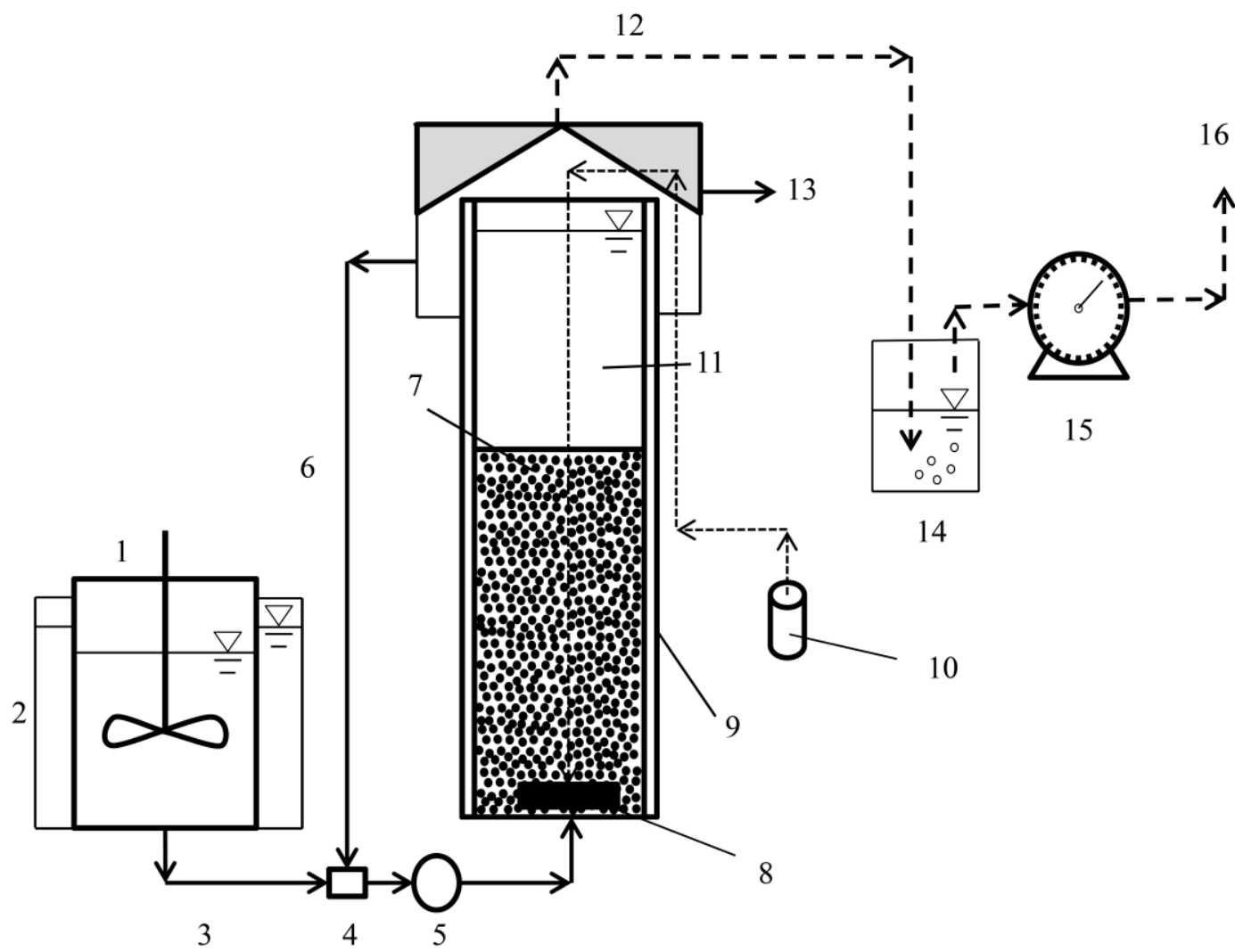

Figure 3-4 Simple schematic diagram of the anaerobic expanded granular sludge bed reactor: (1) pre-acidification tank; (2) heating tank/jacket; (3) feeding line; (4) connection block; (5) pump; (6) recirculation line; (7) granular biomass; (8) gas diffuser; (9) heating jacket; (10) hydrogen gas tank; (11) main reactor; (12) produced biogas line; (13) effluent; (14) gas tank transparent; (15) gas meter; (16) exhaust gas.

During testing, gas production, COD, and VFA concentrations were measured every $24-48$ hours. Approximately 15 to 20 data points were collected per test case. MS Excel was used both for statistical analyses and linear regression for the kinetic modeling. COD strengths and OLR's are summarized in Table 3-3. 
Table 3-3 Summary of COD and OLR loading to assess the impact of HRT

\begin{tabular}{lll}
\hline & & \\
Influent COD Strengths & Test case \# & OLR, g/L/day \\
& & \\
\hline Low $\sim 5 \mathrm{~g} / \mathrm{L}$ & 1A & Low $\sim 3 \mathrm{~g} \mathrm{COD} / \mathrm{L} /$ day \\
& 1B & Medium $\sim 5 \mathrm{~g} \mathrm{COD} / \mathrm{L} /$ day \\
& 1C & Medium-High $\sim 7 \mathrm{~g} \mathrm{COD} / \mathrm{L} /$ day \\
Medium $\sim 10 \mathrm{~g} / \mathrm{L}$ & 1D & High $\sim 9 \mathrm{~g} \mathrm{COD} / \mathrm{L} /$ day \\
& 2A & Low $\sim 3 \mathrm{~g} \mathrm{COD} / \mathrm{L}$ day \\
& 2B & Medium $\sim 5 \mathrm{~g} \mathrm{COD} / \mathrm{L} /$ day \\
Medium-High $\sim 20 \mathrm{~g} / \mathrm{L}$ & 2C & Medium-High $\sim 7 \mathrm{~g} \mathrm{COD} / \mathrm{L} /$ day \\
& 3B & Low $\sim 9 \mathrm{~g} \mathrm{COD} / \mathrm{L} /$ day \\
& 3B & Medium $\sim 5 \mathrm{~g} \mathrm{COD} / \mathrm{L} /$ day \\
& 3C & Medium-High $\sim 7 \mathrm{~g} \mathrm{COD} / \mathrm{L} /$ day \\
& 3D & High $\sim 9 \mathrm{~g} \mathrm{COD} / \mathrm{L} /$ day \\
High $\sim 30 \mathrm{~g} / \mathrm{L}$ & 4A & Low $\sim 3 \mathrm{~g} \mathrm{COD} / \mathrm{L} /$ day \\
& 4B & Medium $\sim 5 \mathrm{~g} \mathrm{COD} / \mathrm{L} /$ day \\
& 4C & Medium-High $\sim 7 \mathrm{~g} \mathrm{COD} / \mathrm{L} /$ day \\
& 4D & High $\sim 9 \mathrm{~g} \mathrm{COD} / \mathrm{L} /$ day \\
\hline
\end{tabular}

\subsection{Procedure: Impact of Hydrogen Addition on Biogas Quality Enhancement and Substrate Removal Efficiency in an Expanded Granular Sludge Bed Reactor}

Supernatant from settled distillery wastewater was loaded into the PA tank for pre-acidifying the wastewater and for $\mathrm{pH}$, temperature, and nutrient adjustment. The wastewater remained in the PA tank for $\sim 24$ hours, where $20-40 \%$ of the initial COD was converted to VFAs, an intermediate product prior to methane formation. Temperature 
was maintained between $32-38{ }^{\circ} \mathrm{C}$, and the $\mathrm{pH}$ was adjusted to the required range of 5 or greater, which was based on the acclimation behavior of this specific (distillery) wastewater, by adding caustic $(\mathrm{NaOH})$ in the pre-acidification (PA) tank . For this particular wastewater there was a sufficient amount of nitrogen and phosphate (Table 31), so these did not require adjustments.

The main 60 liter EGSB AD reactor was seeded with 45 liters of the active fresh biomass. The wastewater (with no dilution) was fed to the $\mathrm{AD}$ reactor with a constant flow rate $(\sim 0.2-0.3 \mathrm{~L} / \mathrm{h})$ for $\sim 20$ days to stabilize and adapt the biomass to the substrate. Subsequently, testing was run with and without hydrogen as described in Table 3-4 with various wastewater volumetric flow rates and organic loading rates (OLR) for a duration of 1-2 HRT. To enhance mixing and conversion efficiency, $30 \%$ of the feed passing through the main reactor was recycled via the recirculation line (Figure 3-4). For the purpose of this study, supplemental hydrogen was injected in lieu of actually capturing hydrogen from the PA tank. Two conservative hydrogen inflow rates $\left(0.15 \mathrm{~L} / \mathrm{L}_{\text {biogas }} / \mathrm{d}\right.$ and $0.30 \mathrm{~L} / \mathrm{L}_{\text {biogas }} / \mathrm{d}$ ) were employed that were less than the theoretical amount of hydrogen generated in the PA tank. The flow rates were controlled using a gas flow controller (Alicat Scientific, Inc., Tucson, AZ, USA) shown in Figure 3-5. These rates also correspond to stoichiometric proportions (hydrogen to carbon dioxide) of 1.4 and 2.8, which is less than the 4:1 stoichiometric ratio (Equation 2-9). A ceramic diffuser (Diffused Gas Technologies, Inc., Lebanon, OH, USA), shown in Figure 3-7, was employed to assist the gas-liquid mass transfer per Luo and Angelidaki (2013). During testing, gas production, COD, and VFA concentrations were measured every 24-48 hours. Approximately 15 to 20 data points were collected per test case. 


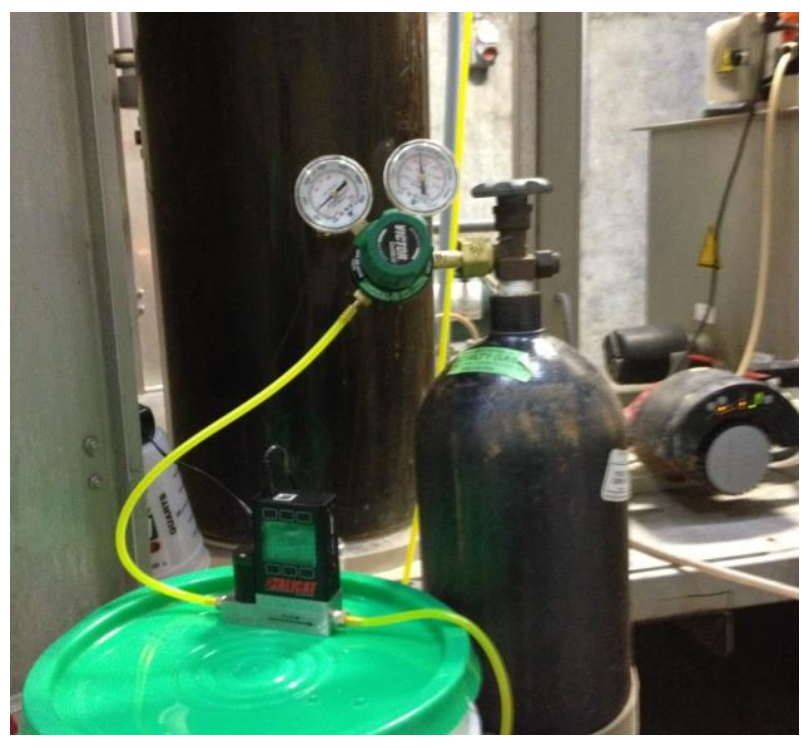

Figure 3-5 Gas flow controller setup to inject the hydrogen gas to the main reactor

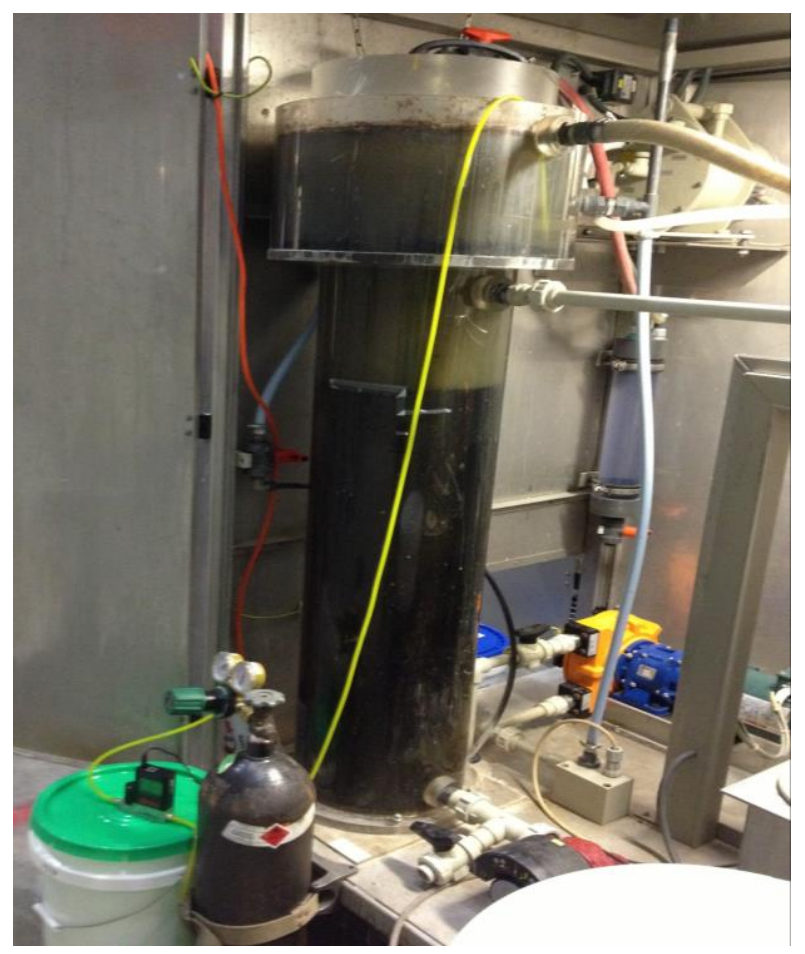

Figure 3-6 Experimental setup to inject the hydrogen gas to the main reactor 


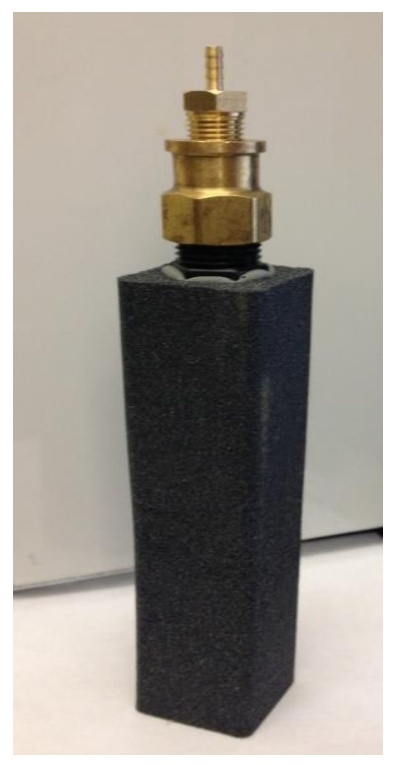

Figure 3-7 Ceramic diffuser used to inject the hydrogen gas

Table 3-4 Summary of hydrogen utilization and OLR to assess the impact of hydrogen introduction for each test case

\begin{tabular}{lll}
\hline $\begin{array}{l}\text { Test } \\
\text { case \# }\end{array}$ & Description & OLR, g/L/day \\
\hline 1 & $\begin{array}{l}\text { No hydrogen gas injection as a } \\
\text { basis background for comparison }\end{array}$ & $\begin{array}{l}\text { Increasing from } \sim 3 \text { to } 9 \mathrm{~g} \\
\text { COD/L/day }\end{array}$ \\
& & \\
$\begin{array}{l}\text { A) Injecting hydrogen gas at low } \\
\text { flow rate } \sim 0.15 \mathrm{~L} / \mathrm{L}_{\text {biogas }} / \mathrm{h}\end{array}$ & $\begin{array}{l}\text { Increasing from } \sim 5 \text { to } 9 \mathrm{~g} \\
\text { COD } / \mathrm{L} / \text { day }\end{array}$ \\
2 & $\begin{array}{l}\text { B) Injecting hydrogen gas at high } \\
\text { flow rate } \sim 0.30 \mathrm{~L} / \mathrm{L}_{\text {biogas }} / \mathrm{h}\end{array}$ & $\begin{array}{l}\text { Increasing from } \sim 5 \text { to } 9 \mathrm{~g} \\
\text { COD } / \mathrm{L} / \text { day }\end{array}$ \\
\hline
\end{tabular}




\section{CHAPTER 4 : IMPACT OF SUBSTRATE-TO-INOCULUM RATIO ON KINETICS DURING ANAEROBIC DIGESTION OF AGRICULTURAL AND BEVERAGE PROCESSING}

WASTEWATERS

\subsection{Gas Analysis}

Methane concentration in the control reactor was $76 \%$ compared to $49 \%, 57 \%$, and $56 \%$ in the soybean $\mathrm{WW}$, brewery $\mathrm{WW}$, and beverage recycling $\mathrm{WW}$ reactors, respectively, and where the difference was made up with more $\mathrm{CO}_{2}$ produced in the three non-control reactors (Table 4-1). Final $\mathrm{pH}$, which was measured twice for each case, equaled $\sim 7$. Therefore, the difference in the $\mathrm{CH}_{4}$ and $\mathrm{CO}_{2}$ compositions is due to the differences in composition of each wastewater, with each having a different degree of reduction of substrate carbon atoms. The presence of organic salts and the differential partitioning of $\mathrm{CO}_{2}$ and $\mathrm{CH}_{4}$ into the aqueous phase results in different amounts of methane content. Nitrogen and hydrogen concentrations were within a range of 1 to $3 \%$ in all reactors. $\mathrm{H}_{2} \mathrm{~S}$ concentration was below the detection limit $(0.04 \%)$ recommended by the manufacturer of the Gas Chromatograph for all WW's except the soybean WW, due to its high sulfate concentration $(5,000 \mathrm{mg} / \mathrm{L})$, which inhibited the methanogens from converting the organics to methane and favored the SRB instead. 
Table 4-1 Average biogas composition (percentage) for each wastewater

\begin{tabular}{lcccc}
\hline Constituent & $\begin{array}{c}\text { Control } \\
\text { Reactor }\end{array}$ & $\begin{array}{c}\text { Soybean } \\
\text { WW }\end{array}$ & $\begin{array}{c}\text { Brewery } \\
\text { WW }\end{array}$ & $\begin{array}{c}\text { Beverage } \\
\text { WW }\end{array}$ \\
\hline $\mathrm{CH}_{4}$ & 76 & 49 & 57 & 56 \\
$\mathrm{CO}_{2}$ & 22 & 44 & 42 & 41 \\
$\mathrm{~N}_{2}+\mathrm{H}_{2}$ & 2 & 3 & 1 & 3 \\
$\mathrm{H}_{2} \mathrm{~S}$ & 0 & 4 & 0 & 0 \\
\hline
\end{tabular}

\subsection{Batch Methane Production Tests}

Gas production and Specific Methanogenic Production (SMP) were determined (Figures 4-1 to 4-2) in order to analyze the anaerobic biomass activity in each reactor. Since there was a close match in the timing of the SMP peaks, an average of all replicated assay data was used to represent gas production and SMP curves for each wastewater. The SMP is expressed as the COD equivalent of the methane production rate per gram of volatile solids, or $\mathrm{g} \mathrm{COD/g} \mathrm{VSS/} \mathrm{Day,} \mathrm{and} \mathrm{is} \mathrm{calculated} \mathrm{from} \mathrm{the} \mathrm{gas} \mathrm{production} \mathrm{data}$ using Equation 4-1 (Young and Cowan, 2004) for each COD level tested for all wastewaters and ethanol (control):

$$
S M P=\frac{2.53 * R_{C H_{4}}}{X_{V}}
$$

where 2.53 is the $\mathrm{g}$ COD equivalent of one liter of methane at $35^{\circ} \mathrm{C}, \mathrm{R}_{\mathrm{CH} 4}$ is the rate of methane production, $\mathrm{L} / \mathrm{d}$ at any point in time, and $\mathrm{X}_{\mathrm{v}}$ is the VSS concentration of the biomass (g VSS/L). Approximately 220 to 280 data points were used to generate Figures 4-1 and 4-2. It was assumed that gas production leveled off when the SMP reached below $0.1 \mathrm{~g} \mathrm{COD} / \mathrm{g} \mathrm{VSS} /$ Day. The final seed culture (blank reactors) biogas production and maximum seed culture were $\sim 20 \mathrm{~mL}$ and $\sim 0.02 \mathrm{~g}$ COD/g VSS/ Day indicating near 
complete digestion of organics stored in the bacterial biomass. The gas production data were corrected by subtracting the data from the amount of gas produced in the blank reactors.
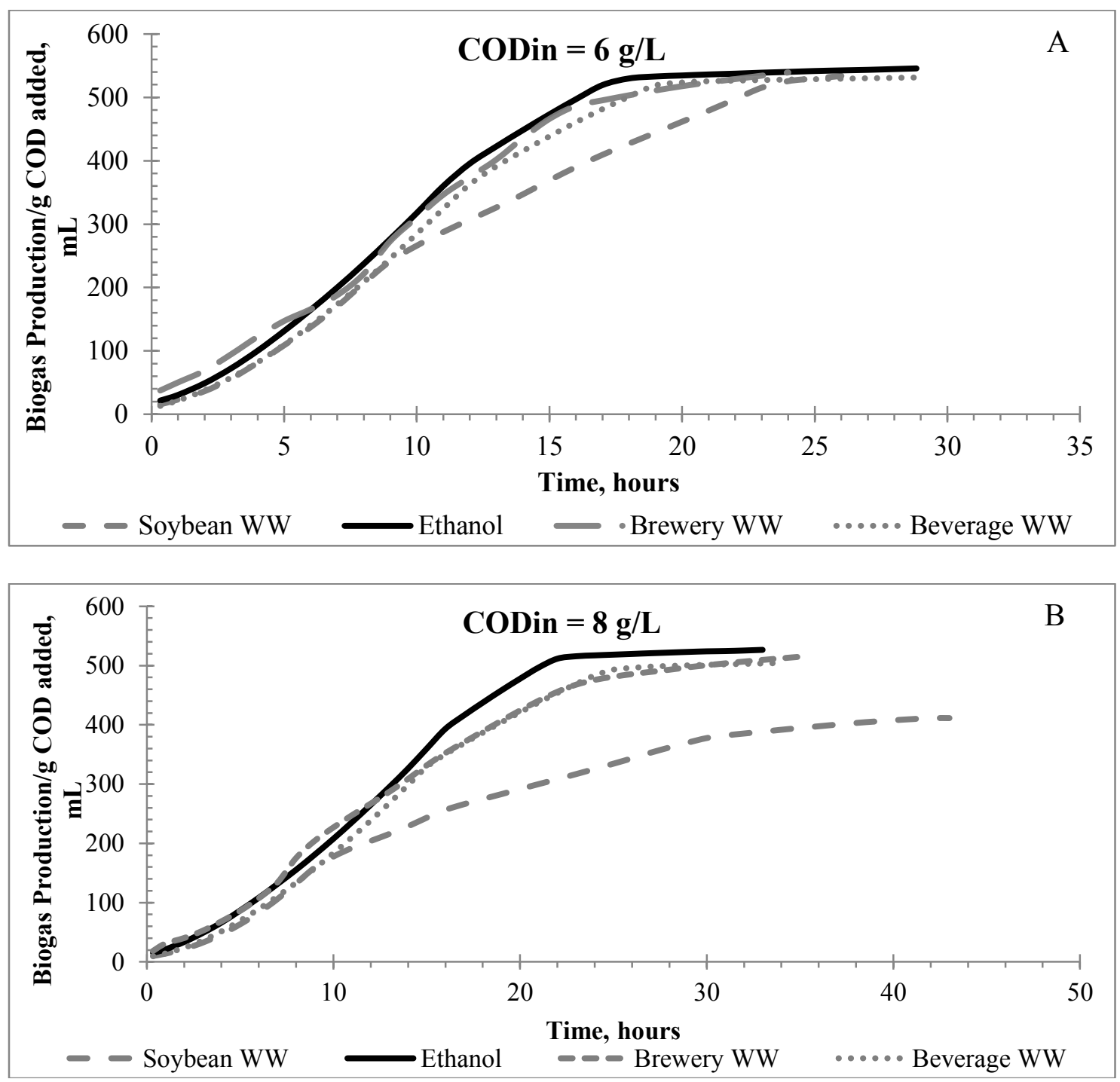

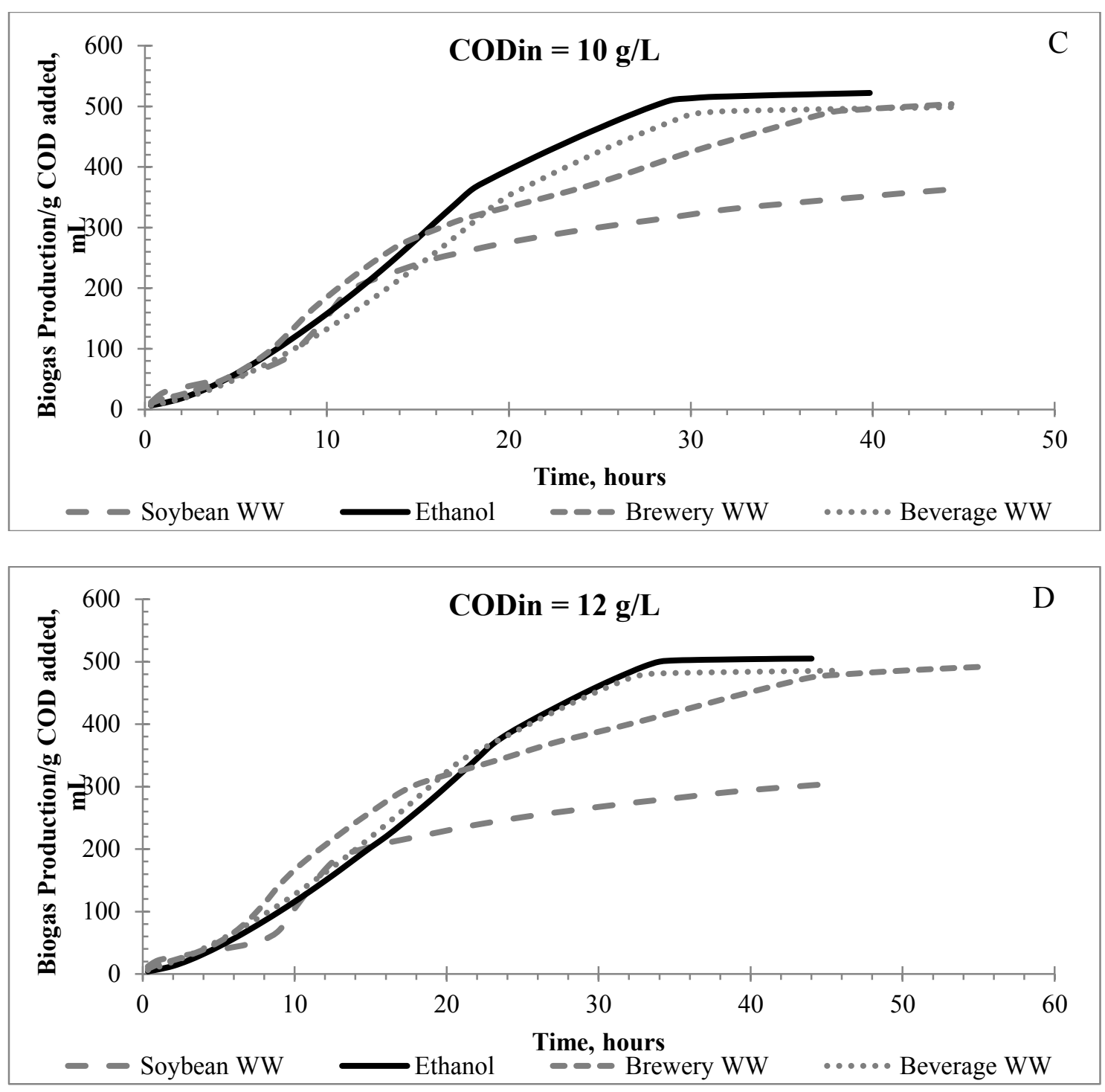

Figure 4-1 Total biogas produced per gram of initial COD added at COD $=6 \mathrm{~g} / \mathrm{L}(\mathrm{A})$, $\mathrm{COD}=8 \mathrm{~g} / \mathrm{L}(\mathrm{B}), \mathrm{COD}=10 \mathrm{~g} / \mathrm{L}(\mathrm{C})$, and $\mathrm{COD}=12 \mathrm{~g} / \mathrm{L}(\mathrm{D})$ 

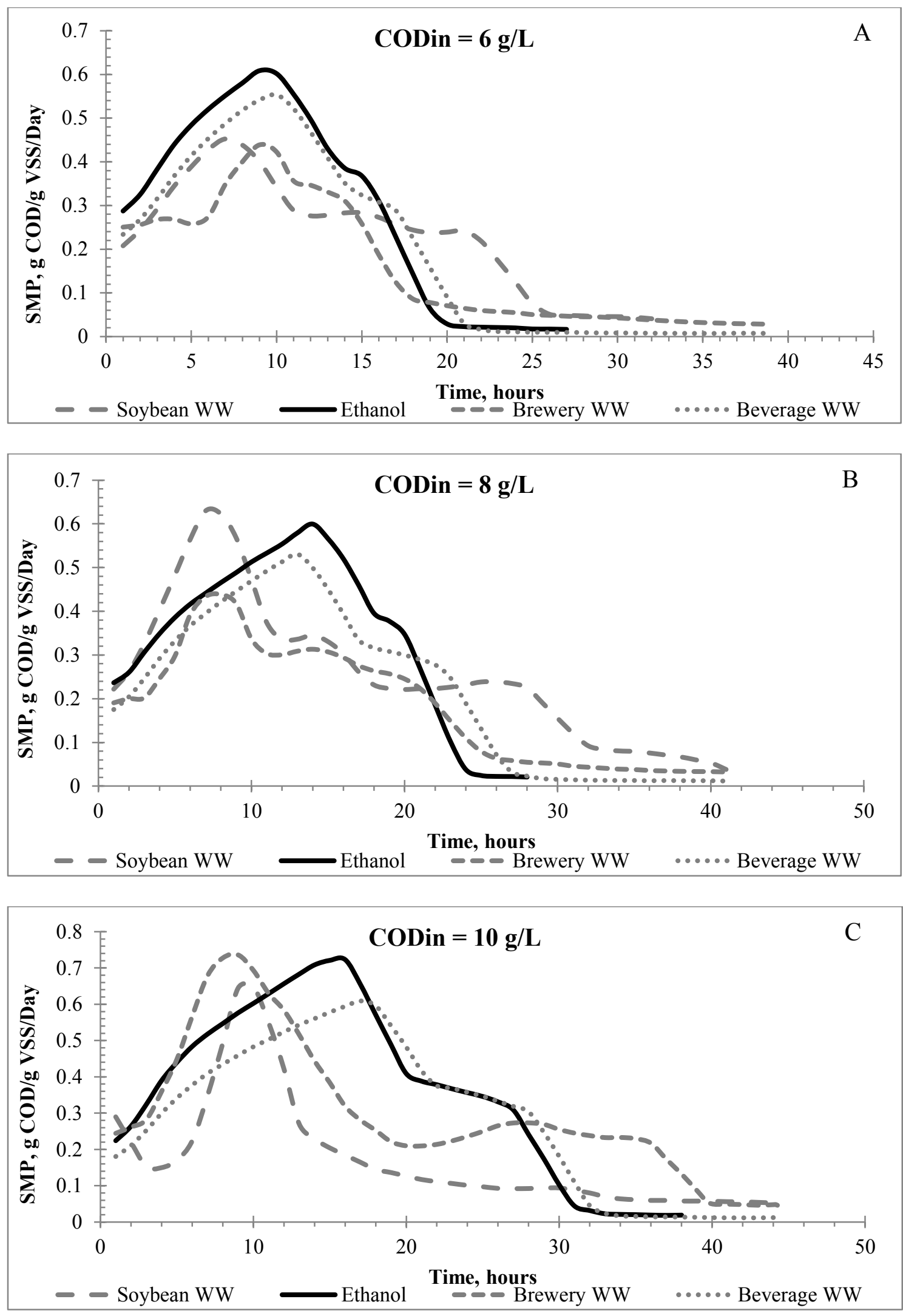


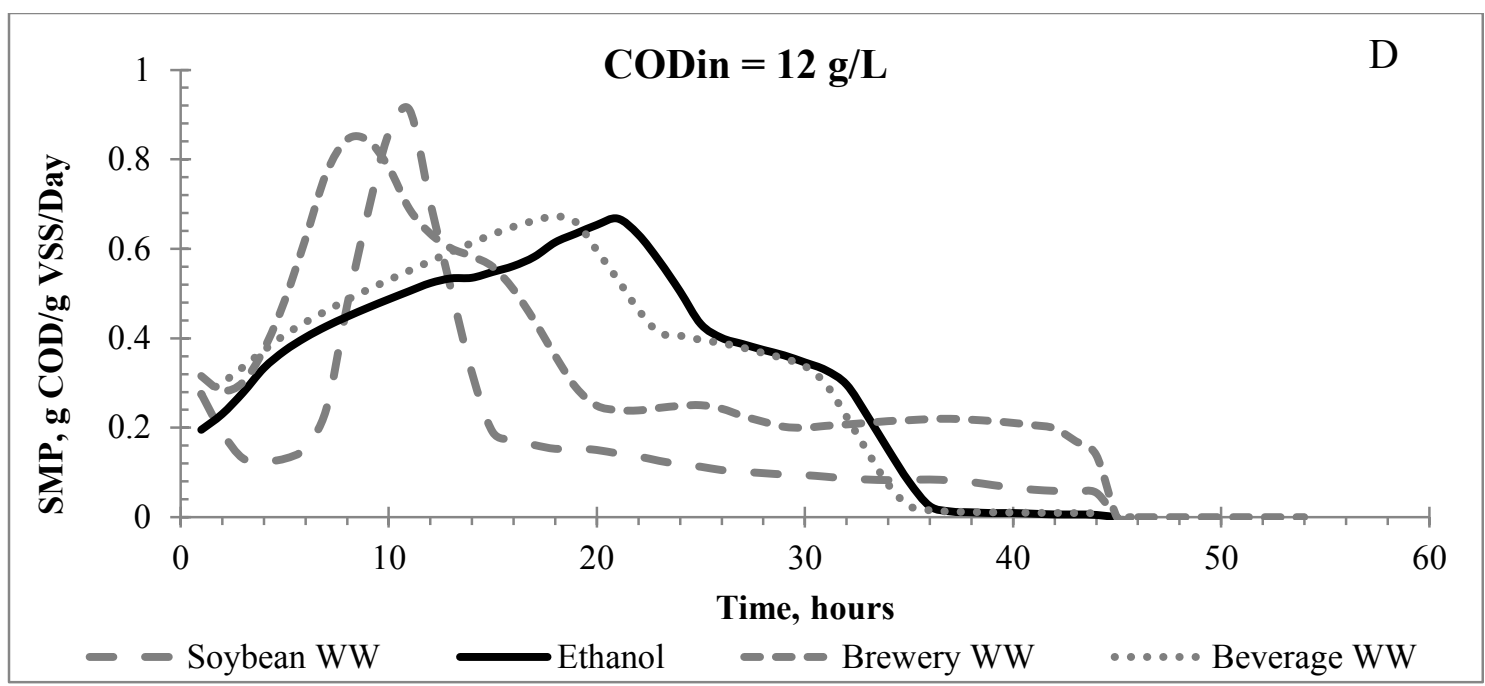

Figure 4-2 Specific methane production rates at $\mathrm{COD}=6 \mathrm{~g} / \mathrm{L}(\mathrm{A}), \mathrm{COD}=8 \mathrm{~g} / \mathrm{L}(\mathrm{B})$, $\mathrm{COD}=10 \mathrm{~g} / \mathrm{L}(\mathrm{C})$, and $\mathrm{COD}=12 \mathrm{~g} / \mathrm{L}(\mathrm{D})$

At the lowest COD level of $6 \mathrm{~g} / \mathrm{L}$, the total amount of gas produced for ethanol, soybean WW, brewery WW, and beverage WW were all within a narrow range of 520 to $530 \mathrm{~mL} / \mathrm{g}$ COD added (Figure 4-1A), while activity in the SMP curves dropped roughly at the same time for each stream (Figure 4-2A). The long tails in Figure 4-2A are due to the digestion of slowly biodegradable organics present in either the WW or stored in the biomass. The methanogenic activity was not inhibited and gas production and biomass behavior were similar for all four WW streams at this COD level. At higher initial COD levels $(8-12 \mathrm{~g} / \mathrm{L})$, the total amount of gas produced for the brewery WW and beverage WW streams remained within $97-98 \%$ of the control, however gas production decreased for the soybean WW stream to $\sim 80 \%(\mathrm{COD}=8 \mathrm{~g} / \mathrm{L}$ - Figure $4-1 \mathrm{~B}), \sim 70 \%(\mathrm{COD}=10$ $\mathrm{g} / \mathrm{L}$-Figure $4-1 \mathrm{C})$, and $\sim 60 \%(\mathrm{COD}=12 \mathrm{~g} / \mathrm{L}$ - Figure $4-1 \mathrm{D})$ of the amount produced in the control reactors.

Also, the amount of time for gas production to level off increased with increasing initial COD, from less than 20 hours at the lowest COD to greater than 30 hours for the 
highest COD for all cases including the control. The time to level off for the beverage WW was always approximately the same as that for the control (Figure 4-1). The ratio of the time to level off for the beverage WW to the time to level off for the control were $\sim 1.06,1.1,1.1$, and 1.03 for $6,8,10$, and $12 \mathrm{~g} / \mathrm{L}$, respectively. The time ratios for the brewery WW were $\sim 1,1.1,1.27$, and 1.32 for $6,8,10$, and $12 \mathrm{~g} / \mathrm{L}$. The time to level off increased more significantly above that for the control for the $10 \mathrm{~g} / \mathrm{L}$ and $12 \mathrm{~g} / \mathrm{L}$ initial COD conditions, which is attributed to overloading of a substrate that is converted to an organic acid intermediate that is more slowly converted to methane.

The SMP peaks for all of the wastewaters were about the same for all COD loadings (Figure 4-2). The SMP curves dropped more quickly at higher COD levels in the soybean WW stream (Figures 4-2B, 4-2C, and 4-2D). There are a couple of plausible explanations. One may be due to the higher COD/VSS ratios (SI ratios), which would cause it to take longer for the biomass to degrade the COD (lower rate during the first 5 hours - Figure 4-1 and 4-2). Another possibility is due to the consumption of COD by sulfate reduction (0.67 g COD/g SO 4 reduced - Young and Cowan, 2004). For example for the COD level of $12 \mathrm{~g} / \mathrm{L}$ : the sulfate concentration in the soybean WW was $5 \mathrm{~g} / \mathrm{L}$ (Table 3-1), multiplied by $0.67 \mathrm{~g} \mathrm{COD/g} \mathrm{SO} 4$ reduced, divided by $12 \mathrm{~g} \mathrm{COD} / \mathrm{L}$ (COD dosage), resulted in a $21 \%$ sulfate-reduction COD potential. This effect was well observed by the data in Figure 4-1D. 


\subsection{Modeling Approach}

\subsubsection{Monod Model}

The empirical Monod model is the most commonly used kinetics model for biological processes, and has been used used by researchers such as Kim et al. (1994) and Young and Cowan (2004):

$$
-r_{C O D}=\frac{k_{m} C_{C O D} X}{K_{s}+C_{C O D}}
$$

where $-\mathrm{r}_{\mathrm{COD}}$ is the COD removal rate (obtained from Equation 4-2), $\mathrm{C}_{\mathrm{COD}}$ is the COD concentration, $\mathrm{X}$ is the biomass concentration, $\mathrm{k}_{\mathrm{m}}$ is the maximum substrate removal rate, and $\mathrm{K}_{\mathrm{s}}$ is the half-saturation coefficient. A discussion on the fundamental mechanism of anaerobic digestion and its relationship to the Monod model is given in Appendix B.

In the Monod model, the reaction order (with respect to the substrate concentration) ranges from zero order at very high substrate concentrations (Equation 43) to first order at low concentrations (Equation 4-4). The reaction order is variable between these two limits. At low soluble COD loading $\mathrm{C}_{\mathrm{COD}}$ can be neglected in the denominator, so the Monod equation (Equation 4-15) becomes:

$$
\begin{gathered}
-r_{C O D}=k_{m} X \\
-r_{C O D}=\left(\frac{k_{m}}{K_{S}}\right) C_{C O D} X
\end{gathered}
$$

The COD concentrations used here were chosen low to accommodate the continuous reactor (EGSB), therefore all data was expected to follow first order kinetics. 


\subsubsection{Kinetic Parameters as a Function of SI Ratio}

The overall digestion process can be treated as a simplified chemical reaction (Borja et al., 1995; Borja et al., 1993; De la Rubia et al., 2011; Hashimoto, 1986; Henze \& Harremoes, 1983; Jimenez et al., 2004; McCarty \& Mosey, 1991; Nielsen \& Feilberg, 2012): COD $\rightarrow$ Products

The rate law for COD consumption is then given by Equation 4-2 (Fogler, 2006):

$$
-r_{C O D}=k_{C O D} C_{C O D}^{\alpha}
$$

where $-\mathrm{r}_{\mathrm{COD}}$ is the COD removal rate and is equal to $-\mathrm{r}_{\mathrm{COD}}=-\mathrm{dC}_{\mathrm{COD}} / \mathrm{dt}$ for a batch reactor, $\mathrm{k}_{\mathrm{COD}}$ is the rate constant $(\mathrm{g} \mathrm{COD} / \mathrm{L} / \mathrm{hr}), \mathrm{C}_{\mathrm{COD}}$ is the substrate $\mathrm{COD}$ concentration, and $\alpha$ is the order of reaction. Biogas and methane production is directly correlated with COD reduction (Borja et al., 2003). A reduction of $2.53 \mathrm{~g}$ COD is equivalent to the production of 1 Liter of methane at $35^{\circ} \mathrm{C}$ (Young and Cowan, 2004). Knowing the COD concentration loaded to the reactor and the volume of methane produced, the soluble COD remaining in the digester can be measured and the biomass yields can be calculated. COD concentrations needed for determining the kinetic parameters were then back calculated using methane generation data. Taking the natural logarithm of both sides of Equation 4-2 gives:

$$
\ln \left(-\frac{d C_{C O D}}{d t}\right)=\ln k_{C O D}+\alpha \ln C_{C O D}
$$

In order to differentiate COD with respect to time to determine the reaction rate, a 
function was needed to perform the differentiation. Therefore, the concentration-time data were first fitted to a 5th-order polynomial for each test (R-squared for each was greater than 0.98):

$$
C_{C O D}=a_{0}+a_{1} t+a_{2} t^{2}+a_{3} t^{3}+a_{4} t^{4}+a_{5} t^{5}
$$

The constants were determined using POLYMATH 6.10, and Equation 4-4 was then differentiated with respect to time:

$$
\frac{d C_{C O D}}{d t}=a_{1}+2 a_{2} t+3 a_{3} t^{2}+4 a_{4} t^{3}+5 a_{5} t^{4}
$$

The polynomial constants $\left(a_{1}, a_{2}, a_{3}, a_{4}\right.$, and $\left.a_{5}\right)$ are the same in both Equations 4-4 and 45. The slope and intercept from the plot of $\ln \left(-\mathrm{d} \mathrm{C}_{\mathrm{COD}} / \mathrm{dt}\right)$ versus $\operatorname{lnC}_{\mathrm{COD}}$ gives the kinetic parameters $\alpha$ and $\mathrm{k}_{\mathrm{COD}}$. The reaction order, $\alpha$, appears to be non-constant (Figure 4-3), which contradicts the assumption in several articles (Borja et al., 1993; Borja et al., 1995; De la Rubia et al., 2011; Hashimoto, 1986; Henze and Harremoes, 1983; Jimenez et al., 2004; McCarty and Mosey, 1991; Nielsen and Feilberg, 2012) that the overall methane fermentation follows a constant first-order kinetic model. 


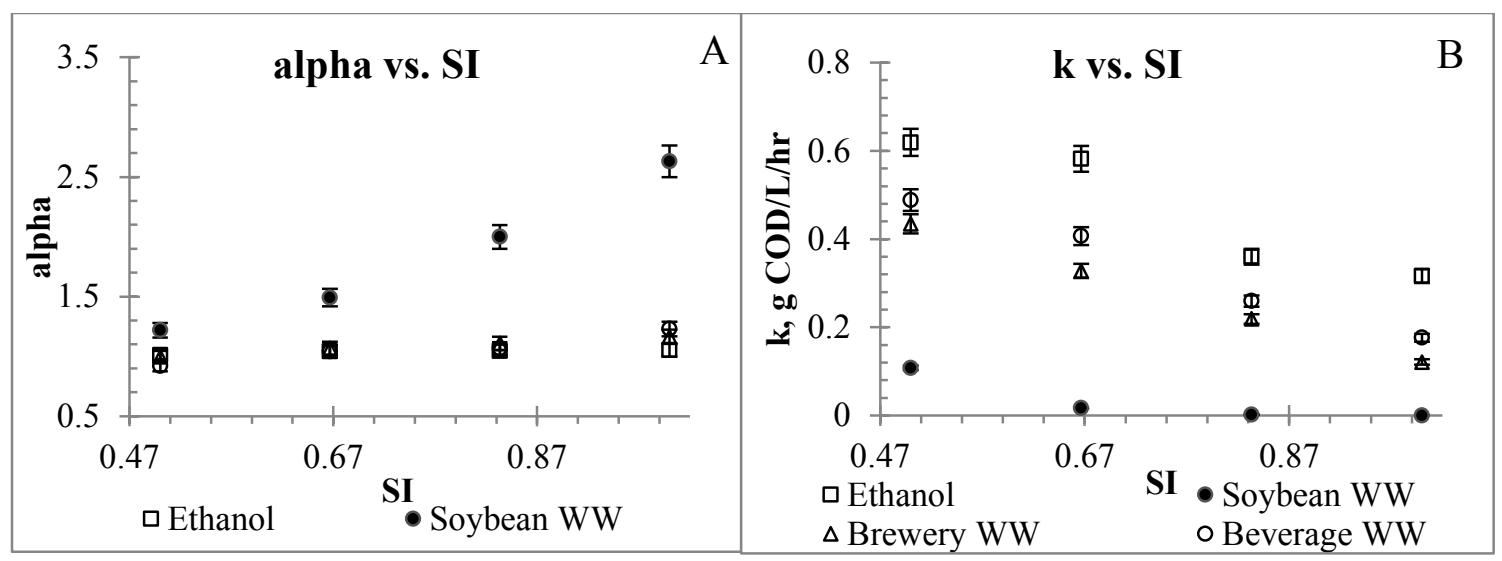

Figure 4-3 Rate order and rate constant as a function of SI ratio.

For the brewery and beverage recycling wastewaters, the reaction order increased slightly (from 1 to 1.2 ) as the SI ratio increased (Figure 4-3A), more or less meeting the expectations of the Monod model. For the soybean processing WW, where sulfates were extremely high, the reaction order increased from 1.21 at SI ratio of 0.5 to 2.63 at SI ratio of 1. A null hypothesis (T-Test) was run in MS Excel on the slope of alpha versus SI ratio in Figure 4-3A to test whether alpha was independent of SI ratio. The p-values for ethanol, brewery WW, beverage WW, and soybean WW were $0.07,0.04,0.05$, and 0.03 , respectively. The p-values for all cases were below the threshold chosen for statistical significance (0.10), so the null hypothesis was rejected in favor of the alternative hypothesis at a 90\% confidence level, indicating that reaction orders do, in fact, vary for all streams as a function of SI ratio. The reaction order remained constant for the ethanol control $(\alpha=1.05)$.

According to the Monod model, the reaction order should not exceed one. Increases in reaction order in the soybean WW case must then be attributed to some other factors and need to be considered in the modeling. To investigate this, the COD removal rate curves were generated and simulated from the kinetic parameters (Table 4-2) 
obtained by the Monod model and compared to curves from experimental measurements (Figure 4-4). By this means, an appropriate mechanism can be inferred.

The reaction rate constants all decreased as the COD loading and SI ratio increased (Figure 4-3B), which conforms to previous reports (Borja et al., 1993; Borja et al., 1995; De la Rubia et al., 2011; Hashimoto, 1986; Henze and Harremoes, 1983; Jimenez et al., 2004; McCarty and Mosey, 1991; Nielsen and Feilberg, 2012). The value of $\mathrm{k}$ dropped by $72 \%$ and $64 \%$ between a SI ratio of 0.5 and 1 for the brewery and beverage streams, by nearly $100 \%$ for the soybean processing stream, and $49 \%$ for the control. The decreases all appeared to be somewhat linear with increasing SI ratio. This decrease in the rate constant is predictable. The relevant reaction rate units, which correspond to SMP, are g COD/g VSS/hr (Figure 4-2). The biomass concentration can be assumed to be relatively constant in a batch anaerobic test. If the lowest concentration is already allowing the biomass to perform at an optimal rate, then a higher concentration will give a lower $\mathrm{g} \mathrm{COD} / \mathrm{L} / \mathrm{hr}$ (units of $\mathrm{k}$ ) even when the rate per unit of biomass (maximum SMP rate, g COD/gVSS/hr) is constant (Figure 4-2).

Table 4-2 Kinetic parameters from the Monod model for soybean processing WW

\begin{tabular}{cc|ccc} 
& \multirow{2}{*}{ SI Ratio } & \multicolumn{4}{|c}{ Monod Model } \\
Substrate & & $\mathrm{k}_{\mathrm{m}}, \mathrm{g} \mathrm{COD} \mathrm{g}^{-1} \mathrm{VSS} \mathrm{h}^{-1}$ & $\mathrm{~K}_{\mathrm{s}}, \mathrm{g}$ COD/L & $\mathrm{R}^{2}$ \\
\cline { 2 - 5 } & 0.67 & $0.05 \pm 0.001$ & 2.20 & 0.98 \\
& 0.83 & $0.08 \pm 0.001$ & 2.35 & 0.98 \\
1 & $0.10 \pm 0.001$ & 2.55 & 0.98
\end{tabular}



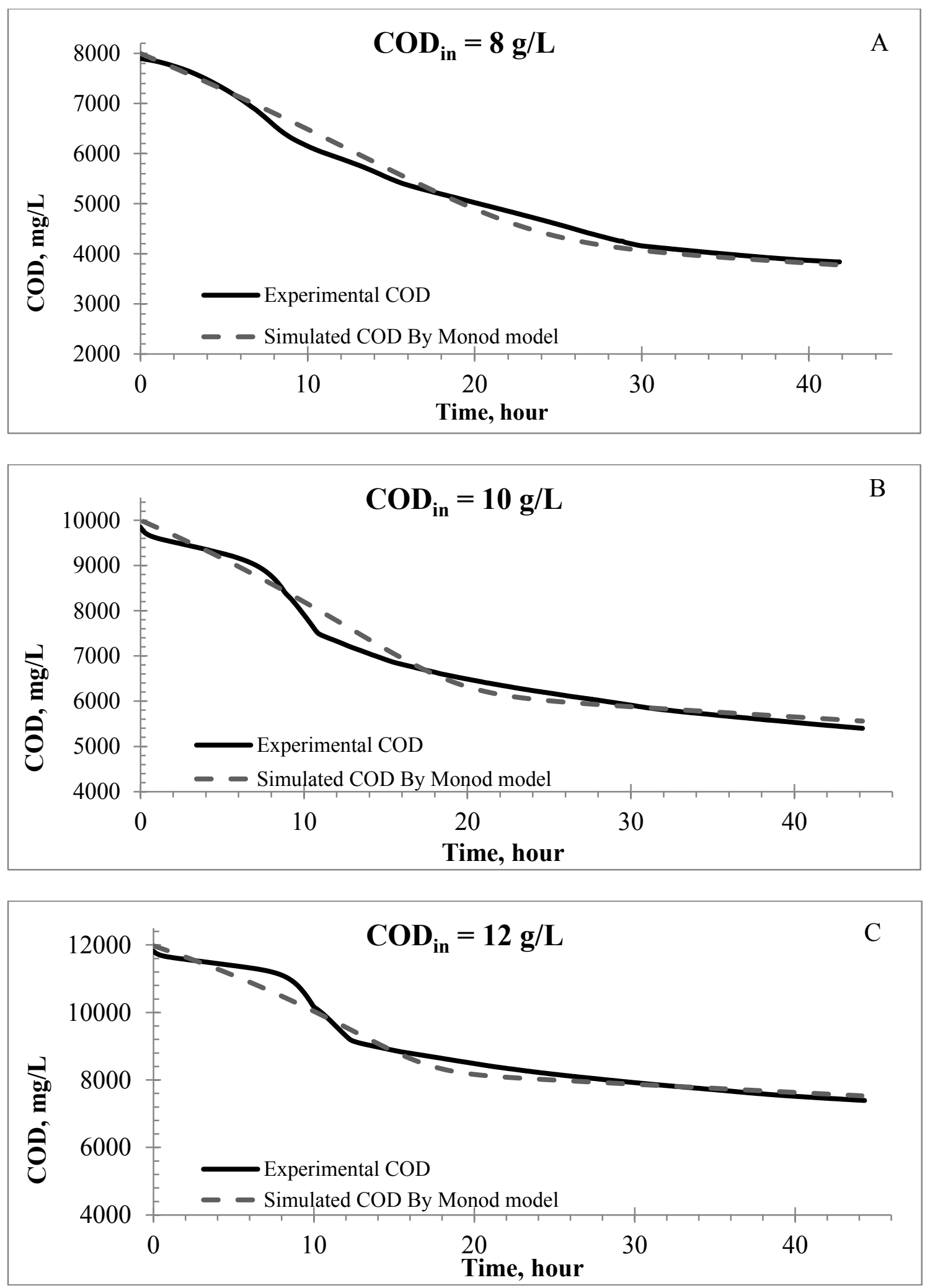
Figure 4-4 Experimental and simulated plots (Monod model) of COD consumption for soybean processing wastewater at $\mathrm{COD}=8 \mathrm{~g} / \mathrm{L}(\mathrm{A}), \mathrm{COD}=10 \mathrm{~g} / \mathrm{L}(\mathrm{B})$, and $\mathrm{COD}=12$ $\mathrm{g} / \mathrm{L}(\mathrm{C})$

The $\mathrm{R}^{2}$ values for the Monod model were $\sim 0.98$ for $8,10,12 \mathrm{~g} / \mathrm{L}$ influent COD concentrations (or SI ratio of $0.67,0.83$, and 1), indicating a good overall fit here. However, the simulated plots did not capture the behavior very well at the beginning of the reactions (first 10-13 hours) where the model predicts a steady decline rather than a lag and sharp drop in the COD that occurred experimentally. This was more pronounced at higher COD concentrations (10 and $12 \mathrm{~g} / \mathrm{L}$ ), signifying a COD (or organics) dependent behavior. This is attributed to a lag in the growth/activity of the SRB's. Once the SRB's were active they began to compete with the methanogens to consume COD to reduce sulfate, and sulfate by-products began to accumulate in the reactor. Per Young and Cowan (2004), to reduce one gram of sulfate, SRB's require $0.67 \mathrm{~g}$ COD (organics as food for metabolism). Further, as COD increased, the amount of sulfate present in the reactor increased, therefore requiring even more $\mathrm{COD}$ consumption due to metabolic activity of the SRB's. Therefore, at higher COD concentration, the amount of organics left for the methanogens for methane formation decreased, and as a result less biogas was produced per g COD added. This is readily apparent in Figure 4-1; as COD increased from $6 \mathrm{~g} / \mathrm{L}$ to $12 \mathrm{~g} / \mathrm{L}$, the biogas production per gram COD added decreased from 530 $\mathrm{mL}$ to $\sim 300 \mathrm{~mL}$ in the soybean cases, indicating the competition between $\mathrm{SRB}$ and methanogens.

The lag in COD reduction followed by a sudden rapid decrease may simply be attributed to acclimation. The biomass in each reactor was stabilized by feeding it with 
ethanol feedstock for three to four feed cycles prior to each test. After this stabilization period, running the reactors for one to two more feed cycles with the same wastewater used in each test might have affected the biomass acclimation, and hence the COD reduction curves. Once acclimated, a common assumption with anaerobic reactions is that acetoclastic methanogenesis is the rate-controlling reaction.

Since the data show a COD dependent trend, it is likely that acclimation of the SRB's impact the kinetics. While the methanogens became activated from the ethanol, there was previously no sulfates present to activate the SRB's. To account for the competition for COD between the methanogens and the SRB's, the Monod model can be modified slightly (per ADM1 modeling) to include a new term that considers competitive uptake of the substrate:

$$
-r_{C O D}=\frac{k_{m} C_{C O D} X}{K_{s}+C_{C O D}} I
$$

where "I" is defined as:

$$
I=\frac{1}{1+S_{I} / C_{C O D}}
$$

where the $\mathrm{S}_{\mathrm{I}} / \mathrm{C}_{\mathrm{COD}}$ ratio changes during the reaction.

Finally, it should be noted that it was assumed here that the COD remaining in the reactor was solely correlated to measured methane production (see Equation 4-4). Other mechanisms of COD consumption, such as for biomass growth and reduction of other biogas constituents (for example sulfur and hydrogen) were neglected. In a batch anaerobic test of the type performed here the biomass concentration can be assumed to be relatively constant during the test (Young and Cowan, 2004). COD reduction that 
contributes to other biogas constituents is minor since components such as hydrogen sulfide and hydrogen constitute only $0-4 \%$ of the biogas.

\subsection{Summary}

The impact of substrate loading on kinetic parameters during anaerobic digestion was assessed for wastewaters from soybean processing, brewery, and beverage recycling industries. For the brewery and beverage recycling wastewaters, the reaction order increased only slightly (from 1 to 1.2 ) as the SI ratio increased. For the soybean processing WW, where sulfates were extremely high, the reaction order increased from 1.21 at SI ratio of 0.5 to 2.63 at SI ratio of 1 . According to the Monod model, the reaction order should remain between zero and one depending on COD content. Increases in reaction order in the soybean WW case likely can be attributed to some other factors and need to be considered in the modeling. To investigate this, the COD removal rate curves were simulated from the kinetic parameters obtained by the Monod model and compared to curves from experimental measurements.

A common assumption with anaerobic reactions is that acetoclastic methanogenesis is the rate-controlling reaction. The $\mathrm{R}^{2}$ values for the Monod model were $\sim 0.98$ for $8,10,12 \mathrm{~g} / \mathrm{L}$ influent COD concentrations (or SI ratio of $0.67,0.83$, and 1 ), indicating a good overall fit here, but it did not capture the behavior very well at the beginning of the reactions (first 10-13 hours). This was primarily attributed to a lag in the growth/activity of the SRB's. Once the SRB's were active they began to compete with the methanogens for the COD consumption to reduce sulfate. To reduce one gram of sulfate, SRB's require $0.67 \mathrm{~g}$ COD (organics as food for metabolism). Therefore, at 
higher COD concentration, the amount of organics left for the methanogens for methane formation decreased, and as a result less biogas was produced per g COD added. As a result, a term should be added to the Monod model to account for the competitive uptake of COD by the SRB's. 


\section{CHAPTER 5 : IMPACT OF HYDRAULIC RETENTION TIME AT CONSTANT ORGANIC LOADING RATE IN A TWO-STAGE EXPANDED GRANULAR SLUDGE BED REACTOR}

\subsection{Reactor Performance}

The temperatures in the PA tank and the EGSB were maintained within the range of $32-38$ and $31-33{ }^{\circ} \mathrm{C}$, respectively. $\mathrm{pH}$ in the PA tank and the EGSB effluent were $\sim 5.5$ and $\sim 7.0$, respectively. The temperature and $\mathrm{pH}$ indicate that the reactor operated normally within the desired mesophilic range.

Pre-acidification during stage-one, where some of the COD converts naturally to VFA's (intermediate products between COD conversion to methane), increases the stability in the main EGSB reactor (stage-two) since a sudden increase in OLR there would cause an accumulation of VFAs, since the acetogens grow at a slower rate than the acidogens (Wang et al., 2010). The degree of pre-acidification (PA degree) during the first stage is determined by:

$$
\text { PA Degree }=\left(1-\frac{C O D_{P A}}{C O D_{i n}}\right) * 100
$$


where $\mathrm{COD}_{\mathrm{PA}}(\mathrm{g} / \mathrm{L})$ is the $\mathrm{COD}$ concentration leaving the PA tank and entering the main digester and $\mathrm{COD}_{\text {in }}(\mathrm{g} / \mathrm{L})$ is the initial COD concentration of the wastewater loaded in the PA tank. Applying this to case 2D as an example (see Table 5-1), the initial COD of the wastewater in the PA tank was $19.6 \mathrm{~g} / \mathrm{L}\left(\mathrm{COD}_{\text {in }}\right)$; the COD reduced to $14.7 \mathrm{~g} / \mathrm{L}\left(\mathrm{COD}_{\mathrm{PA}}\right)$ following the pre-acidification period. The VFA concentration increased from 1.6 to 6 $\mathrm{g} / \mathrm{L}$ during this same period. The PA degree in this example is $25 \%$, indicating $25 \%$ of the initial COD was converted to VFA's.

PA degree was always between 23 and 32\% (Table 5-1), which was within the desirable $20-40 \%$ range as stated by the manufacturer. Means, standard deviations, and coefficient of variations, which is the ratio of the standard deviation to the mean, were calculated for each column in Table 5-1.

Another important characteristic is the VFA concentration of the EGSB effluent, which reflects the acidity and the VFA consumption by methane forming bacteria in the main reactor. The VFA concentrations of the effluent remained consistent (less than 0.15 $\mathrm{g} / \mathrm{L}$ ) and ranged from 0.05 to $0.12 \mathrm{~g} / \mathrm{L}$ over the duration of the study indicating stability and normal operation of the reactor. Over the four different test cases, the standard deviations were between 0 to $0.02 \mathrm{~g} / \mathrm{L}$ and coefficient of variations between 7-24\%.

The total COD removal efficiency increased significantly as HRT increased while maintaining constant OLRs $(\sim 3,5,7$, or $9 \mathrm{~g} \mathrm{COD} / \mathrm{L} / \mathrm{d})$ (Figure 5-1A). At low OLR ( $\sim 3 \mathrm{~g}$ $\mathrm{COD} / \mathrm{L} / \mathrm{d}$ ), the removal efficiency increased from $60 \%$ to $98 \%$ as HRT increased from 1.6 to 10 days; for medium OLR ( $\sim 5 \mathrm{~g} \mathrm{COD} / \mathrm{L} / \mathrm{d})$ the removal efficiency increased from $63 \%$ to $98 \%$ as HRT increased from 1 to 5.9 days; for high-medium OLR $(\sim 7 \mathrm{~g}$ $\mathrm{COD} / \mathrm{L} / \mathrm{d})$, the removal efficiency increased from $65 \%$ to $98 \%$ as HRT increased from 
0.7 to 4.3 days; for the highest OLR ( $\sim 9 \mathrm{~g} \mathrm{COD} / \mathrm{L} / \mathrm{d})$ the removal efficiency increased from $56 \%$ to $98 \%$ as HRT increased from 0.5 to 3.3 days. Increases in removal efficiency were well outside the ranges of all error bars, which were based on standard deviations. Further, coefficients of variation were between $0.4-6 \%$, indicating COD removal efficiency was consistent in each case. These results clearly demonstrate, for equivalent OLR's, higher COD removal is achieved when running high concentration COD at a slower rate compared to lower concentration COD at a faster rate. Nearly $40 \%$ of the wastewater stream used here consists of crude proteins and fats (Table 3-1), which are higher molecular weight and slowly degrading organics, which for lower HRT at the same OLR were likely not efficiently diffusing into the granular biomass. Proteins and fats have been reported as likely to require longer HRT or may flush through a reactor without being digested (Girault et al., 2011).

For equivalent COD concentrations entering the EGSB, removal efficiencies were about equal for all HRT's studied. For example, for $30 \mathrm{~g} / \mathrm{L}$ influent COD content, as the HRT decreased and flow rate increased, the removal efficiency remained $\sim 98 \%$. The trend held for all COD concentrations. The implication is that a given COD concentration can be fed more quickly through the EGSB reactor without losing conversion efficiency. The ability to increase the feed rate (and lower HRT) will likely last until it reaches the destabilization point where the reactor becomes overloaded with the intermediate VFA due to failure during acetogenesis and methanogenesis. At that point the system will become acidified, the $\mathrm{pH}$ drops, and removal efficiency and biogas production will decrease (Rincón et al., 2008; Salminen and Rintala, 2002). 
Biogas production trends mirrored COD removal trends (Figure 5-1B). The biogas production rate increased by $\sim 22-32 \%$ as HRTs increased by $\sim 5-6$ times while maintaining constant OLRs $(\sim 3,5,7$, and $9 \mathrm{~g} \mathrm{COD} / \mathrm{L} . \mathrm{d})$. In the case of low loading rate ( $\sim 3 \mathrm{~g} \mathrm{COD} / \mathrm{L} . \mathrm{d})$, the biogas production rate increased from 78 to $96 \mathrm{~L} / \mathrm{d}$ as HRT increased from 1.6 to 10 days; for the medium loading case $(\sim 5 \mathrm{~g} \mathrm{COD} / \mathrm{L} . \mathrm{d})$ the biogas production rate increased from 123 to $161 \mathrm{~L} / \mathrm{d}$ as HRT increased from 1 to 5.9 days; for the medium-high loading rate $(\sim 7 \mathrm{~g} \mathrm{COD} / \mathrm{L} . \mathrm{d})$ the biogas production rate increased from 167 to $203 \mathrm{~L} / \mathrm{d}$ as HRT increased from 0.7 to 4.3 days; for the high loading case ( $\sim \mathrm{g}$ COD/L.d) the biogas production rate increased from 214 to $259 \mathrm{~L} / \mathrm{d}$ as HRT increased from 0.5 to 3.3 days.

For equivalent COD concentrations entering the EGSB, as the OLR increased from $\sim 3 \mathrm{~g} \mathrm{COD} / \mathrm{L} / \mathrm{d}$ to $\sim 9 \mathrm{~g} \mathrm{COD} / \mathrm{L} / \mathrm{d}$, the biogas production rate increased $\sim 2.4-2.8$ times due to the higher substrate feeding rate. As an example, for a COD concentration of $20 \mathrm{~g} / \mathrm{L}$, as the OLR increased from $3.2 \mathrm{~g} \mathrm{COD} / \mathrm{L} / \mathrm{d}$ to $9 \mathrm{~g} \mathrm{COD} / \mathrm{L} / \mathrm{d}$, the biogas production rate increased from 85 to $239 \mathrm{~L} / \mathrm{d}$, an increase of $\sim 2.8$ times. The more significant finding here is that biogas quality remained similar for all cases as methane, carbon dioxide, and hydrogen sulfide percentages remained within a small range of each other. Methane content for all cases were between $\sim 71-76 \%$ (coefficient of variation of $0.4-$ $2 \%$ ), carbon dioxide content was between $\sim 24-29 \%$ (coefficient of variation of 0.4$1.8 \%$ ), and hydrogen sulfide was between 0.04 and $0.9 \%$ (coefficient of variation of $0.3 \%)$. 
Table 5-1 Substrate and product levels for each OLR and HRT

\begin{tabular}{|c|c|c|c|c|c|c|c|c|c|c|c|c|}
\hline \multicolumn{2}{|c|}{$\begin{array}{l}\text { Test } \\
\text { Case }\end{array}$} & $\begin{array}{l}\text { OLR, } \\
\text { gCOD/L.d }\end{array}$ & $\begin{array}{l}\text { HRT, } \\
\text { d }\end{array}$ & $\begin{array}{c}\mathrm{COD}_{\text {in }}, \\
\mathrm{g} / \mathrm{L}\end{array}$ & $\begin{array}{l}\mathrm{COD}_{\mathrm{PA}}, \\
\mathrm{g} / \mathrm{L}\end{array}$ & $\begin{array}{l}\mathrm{COD}_{\text {out }}, \\
\mathrm{g} / \mathrm{L}\end{array}$ & $\begin{array}{c}\mathrm{VFA}_{\text {in }}, \\
\mathrm{g} / \mathrm{L}\end{array}$ & $\begin{array}{l}\mathrm{VFA}_{P A} \\
\mathrm{~g} / \mathrm{L}\end{array}$ & $\begin{array}{l}\mathrm{VFA}_{\text {out }} \\
\mathrm{g} / \mathrm{L}\end{array}$ & $\begin{array}{l}\text { (PA } \\
\text { Degree) }\end{array}$ & $\mathrm{CH}_{4}$ & $\mathrm{CO}_{2}$ \\
\hline \multirow{4}{*}{1} & A & 3.1 & 10 & 30.8 & 22.3 & 0.5 & 2.2 & 7.2 & 0.1 & $30 \%$ & $72 \%$ & $28 \%$ \\
\hline & $\mathrm{B}$ & 5.1 & 5.9 & 30.3 & 22.4 & 0.6 & 2.1 & 7.2 & 0.1 & $29 \%$ & $71 \%$ & $29 \%$ \\
\hline & $\mathrm{C}$ & 7.1 & 4.3 & 30.1 & 20.5 & 0.6 & 2.2 & 7 & 0.1 & $32 \%$ & $74 \%$ & $26 \%$ \\
\hline & $\mathrm{D}$ & 8.1 & 3.3 & 28.7 & 21.3 & 0.6 & 2.1 & 7.8 & 0.1 & $27 \%$ & $73 \%$ & $27 \%$ \\
\hline \multicolumn{4}{|c|}{ Mean } & 29.6 & 20.8 & 0.6 & 2.2 & 7.4 & 0.1 & $29 \%$ & $73 \%$ & $27 \%$ \\
\hline \multicolumn{4}{|c|}{ Standard Deviation } & 2 & 3.4 & 0.1 & 0.3 & 0.6 & 0.02 & $5 \%$ & $1.8 \%$ & $1.8 \%$ \\
\hline \multicolumn{4}{|c|}{ Coefficient of Variation, $\%$} & 7 & 16 & 16 & 12 & 8 & 20 & 17 & 2 & 7 \\
\hline \multirow{4}{*}{2} & $\mathrm{~A}$ & 3.2 & 5.9 & 19.2 & 14.5 & 1.1 & 1.5 & 5.3 & 0.1 & $28 \%$ & $73 \%$ & $27 \%$ \\
\hline & $\mathrm{B}$ & 4.8 & 4.2 & 20.1 & 14 & 1.1 & 1.5 & 5.2 & 0.1 & $29 \%$ & $76 \%$ & $24 \%$ \\
\hline & $\mathrm{C}$ & 7.4 & 2.7 & 20.4 & 15.3 & 1.2 & 1.6 & 5.9 & 0.1 & $28 \%$ & $76 \%$ & $24 \%$ \\
\hline & $\mathrm{D}$ & 9 & 2.2 & 19.6 & 14.7 & 1.2 & 1.6 & 6 & 0.1 & $27 \%$ & $73 \%$ & $27 \%$ \\
\hline \multicolumn{4}{|c|}{ Mean } & 19.8 & 14.6 & 1.1 & 1.6 & 5.4 & 0.1 & $28 \%$ & $74 \%$ & $25 \%$ \\
\hline \multicolumn{4}{|c|}{ Standard Deviation } & 0.7 & 1.7 & 0.1 & 0.1 & 0.5 & 0.01 & $4 \%$ & $1.5 \%$ & $1.7 \%$ \\
\hline \multicolumn{4}{|c|}{ Coefficient of Variation, $\%$} & 4 & 12 & 15 & 8 & 12 & 11 & 10 & 2 & 7 \\
\hline \multirow{4}{*}{3} & $\mathrm{~A}$ & 3.1 & 3.3 & 10.4 & 7.9 & 2 & 0.7 & 2.8 & 0.1 & $26 \%$ & $74 \%$ & $26 \%$ \\
\hline & $\mathrm{B}$ & 5.3 & 1.9 & 10.4 & 7.9 & 1.8 & 0.7 & 2.7 & 0.1 & $26 \%$ & $74 \%$ & $26 \%$ \\
\hline & $\mathrm{C}$ & 7.2 & 1.4 & 10.8 & 7.9 & 1.9 & 0.9 & 2.9 & 0.1 & $31 \%$ & $74 \%$ & $26 \%$ \\
\hline & $\mathrm{D}$ & 9.2 & 1.1 & 10.8 & 8.4 & 2 & 0.8 & 3 & 0.1 & $28 \%$ & $74 \%$ & $26 \%$ \\
\hline \multicolumn{4}{|c|}{ Mean } & 10.2 & 8.1 & 1.9 & 0.8 & 2.8 & 0.1 & 28 & $73 \%$ & $26 \%$ \\
\hline \multicolumn{4}{|c|}{ Standard Deviation } & 0.3 & 0.3 & 0.2 & 0.1 & 0.2 & 0.01 & $5 \%$ & $0.3 \%$ & $0.5 \%$ \\
\hline \multicolumn{4}{|c|}{ Coefficient of Variation, $\%$} & 3 & 4 & 10 & 11 & 7 & 24 & 16 & 0.04 & 2 \\
\hline \multirow{4}{*}{4} & $\mathrm{~A}$ & 3.1 & 1.6 & 5.1 & 3.8 & 2 & 0.4 & 1.2 & 0.1 & $30 \%$ & $75 \%$ & $25 \%$ \\
\hline & $\mathrm{B}$ & 5 & 1 & 5.1 & 3.8 & 1.9 & 0.4 & 1.2 & 0.1 & $30 \%$ & $73 \%$ & $26 \%$ \\
\hline & $\mathrm{C}$ & 7 & 0.7 & 5 & 3.8 & 1.7 & 0.4 & 1.3 & 0.1 & $27 \%$ & $74 \%$ & $26 \%$ \\
\hline & $\mathrm{D}$ & 9.1 & 0.5 & 5 & 3.7 & 2.2 & 0.4 & 1.3 & 0.1 & $28 \%$ & $75 \%$ & $24 \%$ \\
\hline \multicolumn{4}{|c|}{ Mean } & 5.1 & 4 & 2 & 0.4 & 1.3 & 0.1 & $29 \%$ & $74 \%$ & $25 \%$ \\
\hline \multicolumn{4}{|c|}{ Standard Deviation } & 0.1 & 0.4 & 0.2 & 0 & 0.08 & 0 & $2 \%$ & $0.6 \%$ & $0.4 \%$ \\
\hline \multicolumn{4}{|c|}{ Coefficient of Variation, $\%$} & 2 & 11 & 9 & 2 & 7 & 7 & 6 & 1 & 1 \\
\hline
\end{tabular}

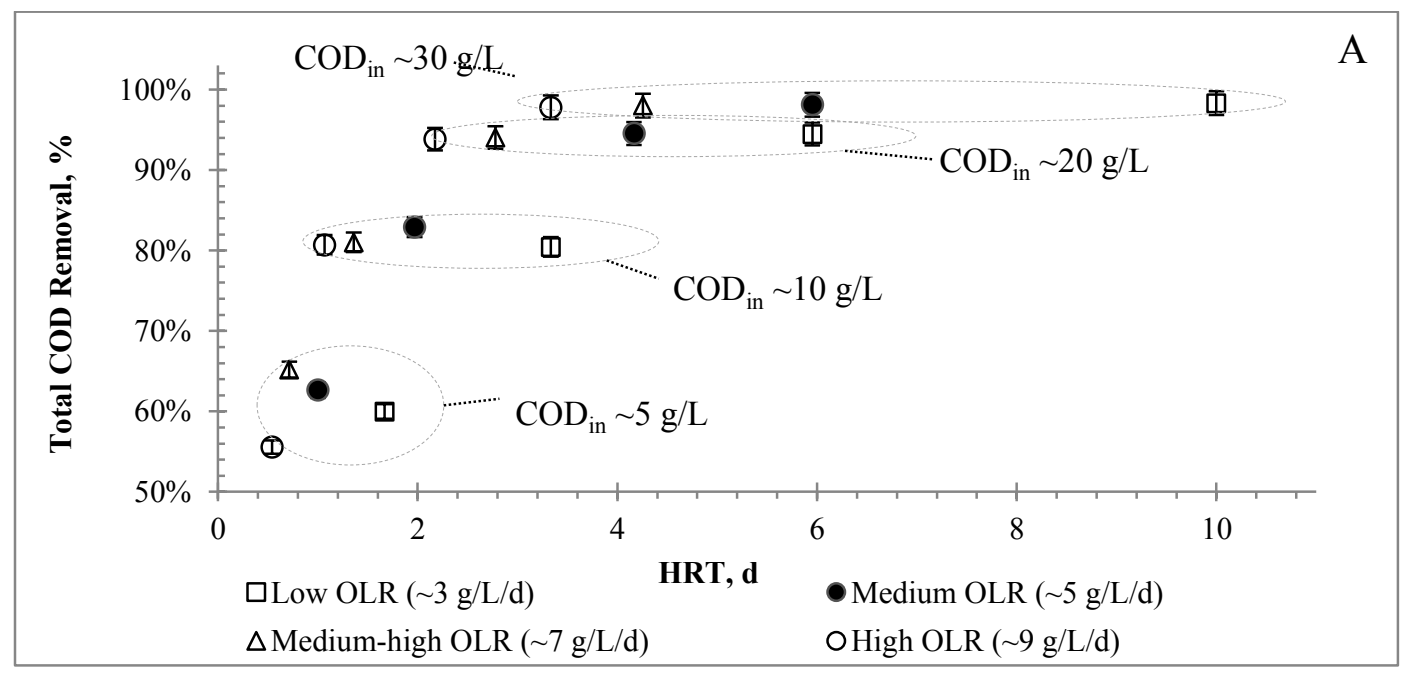




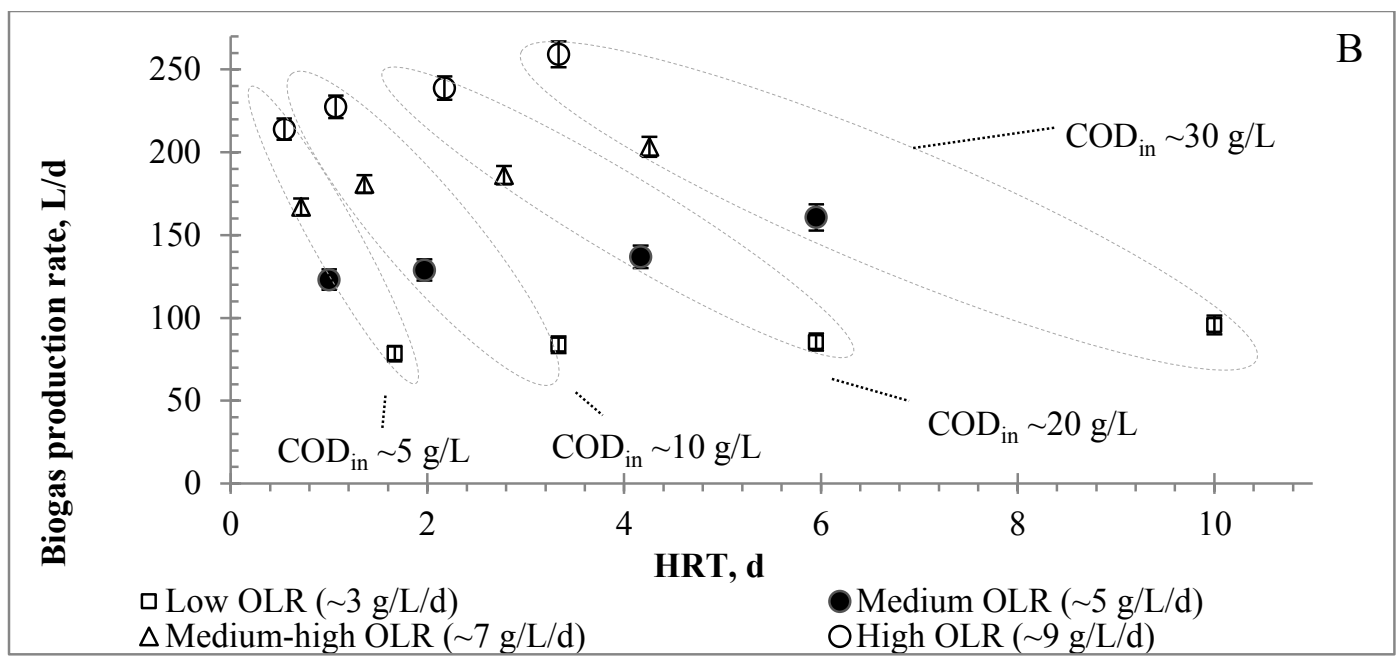

Figure 5-1 Total COD removal efficiency (A) and biogas production rate (B) as a function of HRT for each OLR.

\subsection{Kinetic Analysis of Biomass Stability}

For an up-flow sludge bed reactor, the rate of change of biomass in the system can be expressed as (Hu et al., 2002; Sponza and Uluköy, 2008):

$$
\frac{d X}{d t}=\frac{Q}{V} X_{0}-\frac{Q}{V} X+k X-K_{d} X
$$

where $\mathrm{Q}$ is the flow rate $(\mathrm{L} / \mathrm{d}) ; \mathrm{V}$ is the volume of the reactor $(\mathrm{L}) ; \mathrm{X}_{0}$ and $\mathrm{X}$ are the concentrations (g VSS/L) of the biomass in the influent and the effluent of the reactor, respectively; $\mathrm{k}$ and $\mathrm{k}_{\mathrm{d}}$ are the specific growth rate $\left(\mathrm{d}^{-1}\right)$ and death rate constant $\left(\mathrm{d}^{-1}\right)$, respectively. By assuming the concentration of the biomass in the reactor remains 
constant at steady-state, $\mathrm{dX} / \mathrm{dt}=0$, and defining the $\mathrm{HRT}(\theta)$ as the ratio of reactor volume (V) to the flow rate of the influent (Q), Equation 5-2 reduces to:

$$
k=\frac{1}{\theta}+K_{d}
$$

The specific growth rate can be expressed by the Monod model, which can be applied to anaerobic digestion (Hu et al., 2002; Sponza and Uluköy, 2008; Young and Cowan, 2004) as:

$$
k=\frac{k_{m} S}{K_{S}+S}
$$

where $\mathrm{S}$ is the COD concentration $(\mathrm{g} / \mathrm{L})$ in the effluent, $\mathrm{k}_{\mathrm{m}}$ is the maximum specific growth rate $\left(d^{-1}\right)$, and $K_{s}$ is the half-saturation coefficient $(g / L)$. Setting Equation 5-3 equal to Equation 5-4:

$$
\frac{k_{m} S}{K_{S}+S}=\frac{1}{\theta}+K_{d}
$$

which can be inverted and linearized to give:

$$
\frac{\theta}{1+\theta K_{d}}=\frac{K_{s}}{k_{m}} \frac{1}{S}+\frac{1}{k_{m}}
$$


The rate of change in substrate concentration in the system can be expressed as:

$$
-\frac{d S}{d t}=\frac{Q}{V} S_{0}-\frac{Q}{V} S+k \frac{X}{Y}
$$

where $\mathrm{Y}$ is the yield coefficient ( $\mathrm{g}$ VSS $\mathrm{g} \mathrm{COD}^{-1}$ ) and $\mathrm{S}_{0}$ is the influent COD concentration (g COD/L). Under steady-state condition (-dS/dt=0), substituting Equation 5-3 into Equation 5-7, and rearranging gives:

$$
\frac{S_{0}-S}{\theta X}=\frac{1}{Y}\left(\frac{1}{\theta}\right)+\frac{1}{Y} K_{d}
$$

First, $\mathrm{Y}$ and $\mathrm{k}_{\mathrm{d}}$ were determined from the slope and intercept of a plot of $\left(\mathrm{S}_{0}-\mathrm{S}\right) / \theta \mathrm{X}$ versus $1 / \theta$ in Equation 5-8. Then, $k_{d}$ was used in Equation 5-6 and $k_{m}$ and $K_{s}$ were determined from the slope and intercept of a plot of $\theta /\left(1+\theta K_{d}\right)$ versus $1 / S$. The $R^{2}$ values ranged from $\sim 0.95$ to 0.99 for obtaining all constants from the plots. All kinetic constants are summarized in Table 5-2.

Table 5-2 Kinetic parameters (Monod model) for all cases

\begin{tabular}{lcccc}
\hline Case & $\begin{array}{c}\mathrm{Y} \\
\mathrm{g} \mathrm{VSS} \mathrm{g} \mathrm{COD}^{-1}\end{array}$ & $\begin{array}{c}\mathrm{K}_{\mathrm{d}} \\
\mathrm{d}^{-1}\end{array}$ & $\begin{array}{c}\mathrm{k}_{\mathrm{m}} \\
\mathrm{d}^{-1}\end{array}$ & $\begin{array}{c}\mathrm{K}_{\mathrm{s}} \\
\mathrm{g} / \mathrm{L}\end{array}$ \\
\hline 1 & $2.05 \pm 0.33$ & $0.013 \pm 0.002$ & $0.038 \pm 0.006$ & $0.69 \pm 0.11$ \\
2 & $2.27 \pm 0.34$ & $0.009 \pm 0.001$ & $0.036 \pm 0.005$ & $0.68 \pm 0.10$ \\
3 & $2.22 \pm 0.22$ & $0.009 \pm 0.001$ & $0.035 \pm 0.004$ & $0.68 \pm 0.07$ \\
4 & $2.04 \pm 0.23$ & $0.011 \pm 0.001$ & $0.033 \pm 0.004$ & $0.66 \pm 0.08$ \\
\hline
\end{tabular}

* The \pm values are based on the coefficient of variations (\%) obtained for COD concentrations in each case (Table 5-1).

Values of $\mathrm{k}_{\mathrm{m}}, \mathrm{Ks}$, and $\mathrm{k}_{\mathrm{d}}$ remained either constant when considering the range of error, or at the very least within a narrow range throughout all the tests: $\mathrm{k}_{\mathrm{m}}$ remained 
between $0.033 \pm 0.004$ and $0.038 \pm 0.006 \mathrm{~d}^{-1}, \mathrm{Ks}$ between $0.66 \pm 0.08$ and $0.69 \pm 0.11 \mathrm{~g} / \mathrm{L}$, and $\mathrm{k}_{\mathrm{d}}$ between $0.009 \pm 0.001$ and $0.013 \pm 0.002 \mathrm{~d}^{-1}$. Further, for each COD strength $\mathrm{k}_{\mathrm{m}}$ was always three to four times the value of $k_{d}$. HRT and OLR were shown to be important operational parameters affecting substrate removal and biogas production. The constant or narrow range of biomass-specific kinetic parameters demonstrates biomass stability over the duration of the study, thereby allowing changes in digestion characteristics to be solely attributed to HRT and OLR.

\subsection{Summary}

COD removal efficiency and biogas production rate increased by $\sim 33-42 \%$ and $\sim 22-32 \%$, respectively, as HRTs increased by $\sim 5-6$ times while maintaining a fixed organic loading rate $(\sim 3,5,7$, and $9 \mathrm{~g} \mathrm{COD} / \mathrm{L} / \mathrm{d})$. Better reactor performance was achieved when running high COD concentration at a slower rate compared to lower COD concentration at a faster rate for equivalent OLR's. These results imply a diffusion limiting process where higher molecular weight and slowly degrading organics, such as crude proteins and fats, are not able to efficiently diffuse into the granular biomass to be digested before exiting the reactor.

The Monod model was employed to verify stability of the granular biomass behavior throughout the duration of the testing. The maximum specific growth rate, $\mathrm{k}_{\mathrm{m}}$, the half-saturation coefficient, $\mathrm{K}_{\mathrm{s}}$, and the death rate, $\mathrm{k}_{\mathrm{d}}$, all remained approximately constant, indicating biomass stability and that improvements in COD digestion and biogas production were attributed to differences in HRT and OLR. 


\section{CHAPTER 6 : IMPACT OF HYDROGEN ADDITION ON BIOGAS QUALITY ENHANCEMENT AND SUBSTRATE REMOVAL EFFICIENCY IN AN EXPANDED GRANULAR SLUDGE BED REACTOR}

\subsection{Reactor Stability}

For all cases, temperatures remained within the range of $32-38{ }^{\circ} \mathrm{C}$ in the PA tank and $31-33{ }^{\circ} \mathrm{C}$ in the effluent of the EGSB reactor. $\mathrm{pH}$ in the PA tank was $\sim 5.5$ for all cases; $\mathrm{pH}$ in the effluent from the EGSB was $\sim 7.0$ for case \#1 and 7.3 for cases \#2A and 2B. The slight $\mathrm{pH}$ increase (in the effluent during hydrogen gas injection) conforms with the results reported by Luo and Angelidaki (2013) who attributed the slight increase to the reduction of the carbon dioxide in the biogas reactor. The temperature and $\mathrm{pH}$ indicate that the EGSB reactor was operating normally within the desired mesophilic range.

Pre-acidification during stage-one, where ideally $\sim 20-40 \%$ of the COD is converted to VFA's, increases the stability of the stage-two EGSB reactor where a sudden increase in OLR would cause an accumulation of VFAs since acetogens grow at a slower rate than acidogens (Wang et al., 2010). The degree of pre-acidification in the PA is quantified using Equation 5-1. Applying this to case 2 (OLR of $7.7 \mathrm{~g} \mathrm{COD/L.d)}$ as an example (see Table 6-1), the initial COD of the wastewater in the PA tank was $32.2 \mathrm{~g} / \mathrm{L}$ 
$\left(\mathrm{COD}_{\text {in }}\right)$; the $\mathrm{COD}$ reduced to $23.9 \mathrm{~g} / \mathrm{L}\left(\mathrm{COD}_{\mathrm{PA}}\right)$ following the pre-acidification period. The VFA concentration increased from 2.3 to $8.4 \mathrm{~g} / \mathrm{L}$ during this same period. The PA degree in this example is $26 \%$, indicating $26 \%$ of the initial COD was converted to VFA's.

PA degree was always between 26 and 32\% (Table 6-1) for all cases, which was within the desirable $20-40 \%$ range as stated by the manufacturer. Means, standard deviations, and coefficient of variations, which is the ratio of the standard deviation to the mean, were calculated for each column in Table 6-1.

Another important stability characteristic is the VFA concentration of the effluent from the EGSB, which reflects the acidity and the VFA consumption by acetogenesis and methanogenesis bacteria in that reactor. For all cases, the VFA concentrations of the effluent ranged from 90 to $130 \mathrm{mg} / \mathrm{L}$ yielding VFA removal between 94 and $96 \%$, indicating stability and normal operation of the reactor. COD removal efficiency was consistent and similar for all cases at $\sim 98 \pm 0.3 \%$ (Table $6-1$ ). Coefficient of variations were just $1 \%$ for VFA removal in the EGSB and $0.2 \%$ for overall COD removal from the combined PA and EGSB tanks. 
Table 6-1 Experimental parameters for different operational conditions

\begin{tabular}{|c|c|c|c|c|c|c|c|c|c|c|c|}
\hline $\begin{array}{l}\text { Test } \\
\text { Case }\end{array}$ & $\begin{array}{l}\text { OLR, } \\
\text { gCOD/ } \\
\text { L.d }\end{array}$ & $\begin{array}{l}\mathrm{H}_{2} \\
\text { Flow } \\
\text { Rate, } \\
\mathrm{L} / \mathrm{h}\end{array}$ & $\begin{array}{l}\mathrm{COD}_{\text {in }}, \\
\mathrm{g} / \mathrm{L}\end{array}$ & $\begin{array}{l}\mathrm{COD}_{\mathrm{PA}} \\
, \mathrm{g} / \mathrm{L}\end{array}$ & $\begin{array}{l}\mathrm{COD}_{\text {out }} \\
, \mathrm{g} / \mathrm{L}\end{array}$ & $\begin{array}{l}\text { COD } \\
\text { Removal }\end{array}$ & $\begin{array}{l}\text { PA } \\
\text { Degree }\end{array}$ & $\begin{array}{l}\mathrm{VFA}_{\text {in }}, \\
\mathrm{g} / \mathrm{L}\end{array}$ & $\begin{array}{l}\mathrm{VFA} A_{\mathrm{PA}}, \\
\mathrm{g} / \mathrm{L}\end{array}$ & $\begin{array}{l}\mathrm{VFA}_{\text {out }}, \\
\mathrm{g} / \mathrm{L}\end{array}$ & $\begin{array}{l}\text { VFA } \\
\text { Removal }\end{array}$ \\
\hline \multirow{4}{*}{1} & 3.1 & 0.0 & 30.8 & 22.3 & 0.5 & $98.3 \%$ & $27 \%$ & 2.2 & 7.2 & 0.1 & $96 \%$ \\
\hline & 5.1 & 0.0 & 30.3 & 22.4 & 0.6 & $98.1 \%$ & $26 \%$ & 2.1 & 7.2 & 0.1 & $95 \%$ \\
\hline & 7.1 & 0.0 & 30.1 & 20.5 & 0.6 & $98 \%$ & $32 \%$ & 2.2 & 7 & 0.1 & $95 \%$ \\
\hline & 8.6 & 0.0 & 28.7 & 21.3 & 0.6 & $97.8 \%$ & $26 \%$ & 2.1 & 7.8 & 0.1 & $94 \%$ \\
\hline \multirow{3}{*}{2} & 5.2 & 1.0 & 30.7 & 21.1 & 0.6 & $98.2 \%$ & $31 \%$ & 2.1 & 7.2 & 0.1 & $96 \%$ \\
\hline & 7.7 & 1.3 & 32.2 & 23.9 & 0.6 & $98.3 \%$ & $26 \%$ & 2.3 & 8.4 & 0.1 & $95 \%$ \\
\hline & 9.3 & 1.6 & 31 & 22.9 & 0.6 & $98.2 \%$ & $26 \%$ & 2 & 7.5 & 0.1 & $94 \%$ \\
\hline \multirow{3}{*}{3} & 5.1 & 2.0 & 30.2 & 22.3 & 0.6 & $98.2 \%$ & $26 \%$ & 2 & 7.5 & 0.1 & $95 \%$ \\
\hline & 7.8 & 2.5 & 32.5 & 24.6 & 0.6 & $98.3 \%$ & $24 \%$ & 2.3 & 8.3 & 0.1 & $94 \%$ \\
\hline & 9 & 3.2 & 30.1 & 22.4 & 0.6 & $98.2 \%$ & $26 \%$ & 2.1 & 7.2 & 0.1 & $94 \%$ \\
\hline \multicolumn{3}{|c|}{ Mean } & 30.7 & 22.4 & 0.6 & $98.2 \%$ & $27 \%$ & 2.1 & 7.5 & 0.1 & $95 \%$ \\
\hline \multicolumn{3}{|c|}{ Standard Deviation } & 1.1 & 1.2 & 0.03 & $0.02 \%$ & $2.5 \%$ & 0.1 & 0.5 & 0.02 & $1 \%$ \\
\hline \multicolumn{3}{|c|}{ Variation Coefficient } & $4 \%$ & $6 \%$ & $5 \%$ & $0.2 \%$ & $9 \%$ & $6 \%$ & $7 \%$ & $14 \%$ & $1 \%$ \\
\hline
\end{tabular}

\subsection{Theoretical Intermediate Hydrogen}

A significant amount of intermediate hydrogen gas is produced during preacidification and likely escapes the PA tank, but could theoretically be captured and sent to the second stage EGSB to react with the carbon dioxide. The amount of supplemental hydrogen injected is based on an estimate of the intermediate hydrogen gas produced in the PA tank. Since exact compositions of the industrial waste streams tested here are unknown, ethanol was used as a simple example. Incorporating Equation 2-13, an average PA degree obtained here of $29 \%$, an average COD concentration of $30 \mathrm{~g} / \mathrm{L}$ organics, the molecular weights of ethanol and hydrogen (46 and $2 \mathrm{~g} / \mathrm{g}$-mole), and the density of hydrogen $(0.09 \mathrm{~g} / \mathrm{L})$, the volume of hydrogen produced in the PA tank was on the order of $\sim 17 \mathrm{~L} /$ hour. The actual amount of hydrogen injected here was kept to a 
conservatively low rate to account for inefficiencies such as the possibility of an unknown non-biodegradable fraction, some of the hydrogen remaining dissolved in the liquid, and an inability to capture all of the escaping hydrogen gas. The two rates of hydrogen injection used here $\left(0.15 \mathrm{~L} / \mathrm{L}_{\text {biogas }} / \mathrm{d}\right.$ and $\left.0.30 \mathrm{~L} / \mathrm{L}_{\text {biogas }} / \mathrm{d}\right)$ correspond to 1 and $3.2 \mathrm{~L} /$ hour.

\subsection{Enhanced Reactor Performance with Hydrogen}

Methane percentage increased from $\sim 71$ to $89 \%$, carbon dioxide percentage decreased from 29 to $11 \%$, and methane to carbon dioxide ratio increased from 2.5 to 8.5 when hydrogen was injected at $0.30 \mathrm{~L} / \mathrm{L}_{\text {biogas }} / \mathrm{d}$ compared to no hydrogen injection (Figure 6-1A - 6-1C). Improvements from no hydrogen to the lower hydrogen rate, and from the lower hydrogen rate to the higher hydrogen rate, were all outside the range of error bars. The biogas component percentages and methane-to-carbon dioxide ratios remained relatively unchanged as the wastewater (feed) flow rate increased, indicating that biogas enhancement kept up with increasing feed rates. In the case of no hydrogen injection, the methane, carbon dioxide percentages, and methane-to-carbon dioxide ratio remained $\sim 71-74 \%, \sim 26-29 \%$, and $\sim 2.5-2.9$, respectively; for the low hydrogen injection case $\left(\sim 0.15 \mathrm{~L} / \mathrm{L}_{\text {biogas }} / \mathrm{d}\right)$, the methane, carbon dioxide percentages, and methane-to-carbon dioxide ratio ranged $\sim 79-81 \%, \sim 19-21 \%$, and 3.7 to 4.4 , respectively; for the high hydrogen injection case $\left(\sim 0.30 \mathrm{~L} / \mathrm{L}_{\text {biogas }} / \mathrm{d}\right)$, the methane, carbon dioxide percentages, and methane-to-carbon dioxide ratio ranged $\sim 88-89 \%, \sim 11-12 \%$, and $7.4-8.5$, respectively. Methane content reached a higher percentage (89\%) than Luo and Angelidaki (2013) reported equal to $78.4 \%$, which is attributed to the $30 \%$ ratio of recirculation to fresh feed 
in the EGSB system that kept the hydrogen in the system longer giving it a better chance to react with the carbon dioxide.

Luo and Angelidaki (2012) stated that Hydrogenotrophic archeae (microorganisms) binds $\mathrm{CO}_{2}$ with $\mathrm{H}_{2}$ and convert them to methane through an autotrophic oxidation of hydrogen (or hydrogenotrophic methanogenesis). Autotrophic oxidation is a unique form of metabolism or oxidation found only in bacteria. Inorganic compounds are oxidized directly (without using sunlight) to yield energy (e.g., $\mathrm{H}_{2}, \mathrm{NH}_{3}$, $\mathrm{S}_{2}$, and $\mathrm{Fe}_{2}{ }^{+}$), in this case:

$$
8 \mathrm{H}+\mathrm{CO}_{2} \rightarrow \mathrm{CH}_{4}+2 \mathrm{H}_{2} \mathrm{O}+\text { biomass }
$$

Autotrophic oxidation of hydrogen occurs in microorganisms such as Methanobacteriales, Methanococcales, Methanomicrobials, and Methanosarcinaceae. Acetogenesis and methanogenesis are two main processes involved in anaerobic digestion of methane formation, and there are several key enzymes taking part in these processes (Zehnder 1988). Luo and Angelidaki (2012) reported that in biogas upgrading via hydrogen addition, both acetoclastic and hydrogenotrophic methanogenic are active. However, the acetoclastic methanogenic activities occurs after long-term cultivation, while the hydrogenotrophic methanogenic activities can occur from the early stage of the testing, indicating that hydrogenotrophic methanogens were selectively enriched for the biogas enhancement via hydrogen addition.

For each OLR, the volume of biogas produced increased by $\sim 10-15 \%$ when hydrogen was injected at $0.30 \mathrm{~L} / \mathrm{L}_{\text {biogas }} / \mathrm{d}$ compared to no hydrogen injection (Figure 6- 
1D). For the $\sim 5 \mathrm{~g} \mathrm{COD} / \mathrm{L} . \mathrm{d}$ OLR, biogas production increased from 161 to $181 \mathrm{~L} /$ day; for $\sim 7 \mathrm{~g} \mathrm{COD} / \mathrm{L} . d$, biogas production increased from 203 to $234 \mathrm{~L} /$ day; for $\sim 9 \mathrm{~g} \mathrm{COD} / \mathrm{L} . \mathrm{d}$, biogas production increased from 259 to $287 \mathrm{~L} /$ day. The volume of biogas increased since methane has a specific volume nearly three times larger than the carbon dioxide it replaced.
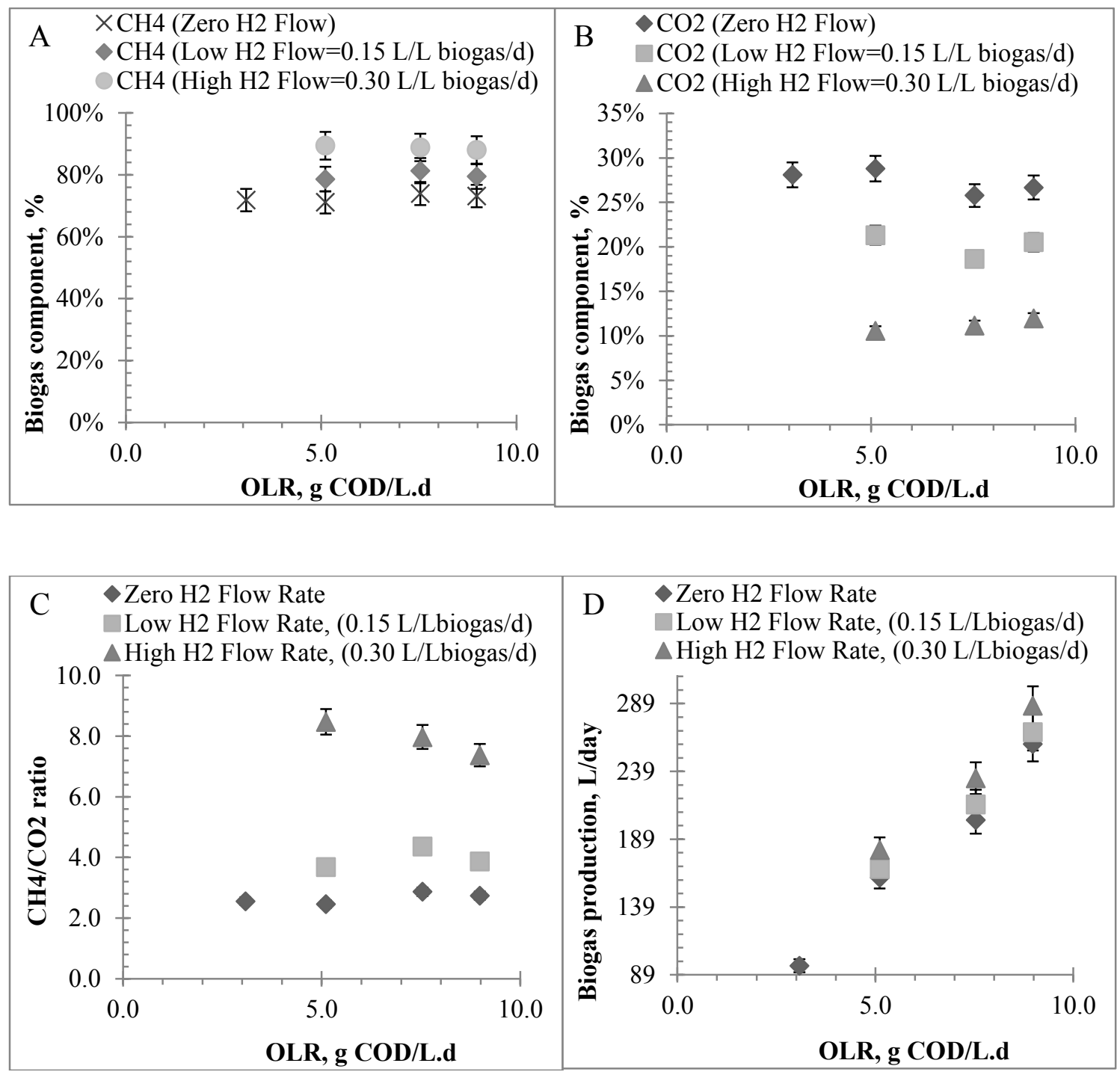
Figure 6-1 Biogas composition of (A) $\mathrm{CH}_{4}$, (B) $\mathrm{CO}_{2}$, (C) $\mathrm{CH}_{4} / \mathrm{CO}_{2}$ ratio, and (D) biogas production rate as a function of organic loading rate.

\subsection{Biogas Energy Yield}

Biogas energy yields in terms of both $\mathrm{kJ} /$ day (Figure $6-2 \mathrm{~A}$ ) and $\mathrm{kJ} / \mathrm{g} \mathrm{COD}_{\text {in }}$ (Figure 6-2B) were calculated for each test case using the volumetric energy content of methane, $40 \mathrm{~kJ} / \mathrm{L}$ (Zhu et al.,2008). For each OLR in Figure 6-2A, the energy yield increased by $\sim 33-42 \%$ when hydrogen was injected at $0.30 \mathrm{~L} / \mathrm{L}_{\text {biogas }} / \mathrm{d}$ compared to no hydrogen injection (Figure 6-2A). Again, improvements from no hydrogen to the lower hydrogen rate, and from the lower hydrogen rate to the higher hydrogen rate, were all outside the range of error bars.. For an OLR of $\sim 5 \mathrm{~g} \mathrm{COD/L.d,} \mathrm{the} \mathrm{energy} \mathrm{yield} \mathrm{increased}$ from 4560 to $6440 \mathrm{~kJ} /$ day; for $\sim 7 \mathrm{~g} \mathrm{COD} / \mathrm{L} . \mathrm{d}$, the energy yield increased from 6019 to $8324 \mathrm{~kJ} /$ day; for $\sim 9 \mathrm{~g} \mathrm{COD} / \mathrm{L} . \mathrm{d}$, the energy yield increased from 7592 to $10131 \mathrm{~kJ} /$ day.

The energy yield per gram of substrate added increased by $\sim 34-42 \%$ when hydrogen was injected at $0.30 \mathrm{~L} / \mathrm{L}_{\text {biogas }} / \mathrm{d}$ compared to no hydrogen injection (Figure 62B). However, the energy yield per gram of substrate added decreased slightly (by 7$12 \%$ ) as the OLR increased. In the case of no hydrogen injection, the energy yield decreased from $\sim 1.2$ to $1.1 \mathrm{~kJ} / \mathrm{g} \mathrm{COD}$ in as the OLR increased from $\sim 3$ to $9 \mathrm{~g} \mathrm{COD/L.d.}$ For the low hydrogen injection case $\left(\sim 0.15 \mathrm{~L} / \mathrm{L}_{\text {biogas }} / \mathrm{d}\right)$, the energy yield decreased from $\sim 1.4$ to $1.3 \mathrm{~kJ} / \mathrm{g} \mathrm{COD}_{\text {in }}$ as the OLR increased from $\sim 5$ to $9 \mathrm{~g} \mathrm{COD} / \mathrm{L} . \mathrm{d}$. For the high hydrogen injection case $\left(\sim 0.30 \mathrm{~L} / \mathrm{L}_{\text {biogas }} / \mathrm{d}\right)$, the energy yield decreased from $\sim 1.7$ to 1.5 $\mathrm{kJ} / \mathrm{g} \mathrm{COD}_{\text {in }}$ as the OLR increased from $\sim 5$ to $9 \mathrm{~g} \mathrm{COD/L.d.} \mathrm{Decreasing} \mathrm{energy} \mathrm{yield} \mathrm{per}$ gram substrate added may be attributed to the gradual saturation of the biomass by the 
organics as the feeding rate increases. Theoretically, the energy yield per gram COD added would slightly decrease until it becomes completely saturated, at which time the biomass could not digest additional organics, and therefore, the yield would decrease drastically.

The overall net energy benefit increased by reacting the hydrogen to methane. One, this hydrogen would have otherwise been lost. Two, hydrogen has a lower volumetric energy content than methane, $12.78 \mathrm{~kJ} / \mathrm{L}(0.09 \mathrm{~g} / \mathrm{L}$ density and $142 \mathrm{~kJ} / \mathrm{g}$ heating value) versus $40 \mathrm{~kJ} / \mathrm{L}(0.72 \mathrm{~g} / \mathrm{L}$ density and $55.6 \mathrm{~kJ} / \mathrm{g}$ heating value $)$. For example, for the $\sim 5 \mathrm{~g} \mathrm{COD} / \mathrm{L} . \mathrm{d}$ OLR, $48 \mathrm{~L} / \mathrm{d}$ of hydrogen was introduced (Table 6-1) that resulted in an increase of methane generated from $114(71 \%$ methane $\times 161 \mathrm{~L} /$ day biogas) to $161 \mathrm{~L} / \mathrm{d}(89 \%$ methane $\times 181 \mathrm{~L} /$ day biogas $)$, so the net energy content increased by $1267 \mathrm{~kJ} / \mathrm{d}$ from $4560(114 \mathrm{~L} / \mathrm{d} \times 40 \mathrm{~kJ} / \mathrm{L})$ to $6440 \mathrm{~kJ} / \mathrm{d}(163 \mathrm{~L} / \mathrm{d} \times 40 \mathrm{~kJ} / \mathrm{L})$ by introducing $613 \mathrm{~kJ} / \mathrm{d}(48 \mathrm{~L} / \mathrm{d} \times 12.78 \mathrm{~kJ} / \mathrm{L})$ hydrogen. Supplemental hydrogen can also be potentially obtained and used to upgrade the biogas quality from external sources such as hydrogen producing $\mathrm{AD}$ reactors, coal gasification, petroleum refinery, petrochemical plants, and soda manufacture as other authors have stated (Luo and Angelidaki, 2012; Luo and Angelidaki, 2013; Luo et al., 2012; Ni et al., 2011). 

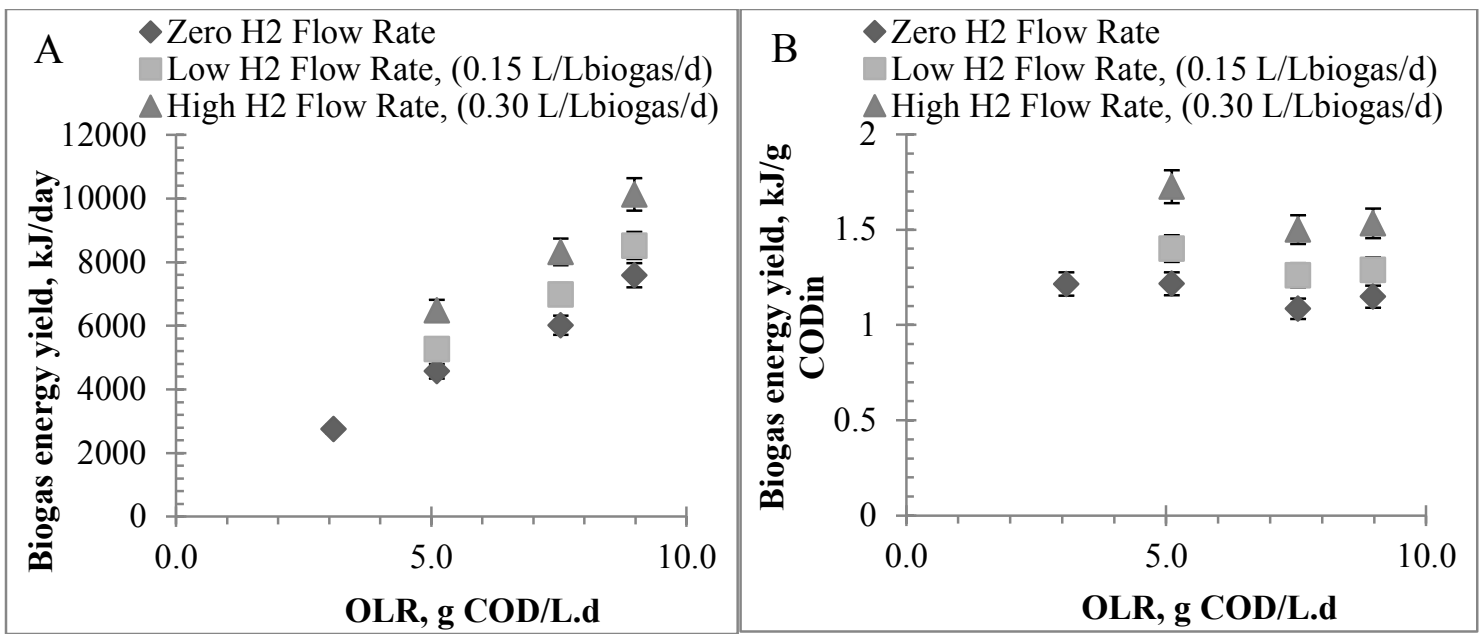

Figure 6-2 Biogas energy yield (A) per day and (B) per gram substrate added as a function of organic loading rate.

\subsection{Impact of Hydrogen Injection on Substrate Removal Efficiency and Kinetics}

COD removal efficiency remained constant, $98 \pm 0.3 \%$, for all cases with and without hydrogen (Table 6-1), indicating that hydrogen injection did not negatively affect overall substrate removal. Comparing kinetic parameters with and without hydrogen injection will further signify if reactor performance and stability were affected by the hydrogen injection. Same kinetic approach as explained in Chapter 5 was employed here.

First, $\mathrm{Y}$ and $\mathrm{k}_{\mathrm{d}}$ were determined from the slope and intercept of a plot of $\left(\mathrm{S}_{0^{-}}\right.$ $\mathrm{S}) / \theta \mathrm{X}$ versus $1 / \theta$ in Equation 5-8. Then, $\mathrm{k}_{\mathrm{d}}$ was used in Equation 5-6 and $\mathrm{k}_{\mathrm{m}}$ and $\mathrm{K}_{\mathrm{s}}$ were determined from the slope and intercept of a plot of $\theta /\left(1+\theta K_{d}\right)$ versus $1 / S$. The $R^{2}$ values ranged from $\sim 0.95$ to 0.99 for obtaining all constants from the plots. All kinetic constants are summarized in Table 5-2. The maximum substrate removal rate, $\mathrm{q}_{\mathrm{m}}\left(\mathrm{g}\right.$ COD $\mathrm{g} \mathrm{VSS}^{-1}$ $\left.\mathrm{d}^{-1}\right)$, is related to the maximum specific growth rate by the yield coefficient: 


$$
q_{m}=\frac{k_{m}}{Y}
$$

All kinetic constants are summarized in Table 6-2.

Table 6-2 Kinetic parameters (Monod model) for all cases

\begin{tabular}{cccccc}
\hline Case & $\begin{array}{c}\mathrm{Y} \\
\text { g VSS g COD }^{-1}\end{array}$ & $\begin{array}{c}\mathrm{K}_{\mathrm{d}} \\
\mathrm{d}^{-1}\end{array}$ & $\begin{array}{c}\mathrm{k}_{\mathrm{m}} \\
\mathrm{d}^{-1}\end{array}$ & $\begin{array}{c}\mathrm{qm}_{\mathrm{m}} \\
\mathrm{g} \mathrm{VSS} \mathrm{g} \mathrm{COD}^{-1} \mathrm{~d}^{-1}\end{array}$ & $\begin{array}{c}\mathrm{K}_{\mathrm{s}} \\
\mathrm{g} / \mathrm{L}\end{array}$ \\
\hline 1 & 2.048 & 0.013 & 0.038 & 0.020 & 0.686 \\
2 & 1.622 & 0.024 & 0.041 & 0.025 & 0.682 \\
3 & 1.813 & 0.005 & 0.052 & 0.028 & 0.642 \\
\hline
\end{tabular}

The $\mathrm{R}^{2}$ values ranged $\sim 0.96$ to 0.99 for obtaining all constants from the plots. The $\mathrm{q}_{\mathrm{m}}$ for case 1 was lower than case 2 and case 3 by $0.005 \mathrm{~g} \mathrm{VSS} \mathrm{g} \mathrm{COD}^{-1} \mathrm{~d}^{-1}(25 \%)$ and

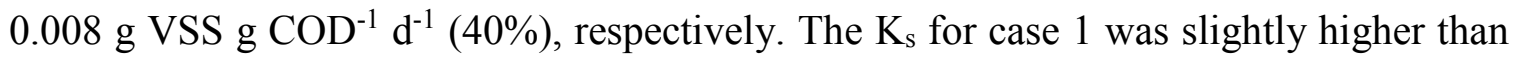
case 2 and case 3 by $0.004 \mathrm{~g} / \mathrm{L}(0.6 \%)$ and $0.044 \mathrm{~g} / \mathrm{L}(6 \%)$, respectively. The observed slight increase and decrease in $\mathrm{q}_{\mathrm{m}}$ and $\mathrm{K}_{\mathrm{s}}$, respectively, with the added hydrogen indicates that hydrogen injection did not affect reactor performance and stability of the biomass.

\subsection{Summary}

Hydrogen gas, an intermediate product generated during pre-acidification (stageone), can be theoretically captured escaping from the PA tank and sent to the second stage EGSB reactor, where methane and carbon dioxide are formed, to enhance the biogas quality by biologically converting the carbon dioxide to methane. 
Pilot-scale tests were conducted by introducing supplemental hydrogen gas, in amounts less than theoretically generated in the PA tank, directly in to the EGSB reactor operating at mesophilic temperature $\left(35^{\circ} \mathrm{C}\right)$. The experimental data demonstrated that biogas quality was enhanced by $\sim 10$ to $20 \%$ depending on the hydrogen injection rate. In addition, the energy yield increased by $\sim 33-42 \%$ with hydrogen injection at 0.30 $\mathrm{L} / \mathrm{L}_{\text {biogas }} / \mathrm{d}$ compared to no hydrogen injection. COD removal efficiency remained constant at about $\sim 98 \%$, both with and without hydrogen, indicating that hydrogen injection did not negatively affect overall substrate removal.

Then, the Monod model was employed to determine if the hydrogen impacted reactor performance or stability. The maximum substrate removal rate, $\mathrm{q}_{\mathrm{m}}$, increased from 0.019 to $0.029 \mathrm{~g} \mathrm{VSS} \mathrm{g} \mathrm{COD} \mathrm{CO}^{-1}$ while the half-saturation coefficient, $\mathrm{K}_{\mathrm{s}}$, only decreased slightly from 0.686 to $0.642 \mathrm{~g} / \mathrm{L}$ when hydrogen was injected compared to no hydrogen, indicating that hydrogen injection did not negatively affect substrate removal efficiency or stability of the reactor in terms of the intrinsic property of biomass. 


\section{CHAPTER 7 : CONCLUSIONS}

Fundamental technical and economic obstacles need to be overcome for AD to become more widely used in the US. Current AD systems are able to achieve high conversion (over $\sim 90 \%$ ), but they are mostly batch systems with very long residence times (on the order of 14-21 days) and/or require large reactor sizes and footprints. Product quality, measured by the amount of methane relative to $\mathrm{CO}_{2}$ produced, also hampers its industrial applications in the US.

A common assumption with anaerobic reactions is that acetoclastic methanogenesis is the rate-controlling reaction. The presence of inhibitors and/or competing constituents in actual wastewaters would necessarily increase with increasing substrate load, implying that wastewater COD loading could affect the steady-state rate of methane gas production and, hence, kinetic modeling constants. In Chapter 4, the impact of substrate loading and COD/VSS ratio on kinetic parameters during anaerobic digestion was investigated for wastewaters from soybean processing, brewery, and beverage recycling industries. For the brewery and beverage recycling wastewaters, the reaction order increased only slightly (from 1 to 1.2 ) as the SI ratio increased. For the soybean processing WW, where sulfates were extremely high, the reaction order increased from 1.21 at SI ratio of 0.5 to 2.63 at SI ratio of 1.

The Monod model suggests that the reaction order should remain between zero 
and one depending on the COD strength. The brewery and wastewater streams primarily remained within these constraints. However, increases in reaction order in the soybean WW case were outside this range indicating other factors were involved and need to be considered in the modeling. Simulated COD removal rate plots were generated from the kinetic parameters obtained and compared to curves from experimental measurements to investigate the possible factors.

The $\mathrm{R}^{2}$ values for the Monod model were $\sim 0.98$ for $8,10,12 \mathrm{~g} / \mathrm{L}$ influent COD concentrations (or SI ratio of $0.67,0.83$, and 1), indicating a good overall fit here, but it did not capture the behavior very well at the beginning of the reactions (first 10-13 hours). This was primarily attributed to a lag in the growth/activity of the SRB's. Once the SRB's were active by the presence of sulfates they began to compete with the methanogens for the COD consumption to reduce the sulfates. To reduce one gram of sulfate, SRB's require $0.67 \mathrm{~g}$ COD (organics as food for metabolism). Therefore, at higher COD concentration, the amount of organics left for the methanogens for methane formation decreased, and as a result less biogas was produced per g COD added. As a result, a term should be added to the Monod model to account for the competitive uptake of COD by the SRB's.

In Chapter 5, COD removal efficiency and biogas production rate increased by $\sim 33-42 \%$ and $\sim 22-32 \%$, respectively, as HRTs increased by $\sim 5-6$ times while maintaining a fixed organic loading rate $(\sim 3,5,7$, and $9 \mathrm{~g} \mathrm{COD} / \mathrm{L} / \mathrm{d})$. Better reactor performance was achieved when running high COD concentration at a slower rate compared to lower COD concentration at a faster rate for equivalent OLR's. These results imply a diffusion limiting process where higher molecular weight and slowly degrading organics, such as 
crude proteins and fats, are not able to efficiently diffuse into the granular biomass to be digested before exiting the reactor.

To verify stability of the granular biomass behavior throughout the duration of the testing, the Monod model was employed. The maximum specific growth rate, $\mathrm{k}_{\mathrm{m}}$, the half-saturation coefficient, $\mathrm{K}_{\mathrm{s}}$, and the death rate, $\mathrm{k}_{\mathrm{d}}$, all remained approximately constant, indicating biomass stability and that improvements in COD digestion and biogas production were attributed to differences in HRT and OLR.

The gaseous hydrogen generated during pre-acidification (stage-one) can be theoretically captured escaping from the PA tank and sent to the second stage EGSB reactor, where methane and carbon dioxide are formed biologically, to enhance the biogas quality by converting the carbon dioxide to methane.

In Chapter 6, pilot-scale testing was conducted by introducing supplemental hydrogen gas, in amounts less than what theoretically generated in the PA tank, directly in to the EGSB reactor operating under mesophilic condition $\left(\mathrm{T}=35^{\circ} \mathrm{C}\right)$. The experimental data demonstrated that biogas quality was enhanced by $\sim 10$ to $20 \%$ depending on the hydrogen injection rate. In addition, the energy yield increased by $\sim 33$ $42 \%$ with hydrogen injection at $0.30 \mathrm{~L} / \mathrm{L}_{\text {biogas }} / \mathrm{d}$ compared to no hydrogen injection. COD removal efficiency remained constant at about $\sim 98 \%$, both with and without hydrogen, indicating that hydrogen injection did not negatively affect overall substrate removal.

Then, similar to Chapter 5, the Monod model was used to determine if the hydrogen impacted reactor performance or stability. The maximum specific growth rate, $\mathrm{k}_{\mathrm{m}}$, the half-saturation coefficient, $\mathrm{K}_{\mathrm{s}}$, and the death rate, $\mathrm{k}_{\mathrm{d}}$, all remained approximately within a narrow range with and without hydrogen injection, indicating that hydrogen 
injection did not negatively affect substrate removal efficiency or stability of the reactor in terms of the intrinsic property of biomass. 


\section{CHAPTER 8 : RECOMMENDATIONS FOR FUTURE STUDY}

\section{Experiment 1: Develop a Method to Capture and Measure the Hydrogen Produced in the PA Tank (first-stage of EGSB)}

As mentioned in Chapter 6, hydrogen gas, an intermediate product generated during pre-acidification (stage-one), can be theoretically captured escaping from the PA tank. The first recommendation is to measure the hydrogen gas actually escaping the system:

1. The PA tank, which currently has an open top, needs to be covered with an air-tight dome to collect the gas produced in the tank.

2. The gas should pass through a filter with a pore size that only allows hydrogen gas to pass through (hydrogen has the smallest atom among all other elements in the nature).

3. The amount of hydrogen gas produced in the PA tank can be measured using a GC.

4. The process efficiency and feasibility can be investigated here. 


\section{Experiment 2: Investigate a Biological Method to React Hydrogen and Carbon Dioxide for Methane Formation}

In Chapter 6, supplemental hydrogen was used to enhance methane formation and energy yield. It is recommended to investigate further biological conversion of hydrogen and carbon dioxide to methane. The current testing was performed using a mixed culture of biomass, which included primarily acetoclastic methanogens with some hydrogenotrophic methanogens.

The experimental plan to investigate the possibility of this method is given here:

1. Testing can be performed at smaller batch scale using the RSA reactor in addition to the larger scale EGSB reactor. The key is to seed either reactor strictly with hydrogenotrophic methanogens (hydrogen-consuming methanogens).

2. Carbon dioxide and hydrogen should be fed to the reactor coming from two separate tanks.

3. The injection rates should be chosen conservatively to allow the gases be solubilized well in the liquid phase and not disturb the expanded granular sludge bed.

4. Initially, this should be run for 2-3 weeks for proper acclimation.

\section{Experiment 3: Investigate the Impact of Higher Degree of Hydrolysis and} Acidification on Digesting Higher Molecular Weight Organics

As determined in Chapter 5, HRT plays an important role in digesting the slowly biodegradable organics. This experiment is recommended to help to maximize the digestion efficiency of higher molecular organics and slowly biodegradable organics such 
as fats and proteins. In this experiment, the slowly biodegradable organics are expected to be degraded further by retaining them longer in the PA tank. The experimental plan to investigate this impact is given here:

1. In this experiment, the wastewater should be retained in the PA tank longer (than what was applied in Chapter 5 - 24 hours) to allow the organics of the wastewater be pre-acidified to levels greater than $\sim 30 \%$ that was used in this testing.

2. A procedure similar to Chapter 5 should be used here to investigate the impact of HRT for each PA degree. COD removal and biogas production should be monitored for a series of PA degrees to determine the optimum PA degree for digesting the higher molecular weight and slowly biodegradable organics. The optimum PA degree is defined as when increasing HRT (at a fixed OLR) no longer impacts COD removal and biogas production. It is theorized here that once the high molecular weight organics, such as fats and proteins, are broken down, the diffusion limiting process and the impact of HRT should diminish at a fixed organic loading rate.

3. Also, recirculating a higher ratio of the wastewater than what it was used ( $30 \%$ recirculation) here might help to digest the higher molecular weight organics efficiently digested. 


\section{REFERENCES}

Abuhamed, T., Bayraktar, E., Mehmetoğlu, T. and Mehmetoğlu, Ü. (2004) Kinetics model for growth of Pseudomonas putida F1 during benzene, toluene and phenol biodegradation. Process Biochemistry 39(8), 983-988.

Ahn, J.H. and Forster, C.F. (2002) A comparison of mesophilic and thermophilic anaerobic upflow filters treating paper-pulp-liquors. Process Biochemistry 38(2), 256-261.

Alphenaar, P.A., Pérez, M.C. and Lettinga, G. (1993) The influence of substrate transport limitation on porosity and methanogenic activity of anaerobic sludge granules. Applied Microbiology and Biotechnology 39(2), 276-280.

Batstone, D.J., Keller, J., Angelidaki, I., Kalyuzhnyi, S.V., Pavlostathis, S.G., Rozzi, A., Sanders, W.T., Siegrist, H. and Vavilin, V.A. (2002) The IWA Anaerobic Digestion Model No 1 (ADM1). Water Science and Technology 45(10), 65-73.

Batstone, D.J., Tait, S. and Starrenburg, D. (2009) Estimation of hydrolysis parameters in full-scale anerobic digesters. Biotechnology and Bioengineering 102(5), 15131520.

Beltrame, P., Beltrame, P.L., Carniti, P. and Pitea, D. (1982) Kinetics of biodegradation of mixtures containing 2,4-dichlorophenol in a continuous stirred reactor. Water Research 16(4), 429-433.

Bhattacharyya, D. and Singh, K. (2010) Understanding the Mixing Pattern in an Anaerobic Expanded Granular Sludge Bed Reactor: Effect of Liquid Recirculation. Journal of Environmental Engineering 136(6), 576-584.

Bhunia, P. and Ghangrekar, M.M. (2008) Analysis, evaluation, and optimization of kinetic parameters for performance appraisal and design of UASB reactors. Bioresource Technology 99(7), 2132-2140.

Borghei, S.M. and Hosseiny, S.H. (2002) Modeling of organic removal in a moving bed biofilm reactor (MBBR). Scientica Iran 9(1), 53-58.

Borghei, S.M., Sharbatmaleki, M., Pourrezaie, P. and Borghei, G. (2008) Kinetics of organic removal in fixed-bed aerobic biological reactor. Bioresource Technology 99(5),

1118-1124. 
Borja, R., Alba, J., Garrido, S.E., Martínez, L., García, M.P., Monteoliva, M. and RamosCormenzana, A. (1995) Effect of aerobic pretreatment with Aspergillus terreus on the anaerobic digestion of olive-mill wastewater. Biotechnology and Applied Biochemistry 22, 233-246.

Borja, R. and Banks, C.J. (1994a) Anaerobic digestion of palm oil mill effluent using an up-flow anaerobic sludge blanket reactor. Biomass and Bioenergy 6(5), 381-389.

Borja, R. and Banks, C.J. (1994b) Treatment of palm oil mill effluent by upflow anaerobic filtration. Journal of Chemical Technology and Biotechnology 61(2), 103-109.

Borja, R. and Banks, C.J. (1995) Comparison of an Anaerobic Filter and an Anaerobic Fluidized Bed Reactor Treating Palm Oil Mill Effluent. Process Biochemistry 30(6), 511-521.

Borja, R., Banks, C.J., Khalfaoui, B. and Martín, A. (1996b) Performance evaluation of an anaerobic hybrid digester treating palm oil mill effluent. Journal of Environmental Science and Health. Part A: Environmental Science and Engineering and Toxicology 31(6), 1379-1393.

Borja, R., Banks, C.J. and Sánchez, E. (1996a) Anaerobic treatment of palm oil mill effluent in a two-stage up-flow anaerobic sludge blanket (UASB) system. Journal of Biotechnology 45(2), 125-135.

Borja, R., Martin, A., Maestro, R., Luque, M. and Duran, M.M. (1993) Enhancement of the anaerobic digestion of wine distillery wastewater by the removal of phenolic inhibitors. Bioresource Technology 45(2), 99-104.

Borja, R., Rincon, B., Raposo, F., Alba, J. and Martin, A. (2003) Kinetics of mesophilic anaerobic digestion of the two-phase olive mill solid waste. Biochemical Engineering Journal 15(2), 139.

Büyükkamaci, N. and Filibeli, A. (2002) Determination of kinetic constants of an anaerobic hybrid reactor. Process Biochemistry 38(1), 73-79.

Chang, I.S., Zhao, J., Yin, X., Wu, J., Jia, Z. and Wang, L. (2011) Comprehensive utilizations of biogas in Inner Mongolia, China. Renewable and Sustainable Energy Reviews 15(3), 1442-1453.

Chen, Y., Cheng, J.J. and Creamer, K.S. (2008) Inhibition of anaerobic digestion process: A review. Bioresource Technology 99(10), 4044-4064.

Chen, Y.R. and Hashimoto, A.G. (1978) Kinetics of methane fermentation. Biotechnology Bioengineering Symposium 8, 269-282.

Chen, Y.R. and Hashimoto, A.G. (1980) Substrate utilization kinetic model for biological 
treatment process. Biotechnology and Bioengineering 22(10), 2081-2095.

Colleran, E., Finnegan, S. and Lens, P. (1995) Anaerobic treatment of sulphatecontaining waste streams. Antonie van Leeuwenhoek 67(1), 29-46.

Colleran, E., Pender, S., Philpott, U., O'Flaherty, V. and Leahy, B. (1998) Full-scale and laboratory-scale anaerobic treatment of citric acid production wastewater. Biodegradation 9(3-4), 233-245.

Converti, A., Del Borghi, A., Arni, S. and Molinari, F. (1999) Linearized Kinetic Models for the Simulation of the Mesophilic Anaerobic Digestion of Pre-hydrolyzed Woody Wastes. Chemical Engineering and Technology 22(5), 429-437.

Davies-Venn, C., Young, J.C. and Tabak, H.H. (1992) Impact of chlorophenols and chloroanilines on the kinetics of acetoclastic methanogenesis. Environmental Science and Technology 26(8), 1627-1635.

De la Rubia, M.A., Fernandez-Cegri, V., Raposo, F. and Borja, R. (2011) Influence of particle size and chemical composition on the performance and kinetics of anaerobic digestion process of sunflower oil cake in batch mode. Biochemical Engineering Journal 58-59(1), 162-167.

Debik, E. and Coskun, T. (2009) Use of the Static Granular Bed Reactor (SGBR) with anaerobic sludge to treat poultry slaughterhouse wastewater and kinetic modeling. Bioresource Technology 100(11), 2777-2782.

Demirel, B. and Yenigun, O. (2002) Two-phase anaerobic digestion processes: a review. Journal of Chemical Technology and Biotechnology 77, 743-755.

Deng, L. and Hägg, M. (2010) Techno-economic evaluation of biogas upgrading process using $\mathrm{CO} 2$ facilitated transport membrane. International Journal of Greenhouse Gas Control 4(4), 638-646.

Donoso-Bravo, A., Mailier, J., Martin, C., Rodríguez, J., Aceves-Lara, C.A. and Wouwer, A.V. (2011) Model selection, identification and validation in anaerobic digestion: A review. Water Research 45(17), 5347-5364.

DuBuisson, M. (2010) Carbon Offset Protocols for Anaerobic Digestion Projects.

Dupla, M., Conte, T., Bouvier, J.C., Bernet, N. and Steyer, J.P. (2004) Dynamic evaluation of a fixed bed anaerobic digestion process in response to organic overloads and toxicant shock loads. Water Science and Technology 49(1), 61-68.

Espinoza-Escalante, F.M., Pelayo-Ortíz, C., Navarro-Corona, J., González-García, Y., Bories, A. and Gutiérrez-Pulido, H. (2009) Anaerobic digestion of the vinasses from the fermentation of Agave tequilana Weber to tequila: The effect of $\mathrm{pH}$, temperature and hydraulic retention time on the production of hydrogen and methane. Biomass and Bioenergy 33(1), 14-20. 
Faisal, M. and Unno, H. (2001) Kinetic analysis of palm oil mill wastewater treatment by a modified anaerobic baffled reactor. Biochemical Engineering Journal 9(1), 2531.

Fang, C., Boe, K. and Angelidaki, I. (2011a) Biogas production from potato-juice, a byproduct from potato-starch processing, in upflow anaerobic sludge blanket (UASB) and expanded granular sludge bed (EGSB) reactors. Bioresource Technology 102(10), 5734-5741.

Fang, C., O-Thong, S., Boe, K. and Angelidaki, I. (2011b) Comparison of UASB and EGSB reactors performance, for treatment of raw and deoiled palm oil mill effluent (POME). Journal of Hazardous Materials 189(1-2), 229-234.

Fogler, H.S. (2006) Elements of chemical reaction engineering, Prentice Hall PTR, Upper Saddle River, NJ, USA.

Fongsatitkul, P., Elefsiniotis, P. and Wareham, D.G. (2010) Effect of mixture ratio, solids concentration and hydraulic retention time on the anaerobic digestion of the organic fraction of municipal solid waste. Waste Management and Research 28(9), 811-817.

Foresti, E. and Paula Jr, D.R. (1992) Kinetic studies on a UASB reactor subjected to increasing cod concentration. Water Science and Technology 25(7), 103-111.

Fuentes, M., Scenna, N.J., Aguirre, P.A. and Mussati, M.C. (2007) Anaerobic Digestion of Carbohydrate and Protein-based Wastewaters in Fluidized Bed Bioreactors. Latin American Applied Research 37(4), 235-242.

Ganesh, R., Rajinikanth, R., Thanikal, J., Ramanujam, R. and Torrijos, M. (2010) Anaerobic treatment of winery wastewater in fixed bed reactors. Bioprocess and Biosystems Engineering 33(5), 619-628.

Ghorbanian, M., Bates, R.W., Barnett, R.A. and Mohsen, J.P. (2014c) VOC Emissions Comparison of Natural Gas and Biogas Usage in Biosolids Drying. Environmental Engineering Science 31(2), 80-87.

Ghorbanian, M., Lupitskyy, R.M., Satyavolu, J.V. and Berson, R.E. (2014a) Impact of Hydraulic Retention Time at Constant Organic Loading Rate in a Two-Stage Expanded Granular Sludge Bed Reactor. Environmental Engineering Science 31(7).

Ghorbanian, M., Lupitskyy, R.M., Satyavolu, J.V. and Berson, R.E. (2014b) Impact of Supplemental Hydrogen on Biogas Enhancement and Substrate Removal Efficiency in a Two-Stage Expanded Granular Sludge Bed Reactor. Environmental Engineering Science 31(6).

Ghosh, S. and Pohland, F.G. (1974) Kinetics of Substrate Assimilation and Product Formation in Anaerobic Digestion. Journal (Water Pollution Control Federation) 
46(4), 748-759.

Girault, R., Bridoux, G., Nauleau, F., Poullain, C., Buffet, J., Steyer, J.P., Sadowski, A.G. and Béline, F. (2012) A waste characterisation procedure for ADM1 implementation based on degradation kinetics. Water Research 46(13), 40994110.

Girault, R., Rousseau, P., Steyer, J.P., Bernet, N. and Béline, F. (2011) Combination of batch experiments with continuous reactor data for ADM1 calibration: application to anaerobic digestion of pig slurry. Water Science and Technology 63(11), 25752582.

Grau, P., Dohanyos, M. and Chudoba, J. (1975) Kinetics of multicomponent substrate removal by activated sludge. Water Research 9(7), 637-642.

Harada, H., Uemura, S. and Momonoi, K. (1994) Interaction between sulfate-reducing bacteria and methane-producing bacteria in UASB reactors fed with low strength wastes containing different levels of sulfate. Water Research 28(2), 355-367.

Hashimoto, A.G. (1986) Pretreatment of wheat straw for fermentation to methane. Biotechnology and Bioengineering 28:12, 1857-1866.

Hashimoto, A.G., Chen, Y.R. and Varel, V.H. (1980) Theoretical Aspects of Methane Production (State-Of-The-Art), pp. 86-91, 95, Amarillo Civic Center, Amarillo, Texas.

Hashimoto, A.G., Varel, V.H. and Chen, Y.R. (1981) Ultimate methane yield from beef cattle manure: Effect of temperature, ration constituents, antibiotics and manure age. Agricultural Wastes 3(4), 241-256.

Henze, M. and Harremoes, P. (1983) Anaerobic Treatment of Wastewater in Fixed Film Reactors - A Literature Review. Water Science and Technology 15(8-9), 1-101.

Hill, D.T. (1991) Steady-State Mesophilic Design Equations for Methane Production From Livestock Wastes. Transactions of the ASAE 34(5), 2157-2163.

Hilton, B. and Oleszkiewicz, J. (1988) Sulfide Induced Inhibition of Anaerobic Digestion. Journal of Environmental Engineering 114(6), 1377-1391.

Ho, C.C. and Tan, Y.K. (1985) Anaerobic treatment of palm oil mill effluent by tank digesters. Journal of Chemical Technology and Biotechnology 35(2), 155-164.

Hosseini, S.E. and Wahid, M.A. (2013) Biogas utilization: Experimental investigation on biogas flameless combustion in lab-scale furnace. Energy Conversion and Management 74(0), 426-432.

Hu, W.C., Thayanithy, K. and Forster, C.F. (2002) A kinetic study of the anaerobic digestion of ice-cream wastewater. Process Biochemistry 37(9), 965-971. 
Hulshoff Pol, L.W., de Castro Lopes, S.I., Lettinga, G. and Lens, P.N. (2004) Anaerobic sludge granulation. Water Research 38(6), 1376-1389.

J.W.H, S., Elferink, O., Visser, A., Hulshoff Pol, L.W. and Stams, A.J.M. (1994) Sulfate reduction in methanogenic bioreactors. FEMS Microbiology Reviews 15(2-3), 119-136.

Jeison, D. and Chamy, R. (1999) Comparison of the Behaviour of Expanded Granular Sludge Bed (EGSB) and Upflow Anaerobic Sludge Blanket (UASB) Reactors in Dilute and Concentrated Wastewater Treatment. Water Science and Technology 40(8), 91-97.

Jewell, W.J. (1987) Anaerobic sewage treatment. Part 6. Environmental Science and Technology 21(1), 14-21.

Jimenez, A.M., Borja, R. and Martin, A. (2004) A comparative kinetic evaluation of the anaerobic digestion of untreated molasses and molasses previously fermented with Penicillium decumbens in batch reactors. Biochemical Engineering Journal 18(2), 121.

Kabasci, S. (2009) Optimizing utilization of biogas: combined heat and power delivers greatest benefits. Cogeneration \& On-Site Power Production

Karim, K., Klasson, K., Drescher, S., Ridenour, W., Borole, A. and Al-Dahhan, M. (2007) Mesophilic Digestion Kinetics of Manure Slurry. Applied Biochemistry and Biotechnology 142(3), 231-242.

Kato, M.T., Field, J.A., Kleerebezem, R. and Lettinga, G. (1994) Treatment of Low Strength Soluble Wastewaters in UASB Reactors. Journal of Fermentation and Bioengineering 77(6), 679.

Kelleher, B.P., Leahy, J.J., Henihan, A.M., O'Dwyer, T.F., Sutton, D. and Leahy, M.J. (2002) Advances in poultry litter disposal technology--a review. Bioresource Technology 83(1), 27-36.

Kesavan, P. and Law, V.J. (2005) Practical identifiability of parameters in Monod kinetics and statistical analysis of residuals. Biochemical Engineering Journal 24(2), 95-104.

Kim, I.S., Tabak, H.H. and Young, J.C. (1997) Modeling of the Fate and Effect of Chlorinated Phenols in Anaerobic Treatment Processes. Water Science and Technology 36(6/7), 287.

Kim, I.S., Young, J.C. and Tabak, H.H. (1994) Kinetics of Acetogenesis and Methanogenesis in Anaerobic Reactions under Toxic Conditions. Water Environment Research 66(2), 119-132.

Kim, J.K., Oh, B.R., Chun, Y.N. and Kim, S.W. (2006) Effects of temperature and 
hydraulic retention time on anaerobic digestion of food waste. Journal of Bioscience and Bioengineering 102(4), 328-332.

Koster, I.W., Rinzema, A., de Vegt, A.L. and Lettinga, G. (1986) Sulfide inhibition of the methanogenic activity of granular sludge at various $\mathrm{pH}$-levels. Water Research 20(12), 1561-1567.

Kroeker, E.J., Schulte, D.D., Sparling, A.B. and Lapp, H.M. (1979) Anaerobic Treatment Process Stability. Journal (Water Pollution Control Federation) 51(4), 718-727.

Lee, P., Bae, J., Kim, J. and Chen, W. (2011) Mesophilic anaerobic digestion of corn thin stillage: a technical and energetic assessment of the corn-to-ethanol industry integrated with anaerobic digestion. Journal of Chemical Technology and Biotechnology 86(12), 1514-1520.

Lettinga, G., van Velsen, A.F.M., Hobma, S.W., de Zeeuw, W. and Klapwijk, A. (1980) Use of the upflow sludge blanket (USB) reactor concept for biological wastewater treatment, especially for anaerobic treatment. Biotechnology and Bioengineering 22(4), 699-734.

Liu, J., Luo, J., Zhou, J., Liu, Q., Qian, G. and Xu, Z.P. (2012) Inhibitory effect of highstrength ammonia nitrogen on bio-treatment of landfill leachate using EGSB reactor under mesophilic and atmospheric conditions. Bioresource Technology 113(0), 239-243.

Łojewska, J., Kołodziej, A., Dynarowicz-Łątka, P. and Wesełucha-Birczyńska, A. (2005) Engineering and chemical aspects of the preparation of microstructured cobalt catalyst for VOC combustion. Catalysis Today 101(2), 81-91.

Luo, G. and Angelidaki, I. (2012) Integrated biogas upgrading and hydrogen utilization in an anaerobic reactor containing enriched hydrogenotrophic methanogenic culture. Biotechnology and Bioengineering 109(11), 2729-2736.

Luo, G. and Angelidaki, I. (2013) Co-digestion of manure and whey for in situ biogas upgrading by the addition of $\mathrm{H} 2$ : process performance and microbial insights. Applied Microbiology and Biotechnology 97(3), 1373-1381.

Luo, G., Johansson, S., Boe, K., Xie, L., Zhou, Q. and Angelidaki, I. (2012) Simultaneous hydrogen utilization and in situ biogas upgrading in an anaerobic reactor. Biotechnology and Bioengineering 109(4), 1088-1094.

MacLeod, F.A., Guiot, S.R. and Costerton, J.W. (1990) Layered structure of bacterial aggregates produced in an upflow anaerobic sludge bed and filter reactor. Applied and Environmental Microbiology 56(6), 1598-1607.

Marcos, N.I., Guay, M. and Dochain, D. (2004) Output feedback adaptive extremum seeking control of a continuous stirred tank bioreactor with Monod's kinetics. Journal of Process Control 14(7), 807-818. 
McCarty, P.L. and Mosey, F.E. (1991) Modelling of Anaerobic Digestion Processes (A Discussion of Concepts). Water Science and Technology 24(8), 17-33.

McCarty, P.L. and Smith, D.P. (1986) Anaerobic wastewater treatment. Environmental Science and Technology 20(12), 1200-1206.

Mittal, A. (2011) Biological Wastewater Treatment. Water Today, 32-44.

Monod, J. (1949) The Growth of Bacterial Cultures. Annual Review of Microbiology 3(1), 371-394.

Mulder, R. and Thomas, P. (2003) Biological wastewater treatment for industrial effluents : technology and operation, Paques, Balk, Netherlands.

Najafpour, G.D., Zinatizadeh, A.A.L., Mohamed, A.R., Hasnain Isa, M. and Nasrollahzadeh, H. (2006) High-rate anaerobic digestion of palm oil mill effluent in an upflow anaerobic sludge-fixed film bioreactor. Process Biochemistry 41(2), 370-379.

Ni, B., Liu, H., Nie, Y., Zeng, R.J., Du, G., Chen, J. and Yu, H. (2011) Coupling glucose fermentation and homoacetogenesis for elevated acetate production: Experimental and mathematical approaches. Biotechnology and Bioengineering 108(2), 345353.

Nielsen, A.M. and Feilberg, A. (2012) Anaerobic digestion of energy crops in batch. Biosystems Engineering 112(3), 248-251.

Ning, Z., Kennedy, K.J. and Fernandes, L. (1997) Anaerobic Degradation Kinetics of 2,4-Dichlorophenol (2,4-DCP) with Linear Sorption. Water Science and Technology 35(2/3), 67 .

O'Flaherty, V., Mahony, T., O'Kennedy, R. and Colleran, E. (1998) Effect of pH on growth kinetics and sulphide toxicity thresholds of a range of methanogenic, syntrophic and sulphate-reducing bacteria. Process Biochemistry 33(5), 555-569.

Osorio, F. and Torres, J.C. (2009) Biogas purification from anaerobic digestion in a wastewater treatment plant for biofuel production. Renewable Energy 34(10), 2164-2171.

Pohland, F.G. and Ghosh, S. (1971) Developments in anaerobic stabilization of organic wastes--the two-phase concept. Environmental Letters 1(4), 255-266.

I. W. A. Task Group for Mathematical Modelling of Anaerobic Digestion Processes. (2002) Anaerobic digestion model no. 1 (ADM1), IWA, London, UK.

Raja Priya, K., Sandhya, S. and Swaminathan, K. (2009) Kinetic analysis of treatment of formaldehyde containing wastewater in UAFB reactor. Chemical Engineering Journal 148(2-3), 212-216. 
Rajagopal, R., Torrijos, M., Kumar, P. and Mehrotra, I. (2013) Substrate removal kinetics in high-rate upflow anaerobic filters packed with low-density polyethylene media treating high-strength agro-food wastewaters. Journal of Environmental Management 116, 101-106.

Rajeshwari, K.V., Balakrishnan, M., Kansal, A., Lata, K. and Kishore, V.V.N. (2000) State-of-the-art of anaerobic digestion technology for industrial wastewater treatment. Renewable and Sustainable Energy Reviews 4(2), 135-156.

Raposo, F., Borja, R., Martin, M.A., Martin, A., de la Rubia, M.A. and Rincon, B. (2009) Influence of inoculum-substrate ratio on the anaerobic digestion of sunflower oil cake in batch mode: Process stability and kinetic evaluation. Chemical Engineering Journal 149(1-3), 70-77.

Raposo, F., Borja, R., Sánchez, E., Martín, M.A. and Martin, A. (2003) Inhibition kinetics of overall substrate and phenolics removals during the anaerobic digestion of two-phase olive mill effluents (TPOME) in suspended and immobilized cell reactors. Process Biochemistry 39(4), 425-435.

Rincón, B., Borja, R., González, J.M., Portillo, M.C. and Sáiz-Jiménez, C. (2008) Influence of organic loading rate and hydraulic retention time on the performance, stability and microbial communities of one-stage anaerobic digestion of twophase olive mill solid residue. Biochemical Engineering Journal 40(2), 253-261.

Rittmann, B.E and McCarty, P.L. (2001) Environmental biotechnology : principles and applications, McGraw-Hill, Boston.

Ryckebosch, E., Drouillon, M. and Vervaeren, H. (2011) Techniques for transformation of biogas to biomethane. Biomass and Bioenergy 35(5), 1633-1645.

Salminen, E.A. and Rintala, J.A. (2002) Semi-continuous anaerobic digestion of solid poultry slaughterhouse waste: effect of hydraulic retention time and loading. Water Research 36(13), 3175-3182.

Sanchez, E., Borja, R., Weiland, P., Travieso, L. and Martin, A. (2001) Effect of substrate concentration and temperature on the anaerobic digestion of piggery waste in a tropical climate. Process Biochemistry 37(5), 483-489.

Sandhya, S., Sarayu, K. and Swaminathan, K. (2008) Determination of kinetic constants of hybrid textile wastewater treatment system. Bioresource Technology 99(13), 5793-5797.

Sandhya, S. and Swaminathan, K. (2006) Kinetic analysis of treatment of textile wastewater in hybrid column upflow anaerobic fixed bed reactor. Chemical Engineering Journal 122(1-2), 87-92.

Scully, C., Collins, G. and O'Flaherty, V. (2006) Anaerobic biological treatment of phenol at $9.5-15{ }^{\circ} \mathrm{C}$ in an expanded granular sludge bed (EGSB)-based 
bioreactor. Water Research 40(20), 3737-3744.

Setiadi, T., Husaini and Djajadiningrat, A. (1996) Palm oil mill effluent treatment by anaerobic baffled reactors: Recycle effects and biokinetic parameters. Water Science and Technology 34(11), 59-66.

Siriwongrungson, V., Zeng, R.J. and Angelidaki, I. (2007) Homoacetogenesis as the alternative pathway for $\mathrm{H} 2$ sink during thermophilic anaerobic degradation of butyrate under suppressed methanogenesis. Water Research 41(18), 4204-4210.

Speece, R.E. (1983) Anaerobic biotechnology for industrial wastewater treatment. Environmental Science and Technology 179.

Speece, R.E. (2008) Anaerobic biotechnology and odor/corrosion control for municipalities and industries, Archae Press, Nashville, TN, USA.

Sponza, D.T. and Uluköy, A. (2008) Kinetic of carbonaceous substrate in an upflow anaerobic sludge sludge blanket (UASB) reactor treating 2,4 dichlorophenol $(2,4$ DCP). Journal of Environmental Management 86(1), 121-131.

Stover, E.L. and Kincannon, D.F. (1982) Rotating biological contactor scale-up and design, Kings Island, Ohio.

Strevett, K.A., Vieth, R.F. and Grasso, D. (1995) Chemo-autotrophic biogas purification for methane enrichment: mechanism and kinetics. The Chemical Engineering Journal and the Biochemical Engineering Journal 58(1), 71-79.

Turkdogan-Aydinol, F.I., Yetilmezsoy, K., Comez, S. and Bayhan, H. (2011) Performance evaluation and kinetic modeling of the start-up of a UASB reactor treating municipal wastewater at low temperature. Bioprocess and Biosystems Engineering 34(2), 153-162.

Ugoji, E.O. (1997) Anaerobic digestion of palm oil mill effluent and its utilization as fertilizer for environmental protection. Renewable Energy 10(2-3), 291-294.

USEPA (2009) Major wastewater discharges by industry (excluding power) in the United States - $\quad$ Cited From http://www.globalwaterintel.com/archive/10/2/analysis/chart.html.

USEPA (2013a) Draft Inventory of U.S. Greenhouse Gas Emissions and Sinks: 19902009 - Cited From http://epa.gov/climatechange/ghgemissions/gases/ch4.html.

USEPA (2013b) Industrial Regulations in the United States - Cited From http://water.epa.gov/scitech/wastetech/guide/industry.cfm.

USEPA (2013c) Combined Heat and Power Partnership - Cited From http://www.epa.gov/chp/basic/. 
USGS (1989) Techniques of water-resources investigations of the United States Geological Survey Book 5, Laboratory Analysis Chapter A1. Fishman, M.J. and Friedman, L.C. (eds), Washington, DC, USA.

Van Lier, J.B., Sanz Martin, J.L. and Lettinga, G. (1996) Effect Of Temperature On The Anaerobic Thermophilic Conversion Of Volatile Fatty Acids By Dispersed And Granular Sludge. Water Research 30(1), 199.

Van Starkenburg, W. (1997) Anaerobic Treatment of Wastewater: State of the Art. Mikrobiologiia 66(5), 588-596.

Wang, L.K., Ivanov, V., Tay, J. and Hung, Y. (2010) Environmental Biotechnology (Volume 10), Springer Science+Business Media, LLC, New York, NY, USA.

Wang, W., Xie, L., Chen, J., Luo, G. and Zhou, Q. (2011) Biohydrogen and methane production by co-digestion of cassava stillage and excess sludge under thermophilic condition. Bioresource Technology 102(4), 3833-3839.

Weiland, P. (2010) Biogas production: current state and perspectives. Applied Microbiology and Biotechnology 85(4), 849-860.

Wik, T., Göransson, E. and Breitholtz, C. (2006) Low model order approximations of continuously stirred biofilm reactors with Monod kinetics. Biochemical Engineering Journal 30(1), 16.

Wilson, F. and Lee, W.M. (1997) Rotating biological contactors for wastewater treatment in an equatorial climate. Water Science and Technology 35(8), 177-184.

Young, J.C. and Cowan, R.M. (2004) Respirometry for environmental science and engineering, SJ Enterprises, Springdale, AR, USA.

Yu, H., Wilson, F. and Tay, J. (1998) Kinetic analysis of an anaerobic filter treating soybean wastewater. Water Research 32(11), 3341-3352.

Zehnder, A.J.B. (1988) Biology of anaerobic microorganisms, Wiley, New York.

Zhang, Y., Yan, L., Chi, L., Long, X., Mei, Z. and Zhang, Z. (2008) Startup and operation of anaerobic EGSB reactor treating palm oil mill effluent. Journal of Environmental Sciences 20(6), 658-663.

Zhu, H., Parker, W., Basnar, R., Proracki, A., Falletta, P., Béland, M. and Seto, P. (2008) Biohydrogen production by anaerobic co-digestion of municipal food waste and sewage sludges. International Journal of Hydrogen Energy 33(14), 3651-3659.

Zupančič, G.D., Škrjanec, I. and Marinšek Logar, R. (2012) Anaerobic co-digestion of excess brewery yeast in a granular biomass reactor to enhance the production of biomethane. Bioresource Technology 124(0), 328-337. 


\section{APPENDIX-A}

\section{ABBREVIATIONS AND NOMENCLATURE}

\section{$\underline{\text { Abbreviations }}$}

$\begin{array}{ll}\text { AAFEBR } & \text { Anaerobic Attached (Film Expanded) Bed Reactor } \\ \text { AD } & \text { Anaerobic Digestion } \\ \text { AFR } & \text { Anaerobic Fluidized Reactor } \\ \text { AFR } & \text { Anaerobic Filter Reactor } \\ \text { BAT } & \text { Best Available Technology Economically Achievable } \\ \text { BCT } & \text { Best Conventional Pollutant Control Technology } \\ \text { BMP } & \text { Biological Methane Potential } \\ \text { BOD } & \text { Biological Oxygen Demand } \\ \text { BPT } & \text { Best Practicable Control Technology } \\ \text { CHP } & \text { Combined Heat and Power } \\ \text { CNG } & \text { Compressed Natural Gas } \\ \text { COD } & \text { Chemical Oxygen Demand } \\ \text { CSTR } & \text { Conventional Stirred Tank Reactor } \\ \text { CWA } & \text { Clean Water Act } \\ \text { EGSB } & \text { Expanded Granular Sludge Blanket } \\ \text { FPD } & \text { Flame Photometric Detector }\end{array}$




$\begin{array}{ll}\text { GHG } & \text { Greenhouse gases } \\ \text { HRT } & \text { Hydraulic Retention time } \\ \text { NSPS } & \text { New Source Performance Standards } \\ \text { OLR } & \text { Organic Loading Rate } \\ \text { PA } & \text { Pre-acidification } \\ \text { PSES } & \text { Pretreatment Standards for Existing Sources } \\ \text { PSNS } & \text { Pretreatment Standards for New Sources } \\ \text { SI } & \text { Substrate-to-Inoculum } \\ \text { SMP } & \text { Specific Methanogenic Production } \\ \text { SRB } & \text { Sulfate Reducing Bacteria } \\ \text { SRT } & \text { Solid Retention Time } \\ \text { TCD } & \text { Thermal Conductivity Detector } \\ \text { TDS } & \text { Total Dissolved Solid } \\ \text { TS } & \text { Total Solid } \\ \text { TSS } & \text { Total Suspended solid } \\ \text { VFA } & \text { Volatile Fatty Acid } \\ \text { VSS } & \text { Volatile Suspended Solid } \\ \text { UASB } & \text { Wastewater Anaerobic Sludge Blanket } \\ \text { USEPA } & \text { WW }\end{array}$

\section{$\underline{\text { Nomenclature }}$}

g COD equivalent of one liter of methane at $35^{\circ} \mathrm{C}$ 


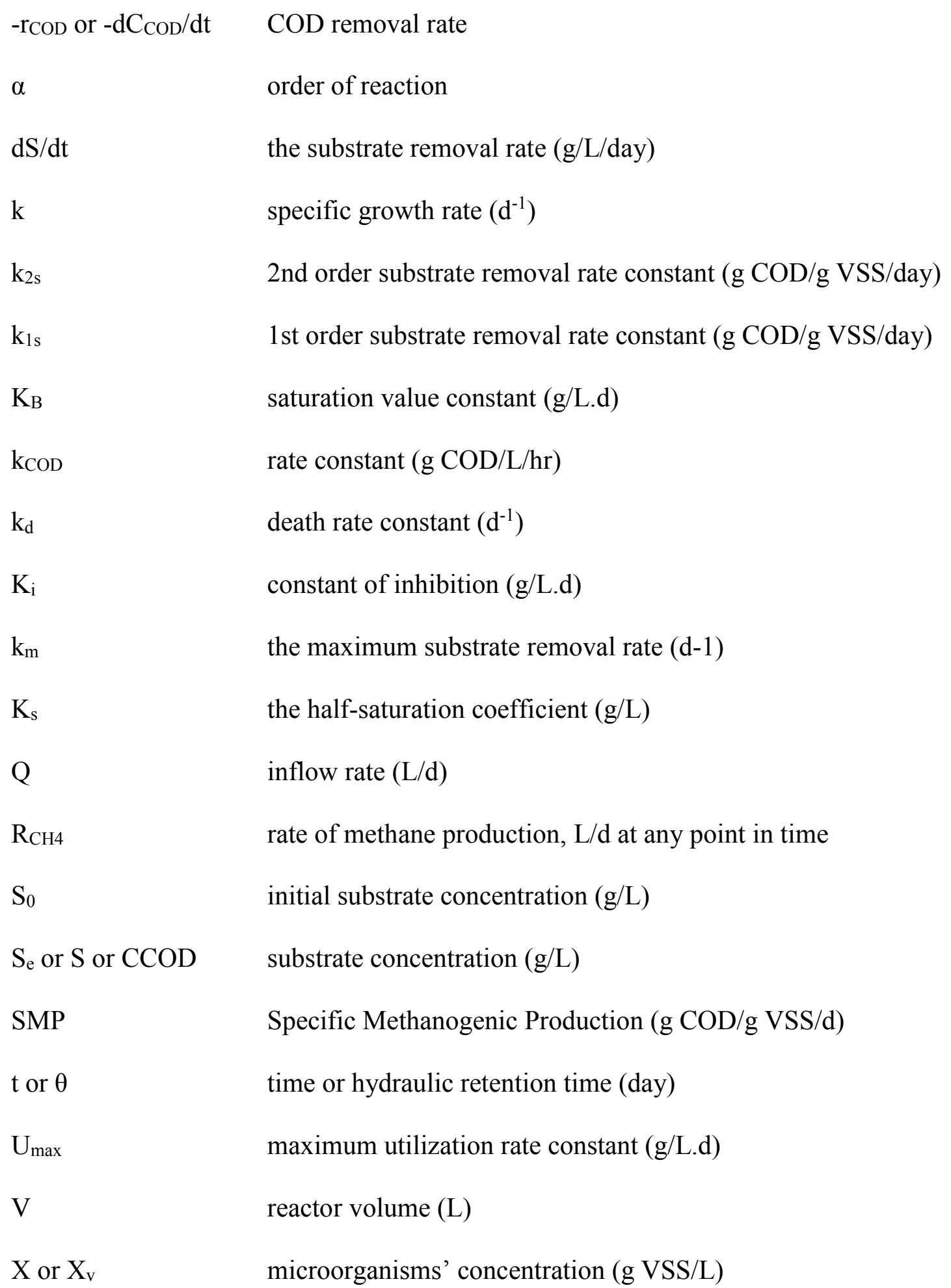




\section{APPENDIX-B}

\section{ANAEROBIC DIGESTION MECHANISM}

A typical substrate conversion curve for biological processes, including anaerobic digestion, is shown in Figure B-1. A COD strength of $8 \mathrm{~g} / \mathrm{L}$ is shown here as an example.

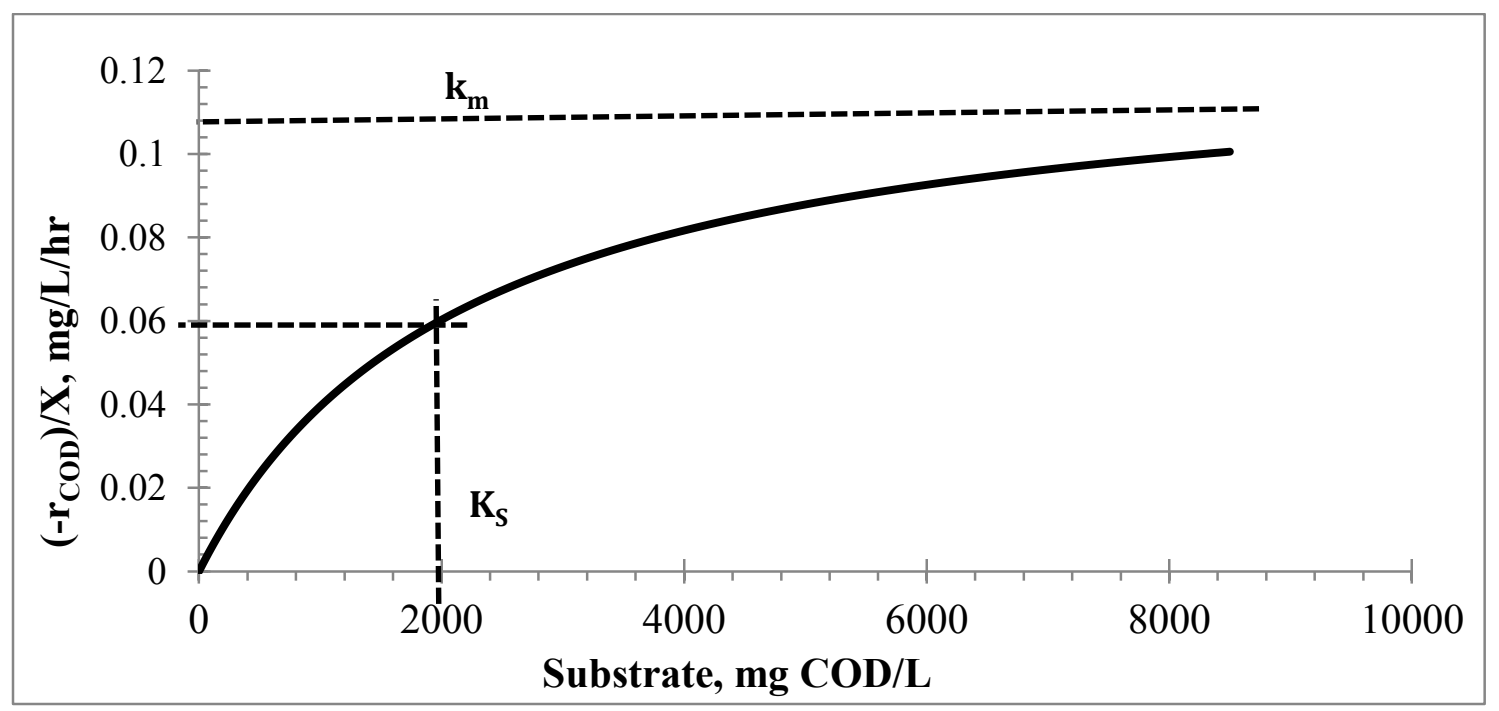

Figure B-1 - A typical Monod substrate conversion curve - 8 g COD/L

Most modeling approaches in the literature that describe this function expressing the rate of consumption of an essential substrate are based on the work of Monod (Monod, 1949), who developed the following empirical relation between rate and substrate concentration:

$$
-r_{C O D}=\frac{k_{m} C_{C O D} X}{K_{s}+C_{C O D}}
$$


where $k_{m}$ is the maximum specific growth rate $\left(d^{-1}\right)$ and $K_{s}$ is the half-saturation coefficient (g/L) (shown in Figure B-1).

A discussion of the anaerobic digestion mechanism follows. Complex polymeric substrates including lipids, proteins, and carbohydrates are first hydrolyzed by hydrolytic enzymes (lipases, proteases, cellulases, amylases, etc.), produced from microbes, into smaller molecules, primarily monomeric units, such as glucose and amino acids. This mostly occurs in the bulk liquid. These smaller molecules then diffuse into the acidogen layer of the granule (See Figure 2-4), where they are converted into higher volatile fatty acids, $\mathrm{H}_{2}$ and acetate. [The substrate used here consisted solely of soluble organics; all suspended solids were first settled out of solution. For streams containing suspended solids, the reaction kinetics would be controlled by an initial hydrolysis step, where the bacteria must first secrete enzymes to break down the solids (Rittmann and McCarty, 2001; Zehnder, 1988).]. These intermediates then diffuse into the acetogen layer where they are converted to acetate, $\mathrm{CO}_{2}$, and $\mathrm{H}_{2}$. Finally, the acetate, $\mathrm{H}_{2}$, and $\mathrm{CO}_{2}$ diffuse into the core of the granule, where the methanogens (hydrogenotrophic methanogens and acetoclastic methanogens) convert them to methane and more $\mathrm{CO}_{2}$. Between $70-80 \%$ of the methane produced is obtained from acetate with acetoclastic methanogenesis (Mulder and Thomas, 2003), with the remainder forming from hydrogenotrophic methanogenesis. The limiting reaction is generally the conversion of acetate to methane by acetoclastic methanogens, which controls the overall reaction (Young and Cowan, 2004). The Monod equation is essentially modeling the methanogenesis reactions. The sequential metabolic reactions using ethanol as an example are shown here:

Hydrolysis and Acidification: 
$\mathrm{CH}_{3} \mathrm{CH}_{2} \mathrm{OH}(\mathrm{aq})+\mathrm{H}_{2} \mathrm{O}(\mathrm{l})=\mathrm{CH}_{3} \mathrm{COO}^{-}(\mathrm{aq})+\mathrm{H}^{+}(\mathrm{aq})+2 \mathrm{H}_{2}(\mathrm{~g}) \quad \Delta \mathrm{G}_{0}=9.65 \mathrm{~kJ}$

Acetogenesis:

$2 \mathrm{H}_{2}(\mathrm{~g})+1 / 2 \mathrm{CO}_{2}(\mathrm{~g})=1 / 2 \mathrm{CH}_{4}(\mathrm{~g})+\mathrm{H}_{2} \mathrm{O}(\mathrm{l})$

$\Delta \mathrm{G}_{0}=-65.37 \mathrm{~kJ}$

Methanogenesis (acetoclastic):

$\mathrm{CH} 3 \mathrm{COO}^{-}(\mathrm{aq})+\mathrm{H}^{+}(\mathrm{aq})=\mathrm{CH}_{4}(\mathrm{~g})+\mathrm{CO}_{2}(\mathrm{~g}) \quad \Delta \mathrm{G}_{0}=-35.83 \mathrm{~kJ}$

Net: $\mathrm{CH}_{3} \mathrm{CH}_{2} \mathrm{OH}(\mathrm{aq})=3 / 2 \mathrm{CH}_{4}(\mathrm{~g})+1 / 2 \mathrm{CO}_{2}(\mathrm{~g}) \quad \Delta \mathrm{G}_{0}=-91.55 \mathrm{~kJ}$

According to the Monod equation, the biochemical reaction order (with respect to the substrate concentration) varies between zero (at high substrate concentration) and one (at low substrate concentration). Factors that affect COD consumption, and hence reaction order, include synthesis, sulfate reduction, substrate inhibition, diauxic (sequential) growth, hydrogen accumulation, and a number of other factors. 


\section{CURRICULUM VITAE}

NAME: $\quad$ Mahyar Ghorbanian

ADDRESS: $\quad$ Department of Chemical Engineering

University of Louisville

Louisville, KY 40292

EDUCATION: $\quad$ B.S., Petroleum Engineering Technical

Petroleum University of Technology, Abadan, Iran

2004-08

M.S., Civil and Environmental Engineering University of Louisville, Louisville, KY

2009-10

Ph.D., Chemical Engineering

University of Louisville, Louisville, KY

2010-14

\section{AWARDS}

- Awarded Graduate Dean's Citation Award, University of Louisville, Spring 2014

- Awarded Doctoral Dissertation Completion Award from School of Interdisciplinary and Graduate Studies, University of Louisville, Spring 2014

- Awarded Graduate Travel Fund from Graduate Student Association, University of Louisville, Fall 2011, Fall 2012, and Fall 2013

- Awarded Travel Fund from Kentucky Institute for the Environment and Sustainable Development, Environmental Engineering Center, University of Louisville, Fall 2011 
- Awarded Graduate Research Assistant at Chemical Engineering Department, University of Louisville, 2010-Present

- Awarded Graduate Teaching Assistant at Civil \& Environmental Engineering Department, University of Louisville, 2009-2010

- Awarded the Tuition \& Living Expense Scholarship for B.S. in Safety and Technical Inspection Engineering from Petroleum University of Technology, 2004-2008

- Ranked 2047 nationwide among nearly 500,000 participants in National Entrance Exam of Universities, Iran, July 2004

\section{PROFESSIONAL SOCIETIES}

- American Water Works Association 2013-Present

- American Institute of Chemical Engineering 2011-Present

- Society of Petroleum Engineers (SPE), 2004-2008, 2014

- American Society of Civil Engineers 2009-2010

- Iranian Technical Inspection \& Safety Association (ITISA), 2004-2006

\section{PUBLICATIONS}

- M. Ghorbanian, R.M. Lupitskyy, J.V. Satyavolu, and R.E. Berson. "Impact of Hydraulic Retention Time at Constant Organic Loading Rate in a Two-Stage Expanded Granular Sludge Bed Reactor". Accepted in Environmental Engineering Science. In Press

- M. Ghorbanian, R.M. Lupitskyy, J.V. Satyavolu, and R.E. Berson. "Impact of Supplemental Hydrogen on Biogas Enhancement and Substrate Removal Efficiency 
in a Two-Stage Expanded Granular Sludge Bed Reactor". Accepted in Environmental Engineering Science. In Press

- M. Ghorbanian, D.C. Russ, and R.E. Berson. "Mixing Analysis of PCS slurries in a Horizontal Scraped Surface Bioreactor". Accepted in Bioprocess \& Biosystems Engineering. In Press

- M. Ghorbanian, R.W. Bates, R.A. Barnett, and J.P. Mohsen. "Emissions Comparison of Natural Gas Usage and Biogas Usage in Biosolids Drying”. Environmental Engineering Science. 2014, 31 (2), 80-87 